Linköping Studies in Science and Technology

Dissertation No. 1962

\title{
Synthesis and characterization of fluorescent stilbene-based probes targeting amyloid fibrils
}

\author{
Jun Zhang
}

Division of Chemistry

Department of Physics, Chemistry and Biology

Linköping University, Sweden

Linköping 2018 
During the course of the research underlying this thesis, Jun Zhang was enrolled in Forum Scientium, a multidisciplinary doctoral program at Linköping University, Sweden.

(C) Copyright Jun Zhang, 2018, unless otherwise noted.

Published articles have been reprinted with the permission of the copyright holder.

Paper I (C) 2017 American Chemical Society

Paper II C 2018 Wiley-VCH

Paper III (C) 2018 Wiley-VCH

Cover: 3D models of three fluorescent probes

Jun Zhang

Synthesis and characterization of fluorescent stilbene-based probes targeting amyloid fibrils

ISSN: 0345-7524

ISBN: 978-91-7685-187-6

Linköping Studies in Science and Technology Dissertation No. 1962

Printed by LiU-Tryck, Linköping, Sweden, 2018 


\section{Abstract}

Alzheimer's disease (AD) is characterized by two main protein aggregate hallmarks in the brain: extracellular deposition of the amyloid- $\beta(\mathrm{A} \beta)$ in senile plaques and intracellular neurofibrillary tangles (NFTs) consisting of hyperphosphorylated tau protein. The past decade has seen great progress in the development of imaging probes for the non-invasive detection of $A \beta$ and tau aggregates. Here positron emission tomography (PET), single-photon emission computed tomography (SPECT) and magnetic resonance imaging (MRI), are highly promising technologies for clinical diagnostics. However, as a research tool, optical imaging is superior because it is real-time, sensitive, inexpensive, not radioactive and that it in particular affords high-resolution studies both in vitro and in vivo. Fluorescent probes are especially useful for designing novel binding scaffolds for structure investigations of protein aggregates. This thesis describes design, synthesis and evaluation of a series of fluorescent probes for detection of amyloid fibrils, especially $\mathrm{A} \beta$ or tau aggregates in vitro.

Firstly, trans-stilbenoid vinylbenzene-1,2-diol with benzene, naphthalene, anthracene, and pyrene are investigated with respect to their photophysical properties free in solution and when bound to amyloid fibrils, including time-resolved fluorescence measurements. It is noted that the extended conjugated systems retained the amyloid targeting properties of the probes and both the anthracene and pyrene moieties extensively enhanced the fluorescence intensity and prolonged lifetimes.

Secondly, the synthesis of two molecules, Py1SA and Py2SA, based on pyrene linked to salicylic acid via a trans-stilbene $\mathrm{C}=\mathrm{C}$ bond is presented. The compounds show strikingly different emission spectra when bound to preformed $A \beta 1-42$ fibrils as well as to fibrils from four other distinct proteins. Additionally, excited state intramolecular proton transfer (ESIPT) coupled-charge transfer (ICT) is observed for the anionic form of the probes in polar solvents. This is likely the reason for the spectral differences of the probes when bound to amyloid fibrils.

Moreover, the synthesis of a further development of the Congo red analogue X-34 [2,5-bis(4'-hydroxy-3'-carboxy-styryl) benzene] by rational 
design and synthesis is described. Full photophysical characterization was performed, including recording absorbance and fluorescence spectra, Stokes shift, quantum yield and fluorescence lifetimes. All ligands displayed high affinity towards recombinant amyloid fibrils of A $\beta 1-42$ and tau as well as selectivity towards the corresponding disease-associated protein aggregates in human post mortem AD tissue.

Lastly, the synthesis of a set of 2,1,3-benzothiadiazole (BTD)-based ligands with different conjugated spacers and variable patterns of $\mathrm{OH}$ substitutions of bis-styryl-BTD prototypes were developed. A $\beta$ binding affinities (A $\beta 1-42$ and $A \beta 1-40$ fibrils) and the specificity towards $A \beta$ plaques of all ligands were determined. These findings extend the structure to activity relationships of BTD-based ligands for A $\beta$ fibril binding.

Throughout the studies in this dissertation, new interesting properties of small molecule fluorescence probes have been discovered and analyzed. This knowledge should facilitate the development of noninvasive probes for early detection of Alzheimer's disease and to distinguish different $A \beta$ fibril polymorphs. 


\section{Populärvetenskaplig sammanfattning}

Alzheimers sjukdom definieras av två i hjärnan tydliga kännetecken: extracellulär avlagring av amyloid- $\beta(A \beta)$ i senila plack och intracellulära neurofibrillära trassel (NFTs) som består av hyperfosforylerat tau-protein. Under det senaste decenniet har stora framsteg skett i utvecklingen av medicinsk avbildning för icke-invasiv kvantifiering av A $\beta$ och tau aggregat. Här är positron emissions tomografi (PET), single-photon emission computed tomography (SPECT) och magnetisk resonans avsbildning (MRI), mycket lovande tekniker för klinisk diagnostik. Som ett forskningsverktyg är däremot optisk avbildning överlägsen eftersom den sker i realtid, är känslig, billig, icke-radioaktiv och att den i synnerhet tillåter högupplösta studier både in vitro och in vivo. Molekylära fluorescensprober är speciellt användbara för utprovning av olika bindningsställen för strukturundersökningar av proteinaggregat. Denna avhandling beskriver en serie syntetiska fluorescerande prober för detektering av $\mathrm{A} \beta$ eller tauaggregat in vitro.

Trans-stilbenoid vinylbensen-1,2-diol med bensen, naftalen, antracen och pyren undersöktes med avseende på deras fotofysikaliska egenskaper fritt i lösning och när de var bundna till amyloidfibriller. Detta inkluderade tidsupplösta fluorescensmätningar. Det visades att de utvidgade konjugerade systemen fortsatt behöll probens amyloidbindande egenskaper och att både antracen- och pyrenderivaten förbättrade i hög grad fluorescensintensiteten och förlängde livstiden för fluorescensen för proberna bundna till amyloida fibriller.

För det andra presenteras syntesen av två nya molekyler, Py1SA och Py2SA, baserade på pyren kopplad till salicylsyra via en trans-stilben $\mathrm{C}$ = C-bindning. Dessa prober visade påfallande olika emissionsspektra när de band till $A \beta 1-42$ fibriller såväl som till fibriller från fyra andra distinkta proteiner. Denna stora skillnad i fluorescensspektra härrör sannolikt från intramolekylär protonöverföring (ESIPT) kopplad till laddningsöverföring (ICT) för den anjoniska formen av proberna. Denna hypotes stärktes av studier av proberna i polära lösningsmedel. 
Dessutom beskrivs syntesen av en samling derivat av X-34 [2,5-bis (4'hydroxi-3'-karboxi-styryl) bensen]. X-34 är analog till amyloidproben Kongo röd. Full fotofysikalisk karakterisering utfördes vilket innefattande absorbans- och fluorescensspektra, Stokes shift, kvantutbyte och fluorescenslivstider. Alla ligander uppvisade hög affinitet gentemot rekombinanta amyloidfibriller av A $\beta 1-42$ och tau såväl som selektivitet mot motsvarande sjukdomsassocierade proteinaggregat i vävnad från Alzheimers sjukdom.

Slutligen utvecklades syntesen av en uppsättning 2,1,3-bensotiadiazol (BTD)-baserade prober med olika konjugerade system och med variabla mönster av $\mathrm{OH}$-substitutioner av bis-styryl-BTD-derivat. A $\beta$ - bindningsaffiniteter (A $\beta 1-42$ och $A \beta 1-40$ fibriller) och specificiteten mot $A \beta$-plack av samtliga prober bestämdes. Dessa fynd utökar kunskapen av strukturaktivitets-samband för BTD-baserade ligander för A $\beta$-fibril bindning.

Genomgående för studierna i denna avhandling så har nya intressanta egenskaper hos småmolekylära fluorescensprober påvisats och analyserats. Denna kunskap bör underlätta utvecklingen av icke-invasiva prober för tidig detektion av Alzheimers sjukdom och för att särskilja olika A $\beta$ fibrilpolymorfer. 


\section{Acknowledgements}

I would like to extend my gratitude to my supervisors, colleagues and friends as well as my family.

My main supervisor, Peter Konradsson, for accepting me as a $\mathrm{PhD}$ student at the department of IFM, Linköping University, for providing me with the freedom and wise suggestions to follow my ideas and encouraging me all the way.

My co-supervisor, Per Hammarström, for providing excellent guidance and support over the years, for always taking the time to discuss research and provide feedback. I am benefited a great deal from your immense knowledge.

My co-supervisor, Xiongyu Wu, for your great support in many different aspects, especially in the synthesis of fluorescent probes.

Our collaborator in Norwegian University of Science and Technology (NTNU), Mikael Lindgren, for providing experimental data and paper revision.

Peter Nilsson, for your excellent ideas of paper revision.

Sofie Nyström, for intriguing scientific discussions and answering patiently my questions every time.

Zhangjun $\mathrm{Hu}$, for always providing scientific discussions when I need.

Alexander Sandberg, for providing amyloid fibrils.

Audun Konsmo, for helping me measure the data in NTNU.

Mattias, Jakob, Anders, Hamid, Mathias, Bäck, Linda, Katriann, Therese, Tobias, Rogga, Maria and Afshan, for always providing support when I need. And all other colleagues at IFM who have assisted me in any way.

My Chinese friends in Sweden (Tianwei Xu, Zhe Chen, Ming Guo, Jiawen Xi and Shengnan Zhuang as well as others) for having nice parties and making me every day in Sweden lovely. 
My parents-in-law, Shiyi Zhao and Denghua Ren, for your understanding and support along the process, which I will remember forever.

My parents, Yonglie Zhang and Xingju Li, for always believing in me and supporting my decisions. My siblings, Hongchuan Zhang and Hongwei Zhang, for always your understanding and helping me look after our father (in sick).

Last but not the least, to my wife, Meiyi Zhao, for giving up your stable job in China and coming to Sweden to stay with me, for cooking so much delicious Chinese food. I love you forever with my heart! 


\section{Papers included in the thesis}

I. Trans-stilbenoids with Extended Fluorescence Lifetimes for Characterization of Amyloid Fibrils

J. Zhang, A. Sandberg, X. Y. Wu, S. Nyström, M. Lindgren, P. Konradsson and P. Hammarström* ACS Omega 2017, 2, 4693.

II. Intramolecular proton and charge transfer of pyrene-based trans-stilbene salicylic acids applied to detection of aggregated proteins

J. Zhang, J. Wang, A. Sandberg, X. Y. Wu, S. Nyström, H. LeVine III, P. Konradsson, P. Hammarström, B. Durbeej and M. Lindgren*

Chemphyschem 2018, 19, 1 (Cover Feature).

III. Detection and imaging of Aß1-42 and Tau fibrils by redesigned fluorescent $\mathrm{X}-34$ analogues

J. Zhang, A. Sandberg, A. Konsmo, X. Y. Wu, S. Nyström, K. P. R. Nilsson, P. Konradsson, H. LeVine III, M. Lindgren and P. Hammarström*

Chem. Eur. J. 2018, 24, 7210.

IV. Phenolic bis-styrylbenzo[c]-1,2,5-thiadiazoles as probes for fluorescence microscope mapping of $A \beta$ plaque heterogeneity

J. Zhang, A. Konsmo, A. Sandberg, X. Y. Wu, S. Nyström, U. Obermüller, B. M. Wegenast-Braun, P. Konradsson, M. Lindgren and P. Hammarström*

J. Med. Chem. 2018 (submitted). 



\section{Contribution to included papers}

I. Jun Zhang (JZ) participated in the planning of the project, performed all the experiments, except the purification of proteins and the preparation of corresponding fibrils. JZ analysed the results and wrote the manuscript draft.

II. JZ participated in the planning of the project, performed all the experiments, except the purification of proteins and the preparation of corresponding fibrils as well as $\mathrm{EC}_{50}$ assay. $\mathrm{JZ}$ analysed the results and wrote the manuscript draft.

III. JZ participated in the planning of the project, performed all the experiments, except the purification of proteins and the preparation of corresponding fibrils as well as $\mathrm{EC}_{50}$ assay. JZ analysed the results and wrote the manuscript draft.

IV. JZ participated in the planning of the project, performed all the experiments, except the purification of proteins and the preparation of corresponding fibrils as well as lifetime and quantum yield assays. JZ analysed the results and wrote the manuscript draft. 



\section{Conference contributions}

* $1^{\text {st }}$ National Meeting of Swedish Chemical Society. Jun. 17-20 2018, Lund Sweden

[Poster] Zhang J., Sandberg A., Nyström S., Wu X. Y., Konradsson P., Lindgren M. and Hammarström P. Synthesis and characterization of phenolic bis-styryl-benzo [c]-1,2,5-thiadiazoles as long-wavelength probes for imaging of $A \beta$ aggregates in Alzheimer's disease.

* $6^{\text {th }}$ Amyloid Disease Annual Meeting - Molecular Perspectives of Misfolded Proteins. Sep. 06-08 2017, Norrköping Sweden [Poster] Zhang J., Sandberg A., Wu X. Y., Nyström S., Lindgren M., Konradsson P., and Hammarström P. Fluorescent derivatives of Congo red for the detection of $A \beta$ and Tau aggregates.

$5^{\text {th }}$ Global Chemistry Congress. Sep. 04-06 2017, London UK [Poster] Zhang J., Sandberg A., Wu X. Y., Nyström S., Lindgren M., Konradsson P., and Hammarström P. Fluorescent derivatives of Congo red for the detection of $A \beta$ and Tau aggregates. 



\section{Thesis Committee}

\section{SUPERVISOR}

Peter Konradsson, Professor

Division of Chemistry, Department of Physics, Biology and Chemistry Linköping University, Sweden

CO-SUPERVISOR

Per Hammarström, Professor

Division of Chemistry, Department of Physics, Biology and Chemistry Linköping University, Sweden

Xiongyu Wu, Research Engineer

Division of Chemistry, Department of Physics, Biology and Chemistry Linköping University, Sweden

\section{FACULTY OPPONENT}

Lin Li, Professor

Institute of Advanced Materials

Nanjing Tech University, China

COMMITTEE BOARD

Anja Sandström, Associate Professor

Department of Medicinal Chemistry

Uppsala University, Sweden

Malin Wennström, Associate Professor

Department of Clinical Sciences

Lund University, Sweden

Martin Ingelsson, Professor

Department of Public Health and Caring Sciences

Uppsala University, Sweden 



\section{Abbreviations}

$\begin{array}{ll}\text { AD } & \text { Alzheimer's disease } \\ \text { A } \beta & \text { Amyloid beta fragment from amyloid- } \beta \text { precursor protein } \\ \text { APP } & \text { Amyloid precursor protein } \\ \text { BBB } & \text { Blood-brain barrier } \\ \text { BINAP } & \text { 2,2'-bis(diphenylphosphino)-1,1'-binaphthyl } \\ \text { BODIPYs } & \text { Boron-dipyrromthenes } \\ \text { BTD } & \text { 2,1,3-benzothiadiazole } \\ \text { DCM } & \text { Dichloromethane } \\ \text { DMF } & \text { N, N-Dimethylformamide } \\ \text { DMSO } & \text { Dimethyl Sulfoxide } \\ \text { EA } & \text { Ethyl acetate } \\ \text { ESIPT } & \text { Excited state intramolecular proton transfer } \\ \text { FDA } & \text { Food and Drug Administration } \\ \text { GSIPT } & \text { Ground state intramolecular proton transfer } \\ 3,2-H N A & 3 \text {-hydroxy-2-naphthoic acid } \\ \text { HOMO } & \text { Highest occupied molecular orbital } \\ \text { ICT } & \text { Intramolecular charge transfer } \\ \text { Ins. } & \text { Insulin } \\ \text { IMHB } & \text { Intramolecular hydrogen bond } \\ \text { LUMO } & \text { Lowest unoccupied molecular orbital } \\ \text { Lys. } & \text { Lysozyme } \\ \text { MRI } & \text { Magnetic resonance imaging } \\ \text { MS } & \text { Methyl salicylate } \\ \text { NFT } & \text { Neurofibrillary tangle } \\ \text { NiCl } 2 \text { (dppf) } & {[1,1 \text { '-bis(diphenylphosphino)ferrocene]dichloronickel(II) }} \\ \text { NIRF } & \text { Near-infrared fluorescence } \\ \text { NMDA } & \text { N-methyl-D-aspartate receptor } \\ \text { NMR } & \text { Nuclear magnetic resonance } \\ \text { PBS } & \text { Phosphate-buffered saline } \\ \text { PET } & \text { Positron emission tomography } \\ \text { PHOX } & \text { Phosphinooxazolines } \\ \text { PrP. } & \text { Prion protein } \\ \text { Pd(dppe)Cl } 2 & {[1,2-\text {-Bis(diphenylphosphino)ethane]dichloropalladium(II) }} \\ & \end{array}$


$\operatorname{Pd}(\mathrm{dppf}) \mathrm{Cl}_{2}[1,1 \quad$ ' - -Bis(diphenylphosphino)ferrocene $]$ dichloropalladium(II)

$\mathrm{Pd}\left(\mathrm{PPh}_{3}\right)_{4} \quad$ Tetrakis(triphenylphosphine)palladium

$\mathrm{Pd}\left(\mathrm{PPh}_{3}\right)_{2} \mathrm{Cl}_{2}$ Bis(triphenylphosphine)palladium(II) dichloride

PT Proton transfer

SA Salicylic acid

SAR Structure-activity relationship

SPECT Single-photon emission computed tomography

SSNMR Solid state nuclear magnetic resonance

Tau Microtubule associated protein tau

TCSPC Time-correlated single-photon counting

TLC Thin-layer cheromatography

TTR Transthyretin

ThT Thioflavin T 


\section{Table of Contents}

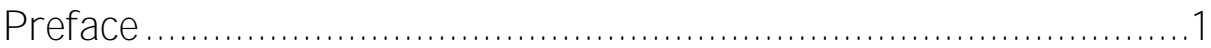

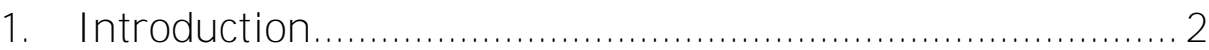

1.1. Palladium-catalyzed coupling reactions.................................. 2

1.1.1. Heck reaction............................................................. 2

1.1.2. Sonogashira reaction ............................................... 3

1.1.3. Suzuki reaction ....................................................... 5

1.2. Excited state intramolecular proton transfer (ESIPT) .............. 7

1.3. 2,1,3-Benzothiadiazole (BTD) derivatives as fluorescent probes: beyond classical scaffolds .................................................... 8

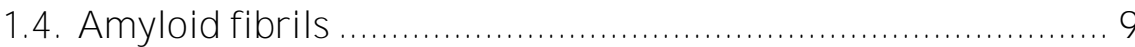

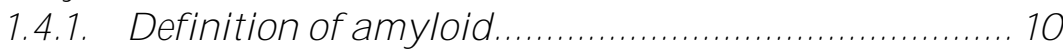

1.4.2. Amyloid structure ......................................................... 11

1.4.3. Amyloid formation ..................................................13

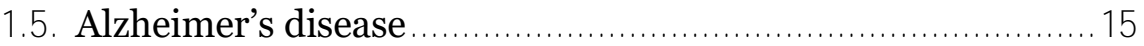

1.5.1. Amyloid- $\beta$ cascade hypothesis ...................................15

1.5.2. Tau cascade hypothesis..............................................17

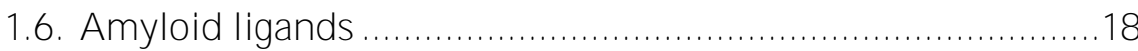

1.6.1. Pan-amyloid probes ..................................................19

1.6.2. A $\beta$ fibril fluorescent probes .........................................21

1.6.3. Tau fibril fluorescent probes .....................................30

2. Research aim .................................................................. 37

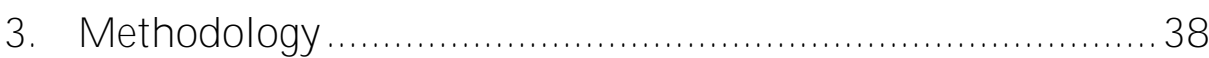

3.1. Fluorescence spectroscopy .................................................. 39

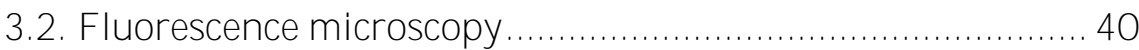

3.3. Time-correlated single-photon counting (TCSPC) ...................41

3.4. Determination of fluorescence quantum yield ...................... 42

3.5. Dissociation constant $\left(\mathrm{K}_{\mathrm{d}}\right)$ by fluorescence spectroscopy ...... 43

4. Summary of papers......................................................... 44

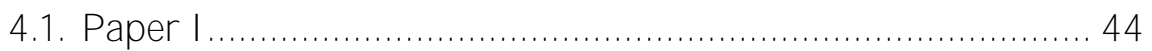

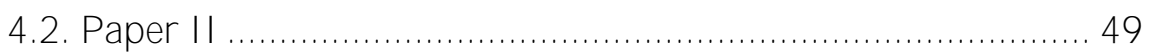




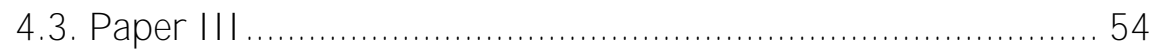

4.4. Paper IV ………………………………………………. 58

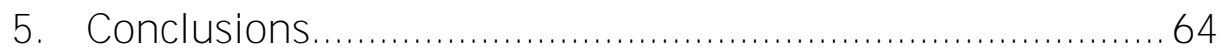

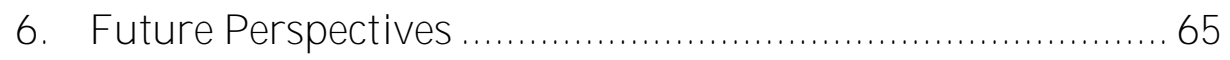

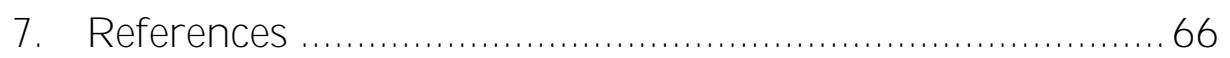




\section{Preface}

Several years ago, my grandma was diagnosed with Alzheimer's disease (AD) and I saw all of the symptoms in different stages until her death. Then an interest for neurological diseases, especially AD, in general was born. During this period, my major, as a master student, is medicinal chemistry focusing on asymmetric synthesis in Sichuan University (China). It always appeared in my mind whether I can combine organic synthesis and neurological diseases. Then $\mathrm{I}$, as a $\mathrm{PhD}$ student, have a chance to study focusing on organic synthesis under the direction of Peter Konradsson in Linköping University supported by China ScholarshipCouncil (CSC). And I know that my co-supervisor is interested in protein misfolding, amyloid formation and disease, both on the molecular level and in the cellular perspective. Then I have my own research topic: synthesis and characterization of fluorescent stilbene-based probes for detection and imaging of disease-associated protein aggregates.

This thesis summarized the results obtained during my PhD studies. The first part of the thesis is to give the reader a general introduction of this field and the current findings, as well as the methods used for my research. Next, a brief summary of the conclusions and findings from my papers can be found. Finally, future perspectives are discussed.

After four years training as a $\mathrm{PhD}$ student, I found myself particularly interested in this field and want to further pursue this area for postdoctoral training. I hope this thesis emphasizes the importance and significances of current research, and will increase your knowledge within the Alzheimer's field.

Hope you will enjoy reading my thesis!

Yours sincerely,

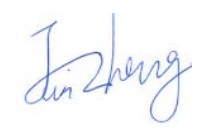

Linköping, September 2018 


\section{Introduction}

\subsection{Palladium-catalyzed coupling reactions}

Palladium (Pd)-catalyzed coupling reactions consist of a family of crosscoupling reactions with different substrates: Kumada, Heck, Sonogashira, Negishi, Suzuki reaction et al. and have become one of the most widely applied methodology for C-C bond construction. ${ }^{1}$ Due to the great successes and significance, the 2010 Nobel prize in chemistry was awarded to Richard Heck, Ei-ichi Negishi and Akira Suzuki for their roles in "palladium-catalyzed cross-couplings in organic synthesis". All the synthesized fluorescent probes in this thesis mainly involve Heck, Sonogashira and Suzuki reactions, as summarized as follows.

\subsubsection{Heck reaction}

The Heck reaction (also called the Heck-Mizoroki reaction) was discovered independently by Mizoroki in 1971 and Heck in 1972, and is generally referred to as the Pd-catalyzed reaction of an alkene with an unsaturated halide (or triflate) to give a substituted alkene, as shown in Scheme $1.1 \mathrm{~A} .{ }^{2}$ The alkene, containing at least one hydrogen, is often electrondeficient such as an acrylate ester, and the halide $(\mathrm{Cl}, \mathrm{Br}, \mathrm{I})$ or triflate is an aryl, or vinyl compound. Pd is usually the preferred metal as it tolerates a wide variety of functional groups such as carbonyl and hydroxyl groups, and commonly used Pd-catalysts are palladium(II) acetate, tetrakis (triphenylphosphine) palladium $\left[\mathrm{Pd}\left(\mathrm{PPh}_{3}\right)_{4}\right]$ or palladium chloride and the like. The commonly used ligands are phosphine ligands such as triphenylphosphine, 2,2 ' -bis(diphenylphosphino)-1,1 ' -binaphthyl (BINAP) or phosphinooxazolines (PHOX). The commonly used bases include potassium carbonate, sodium acetate or triethylamine..$^{3-4}$

The Heck reaction mechanism, based on the Pd catalyst, includes 4 steps (Scheme 1.1B). ${ }^{5}$

Step A: oxidative addition in which Pd inserts itself into the aryl$\mathrm{X}$ bond to form a tetra-substituted complex II. 
Step B: syn insertion in which the alkene inserts itself into the Pd$\mathrm{C}$ bond to form complex III.

Step C: $\beta$-hydride elimination with the formation of a target compound.

Step D: reductive elimination in which the $\operatorname{Pd}(0)$ compound is regenerated by the addition of base.

(A)
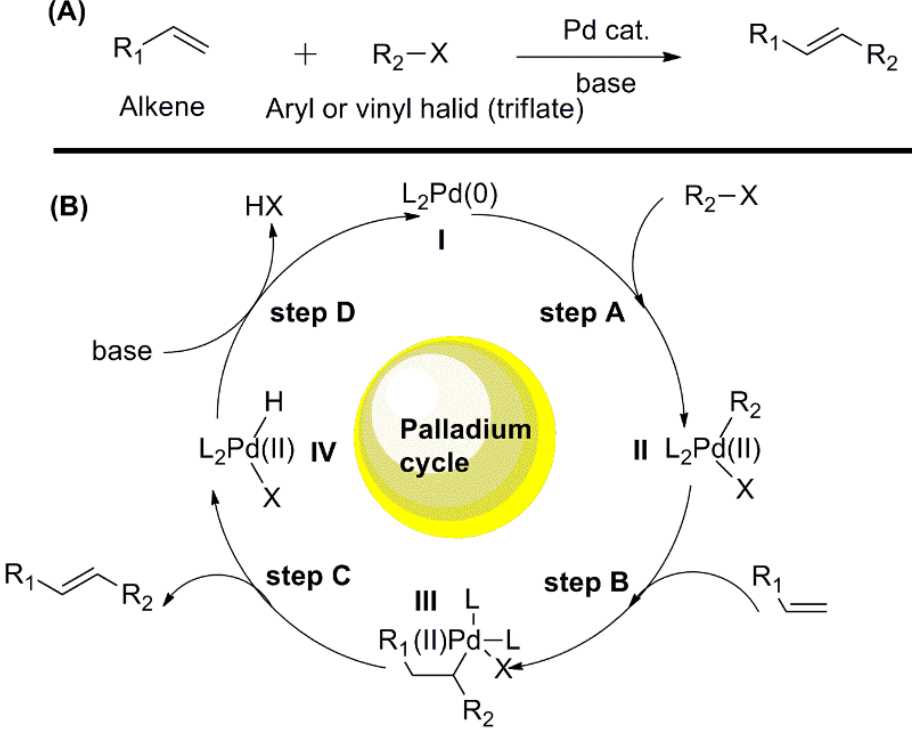

Scheme 1.1 A) General Heck-type reaction. B) General catalytic cycle. ${ }^{5}$

\subsubsection{Sonogashira reaction}

The Sonogashira reaction (also called the Sonogashira-Hagihara reaction) is a Pd and copper(I) catalyzed cross-coupling reaction of a terminal alkyne and an aryl or vinyl halide to give a substituted alkyne, as presented in Scheme 1.2A. ${ }^{6}$ The most common catalysts used are bis(triphenylphosphine)palladium(II) dichloride $\left[\mathrm{Pd}\left(\mathrm{PPh}_{3}\right)_{2} \mathrm{Cl}_{2}\right]$ and $\mathrm{Pd}\left(\mathrm{PPh}_{3}\right)_{4}$. $\mathrm{Pd}\left(\mathrm{PPh}_{3}\right)_{2} \mathrm{Cl}_{2}$ is more soluble in water and stable than $\mathrm{Pd}\left(\mathrm{PPh}_{3}\right)_{4}$, both catalysts require up to $5 \%$ loading to afford good yield. In addition to this, bidentate ligands have also been used, such as [1,2-bis(diphenylphosphino)ethane]dichloropalladium(II) $\left[\mathrm{Pd}(\mathrm{dppe}) \mathrm{Cl}_{2}\right]$ and $\left[1,1^{\prime}\right.$ bis(diphenylphosphino)ferrocene]dichloropalladium(II) [Pd(dppf) $\left.\left.\mathrm{Cl}_{2}\right)\right]$. 
The copper(I) catalyst is usually a copper(I) salt, such as copper iodide. The reaction mechanism is not clearly understood but revolves around a Pd cycle and a copper cycle (Scheme 1.2B). ${ }^{7}$

The Pd cycle includes four steps:

* Oxidative addition in which the active Pd catalyst $\mathrm{L}_{2} \mathrm{Pd}(0)$, complex I (14 electron compound) inserts itself into the aryl or vinyl$\mathrm{X}$ to produce a $\mathrm{Pd}(\mathrm{II})$ intermediate, complex II. This step is believed to be the rate-limiting step of the reaction.

* Trans-metalation in which complex II reacts with the copper acetylide produced in the copper cycle to yield complex III, expelling the copper halide.

* Trans-cis isomerization in which both organic ligands are transoriented and converted to cis to produce complex IV.

- Reductive elimination as the final step in which complex IV is reduced to produce the alkyne with regeneration of the Pd catalyst.

The copper cycle consists of two steps:

* The presence of base results in the formation of a $\pi$-alkyne complex, which further makes the terminal proton on the alkyne more acidic, leading to the formation of copper acetylide.

* Then the copper acetylide reacts with the palladium intermediate II via trans-metalation with regeneration of the copper halide. 
(A)

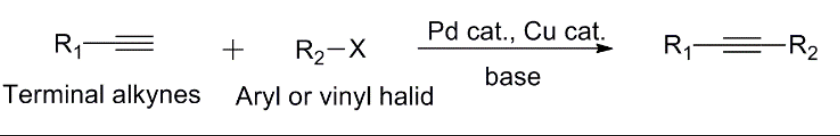

(B)

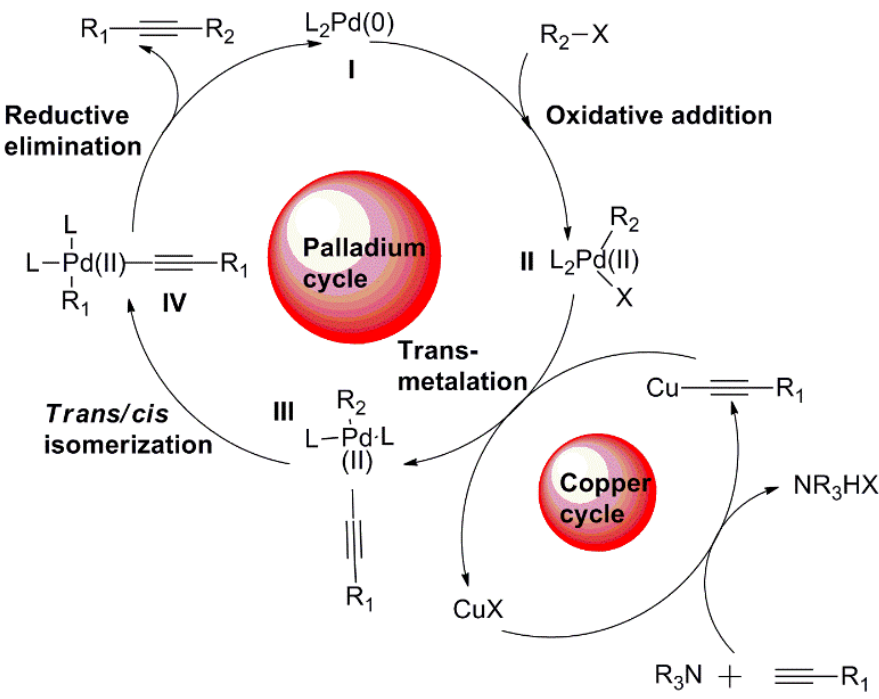

Scheme 1.2 A) General Sonogashira-type reaction. B) General catalytic cycle. ${ }^{7}$

\subsubsection{Suzuki reaction}

The Suzuki reaction ( also called Suzuki-Miyaura reaction or Suzuki coupling) is referred to as the reaction of an organoboron and an organohalide or triflate catalyzed by a $\operatorname{Pd}(0)$ complex (Scheme $1.3 \mathrm{~A}$ ), which was first published in 1979 by Akira Suzuki. ${ }^{8}$ Organoboranes include aryl boronic acids and aryl-trifluoroborate salts. The Pd-based catalysts have been the most frequently used ones, like $\mathrm{Pd}\left(\mathrm{PPh}_{3}\right)_{4}$, although nickel catalysts have also been used such as [1,1'-bis(diphenylphosphino)ferrocene]dichloronickel(II) $\left[\mathrm{NiCl}_{2}\right.$ (dppf)]. ${ }^{9}$ Being able to use relatively cheap and easily prepared reagents, especially using water as a solvent, makes this reaction more economical and practical.

From the perspective of Pd catalyst, the Suzuki reaction mechanism contains three basic steps: oxidative addition, trans-metalation, and reductive elimination as demonstrated in Scheme $1.3 \mathrm{~B} .^{8}$ 
* Oxidative addition: complex I reacts with the aryl or vinyl halide to yield complex II, which is a $\mathrm{Pd}(\mathrm{II})$ intermediate. The oxidative addition is the rate determining step in the catalytic cycle.

Trans-metalation: the reaction of complex III with an organoborane compound produced by the reaction of boronic acid with base via trans-metalation, produces a complex IV in the catalytic cycle.

Reductive elimination: this step gives the desired coupling product and regenerates the $\operatorname{Pd}(0)$ complex for the catalyst under basic conditions.

Base is significantly important for Suzuki reaction as investigated by many chemists. Among them, Duc and coworkers found that the base has three functions: 1) forming the palladium complex III; 2) producing the trialkyl borate; 3 ) the acceleration of the reductive elimination. ${ }^{10}$

(A) $\quad \mathrm{R}_{1}-\mathrm{BY}_{2}+\mathrm{R}_{2}-\mathrm{X} \underset{\text { base }}{\stackrel{\text { Pd cat. }}{\longrightarrow}} \mathrm{R}_{1}-\mathrm{R}_{2}$

$\mathrm{R}_{1}=\mathrm{R}_{2}=$ aryl, alkene (vinyl), alkyne

$\mathrm{X}=$ halide $(\mathrm{I}, \mathrm{Br}, \mathrm{Cl})$, triflate $(-\mathrm{OTf})$

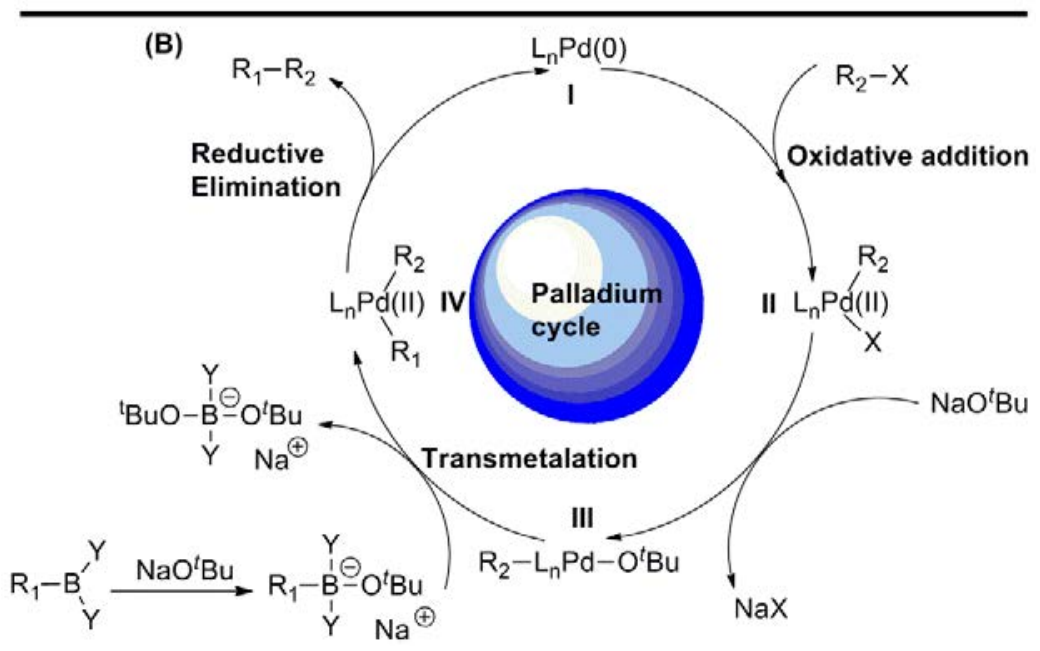

Scheme 1.3 A) General Suzuki-type reaction. B) General catalytic cycle. ${ }^{8}$ 


\subsection{Excited state intramolecular proton transfer (ESIPT)}

In 1956, Weller firstly introduced the field of photochemistry to a new area of research through experiments with salicylic acid (SA) and methyl salicylate (MS), namely ESIPT reaction. ${ }^{11-12}$ As displayed in Scheme 1.4, SA mainly exists as R-form and E-form in solutions, and the latter is the dominant form because of the stronger intramolecular hydrogen bond. Rform cannot undergo excited-state tautomerization, since it involves a weak $\mathrm{O}-\mathrm{H} \cdots \mathrm{O}-\mathrm{H}$ bond between the acidic phenolic $\mathrm{OH}$ and the oxygen atom of the carboxylic $\mathrm{OH}$ and is responsible for the UV band. The Eform can undergo excited-state tautomerization because it involves a strong $\mathrm{O}-\mathrm{H} \cdots \mathrm{O}=\mathrm{C}$ bond between the acidic phenolic $\mathrm{OH}$ and the oxygen atom of the carboxylic $\mathrm{C}=\mathrm{O}$ and the large Stokes shifted fluorescence is assigned to the formation of the K-form*, resulting from ESIPT. Following the pioneering work of Weller, a great deal of research based on SA and its relatively simple derivatives has been directed to the study of photoinduced proton transfer (PT) process across intramolecular hydrogen bonds (IMHBs). Among the studies, the ESIPT is more facile in the neutral form than in the anion of SA and its derivatives. However, few examples do exist. Mishra et al. has reported that ESIPT is observed only in the anionic form of 3-hydroxy-2-naphthoic acid by experimental and theoretical investigations. ${ }^{13}$ In addition, quite a few reports have appeared in literature on the study of substitution effect on ESIPT of SA. ${ }^{14-15}$ 


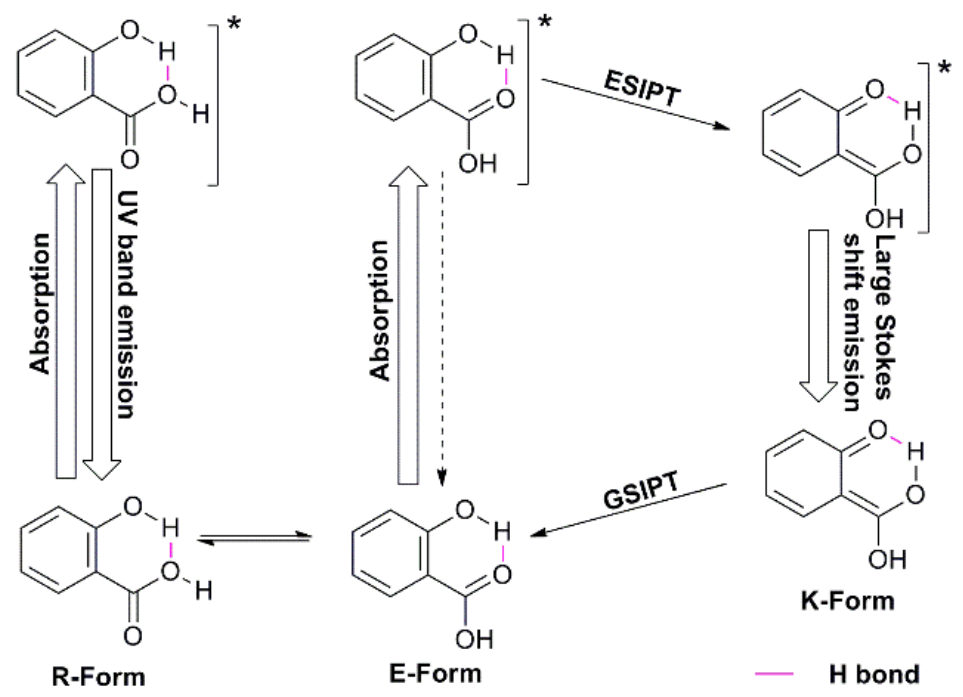

Scheme 1.4 A) Theory of the ground- and excited-state species of SA as well as a schematic of its photo-physics. B) Different species of SA. GSIPT = ground state intramolecular proton transfer.

\subsection{2,1,3-Benzothiadiazole (BTD) derivatives fluorescent probes: beyond classical scaffolds}

To date, Coumarins, fluoresceins, rhodamines, boron-dipyrromthenes (BODIPYs), cyanines, and phenoxazines are among the most used fluorescent derivatives. ${ }^{16}$ Meantime, the limitations associated within them are already well-known. ${ }^{16}$ 2,1,3-benzothiadiazole (BTD) derivatives, as small fluorescent molecules, are a new class of bio-probes with attractive photophysical properties (see Figure 1.1A): high molar extinction coefficients, large stokes shifts, high quantum yields, high storage stability, bright emission, good signal-to-noise ratios and low fading after long periods of irradiation as well as easy to pass the cell membranes. ${ }^{17}$ Although a large number of fluorescent small molecule BTD derivatives were applied to bioimaging analyses of several cell types, little is known about this class of bio-probes used to stain A $\beta$ plaques and NFTs in Alzheimer's disease (AD). Nilsson and coworkers reported on L3 (Figure 1.1B), 
which can intensely stain $\mathrm{A} \beta$ plaques, ${ }^{18}$ and HS-169 (Figure 1.1B) intensely stain $A \beta$ plaques and NFTs. ${ }^{19}$ In view of all the positive effects of the photoluminescent properties of $\pi$-extended BTDs, we wish this new class of bio-probes could fill the gap not occupied by the use of current classical scaffolds and be key player in the future of molecular bio-probes, especially in the field of AD.

(A)

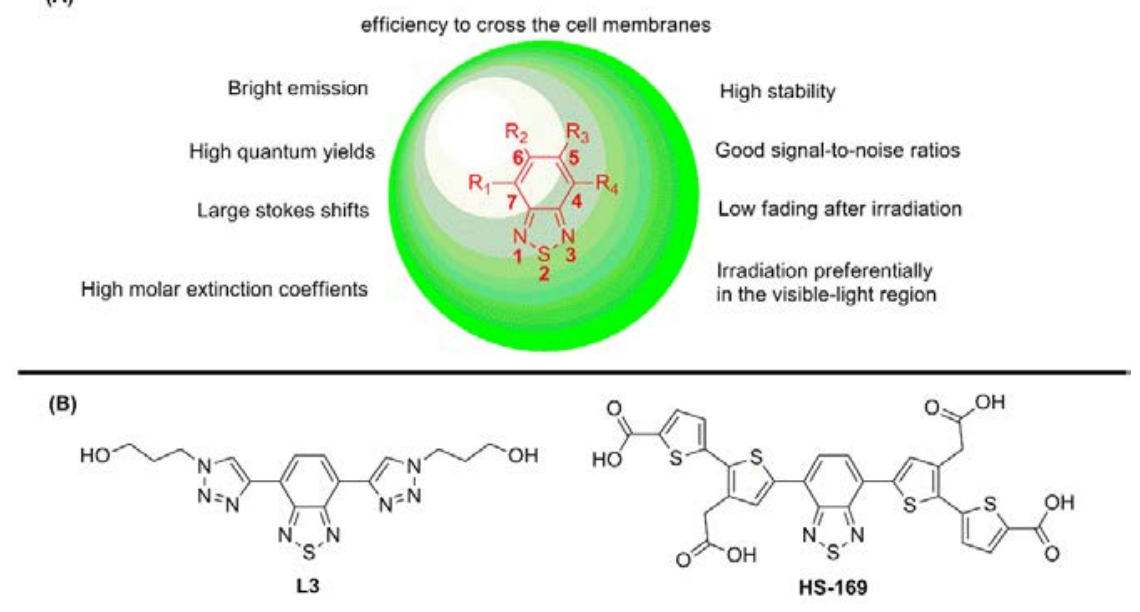

Figure 1.1 A) Chemical structure of BTD derivatives and their attractive photophysical properties. ${ }^{17}$ Note that $R_{2}$ and $R_{3}$ are usually $H$ atoms and that $R_{1}$ and $R_{4}$ are the groups in the positions commonly used for $\pi$-extensions. B) Chemical structures of BTD derivatives reported previously. ${ }^{18-19}$

\subsection{Amyloid fibrils}

Proteins, as large biomolecules, control and regulate essentially every chemical process required for life, such as responding to stimuli, DNA replication, catalyzing metabolic reactions and transporting molecules from one location to another. Each protein is composed of amino acids that are joined by consecutive peptide bonds forming long polymeric chains. Under physiological conditions, these strings of amino acids fold in a specific manner to adopt a particular three-dimensional structure. This structure, referred to as the native state, is necessary for the protein to perform its function. The cell has evolved a range of auxiliary systems 
to assist in the protein folding process but these systems might get overwhelmed during pathologic conditions resulting in the assembly of misfolded proteins. For a certain class of proteins, this situation causes them to aggregate and give rise to deposits of highly organized fibrillar material referred to as amyloid, leading to various human diseases, for example, $A \beta$ peptides in Alzheimer's disease (AD, introduced in the following sections), $\alpha$-synuclein in Parkinson's disease and the prion protein in Creutzfeldt-Jakob disease. ${ }^{20}$

\subsubsection{Definition of amyloid}

The term, amyloid, derived from the Latin amylum and the Greek amylon, comes from the early mistaken identification in 1854 by the German physician scientist Rudolph Virchow of the substance as starch, based on crude iodine-staining techniques. ${ }^{21}$ For a period, the scientific community debated whether or not amyloid deposits are fatty deposits or carbohydrate deposits until it was found (in 1859) that they are, in fact, deposits of proteinaceous material. ${ }^{21}$

The classical, histopathological definition of amyloid according to the Nomenclature Committee of the International Society of Amyloidosis is that amyloid is an extracellular, proteinaceous deposit exhibiting $\beta$-sheet structure perpendicular to the fibril axis. identified by apple-green birefringence when stained with Congo red and seen under polarized light. ${ }^{22}$ These deposits often recruit various sugars and other components such as Serum Amyloid P component, resulting in complex, and sometimes inhomogeneous structures. ${ }^{23}$ Recently this definition has come into questions due to some classic amyloid species have been observed in distinctly intracellular locations. ${ }^{24}$

* A more recent biophysical definition is broader, including any polypeptide that polymerizes to form a cross- $\beta$ structure, in vivo or in vitro. Some of these, although demonstrably cross- $\beta$ sheet, do not show some classic histopathological characteristics such as the Congo-red birefringence. Microbiologists and biophysicists 
have largely adopted this definition, ${ }^{25-26}$ leading to some conflicts in the biological community.

\subsubsection{Amyloid structure}

Amyloid fibrils are insoluble and heterogeneous, so commonly used methods of structure determination of soluble proteins are difficult to apply on amyloids. Therefore, most studies have involved electron microscopy, ${ }^{27} \mathrm{X}$-ray fiber diffraction, ${ }^{28-29}$ and more recently, solid state nuclear magnetic resonance (SSNMR) $)^{30}$ and electro-paramagnetic resonance. ${ }^{31-}$ 32

Electron and atomic force microscopy have shown that fibrils are straight, long and unbranched (Figure 1.2A) ranging in width from 60 to $130 \AA$ with indefinite length ${ }^{33}$ and usually consist of individual subunits named "protofilaments". ${ }^{34-36}$ These may vary in number and are often observed to twist around one another to form the mature fibril. ${ }^{34,36-38}$ Synthetic amyloid-like fibrils, may vary in morphology and this may depend upon the assembly conditions. ${ }^{36}$ Further cryo-electron microscopy studies demonstrated that synthetic amyloid fibrils formed by lysozyme, ${ }^{38}$ insulin, ${ }^{37}$ and $A \beta(1-42)^{39}$ are also composed of several protofilaments wound around one another. The numbers of protofilaments can differ from 2 to $6^{37}$

$\mathrm{X}$-ray diffraction analysis has revealed that amyloid fibrils is "cross- $\beta$ " (Figure 1.2B), sharing a particular core structure consisting of $\beta$-sheet conformation in which the $\mathrm{NH}$ and $\mathrm{CO}$ hydrogen bonding direction runs parallel to the fiber axis and perpendicular to the $\beta$-strands, much like the rungs of a ladder. In addition, the spacing between adjacent $\beta$-strands is approximately $4.7 \AA$, corresponding well with the standard length of hydrogen bonds between $\mathrm{NH}$ and $\mathrm{CO}$ groups of $\beta$-sheets, arranging in a parallel or antiparallel. The $\beta$-sheets are separated by approximately $10 \AA .{ }^{27}$, ${ }^{40-41}$ More detailed X-ray diffraction patterns have been obtained from synthetic amyloid fibrils and additional information obtained has enabled molecular models to be proposed. ${ }^{42}$ In general, these models are cross- $\beta$ in nature and the core of the structure is $\beta$-sheet conformation. The $\beta$-sheet ribbons are associated via side chain interactions that serve to stabilize the structure. ${ }^{42}$ So individual protomers are folded as a $\beta$-arch. 
(A)

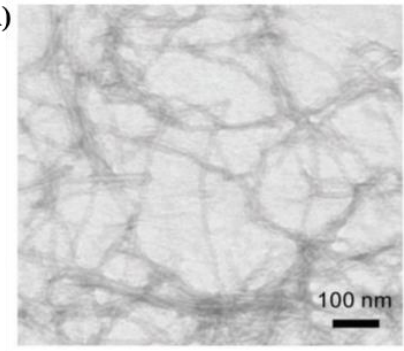

(B)

(D)

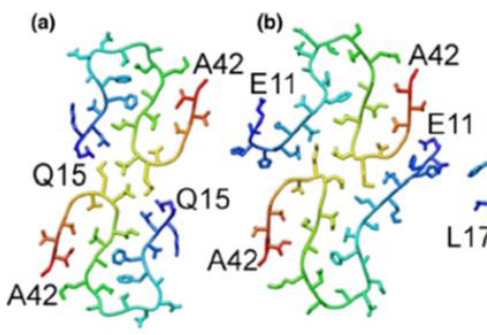

(C)

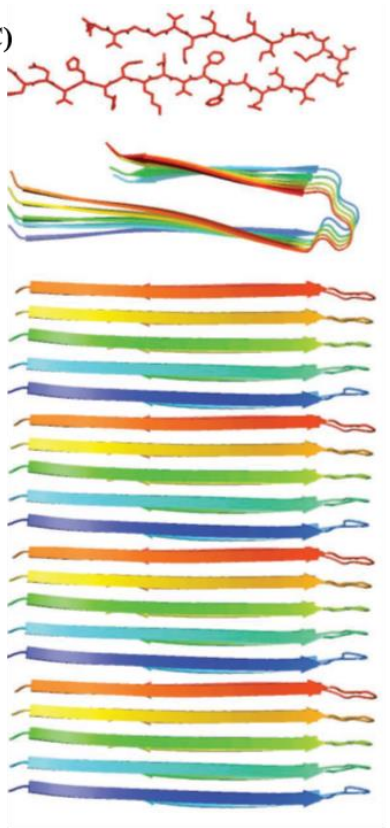

(d)

Figure 1.2 A $\beta$ fibrils in vitro. A) electron micrograph revealing straight, long, unbranching fibrils. B) X-ray micrograph revealing the characteristic "cross- $\beta$ " diffraction pattern. C) SSNMR structural studies revealing the top view of the fiber with side chains (top) and as a carbon (middle) as well as showing the side view (down). D) Cross-sections of molecular models demonstrating polymorphism of A $\beta 1-42$ fibrils. $(a, b)$ Two structures were almost identical; (c) whilst a different peptide fold and protofilament structure was observed with a third sample of A $\beta 1$ 42 fibrils assembled in vitro and (d) combining cryo-EM and NMR in a recent study. Structures were generated in PyMol using the PDB codes: (a) 5KK3 (b) 2NAO (c) 5AEF (d) 5OVQ. (A-C) reproduced with permission from Prion, 2008, 2, 112-117. And (D) reproduced with permission from J. Intern. Med., 2018, 283, 218-237. 
Recently, SSNMR structural studies have significantly gained our knowledge of the molecular structure of amyloid fibrils ${ }^{43}$ and this work has been complemented by amyloid formed by a number of different disease associated peptides. ${ }^{32}$ SSNMR studies of A $\beta$ fibrils associated with $\mathrm{AD}$ have shown that $\beta$-sheet, depending on the properties of the precursor polypeptide, could be arranged parallel or anti-parallel within the protofilaments. ${ }^{44-46} \mathrm{~A} \beta$ peptide folds into a $\beta$-arch structure that then associates with other molecules to form parallel, in register $\beta$-structure (Figure $1.2 \mathrm{C}) .{ }^{47-48}$ In addition, over the past $10-15$ years, it has been acknowledged that amyloid fibrils are generally polymorphic at the molecular level. ${ }^{49-50}$ For instance, SSNMR or electron cryo-microscopy (cryo-EM) studies recently provided that $A \beta$ 1-42 peptide can attain variable stable folds and protofilament structures (Figure 1.2D). ${ }^{51}$

\subsubsection{Amyloid formation}

In order for the protein to perform its natural task, the newly synthesized polypeptide chain needs to fold in a specific manner to adopt a particular three-dimensional structure, referred to as the native state. However, when a natively soluble and functional protein becomes partly unfolded or misfolded due to mutations, changes in the environmental conditions or chemical modifications, the protein begins to rearrange into aggregate and form amyloid aggregates leading to the associated amyloid disease. ${ }^{52}$ Both processes can be described as a multidimensional energy landscape (Figure 1.3) with Gibb's free energy on the y-axis and the width of the funnel representing entropy. ${ }^{53-54}$ Initially, the unfolded protein has a lot of conformational freedom but as the folding process proceeds, the molecule becomes more restricted giving rise to a conformational volume with the appearance of a funnel (green and red). Additionally, the amyloid state of protein can even be more stable. However, it is difficult to convert to the more stable amyloid state due to the high free energy barriers. $^{55}$ 


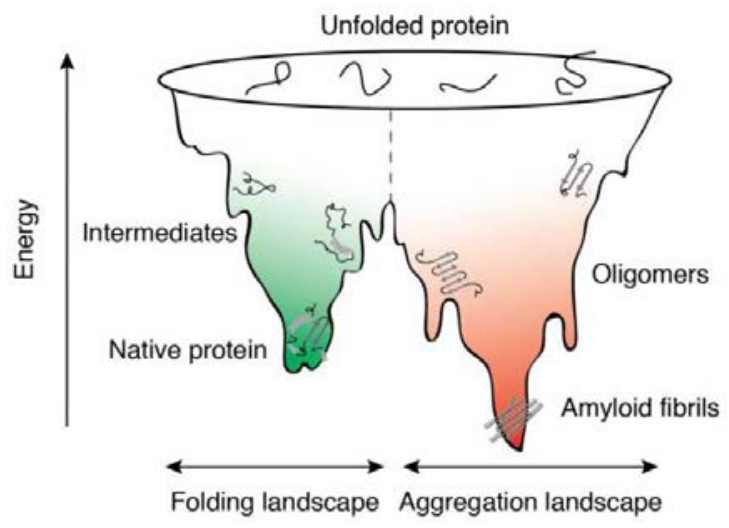

Figure 1.3 The protein folding energy landscape. The green area depicts the folding of native proteins and the red area depicts the misfolding of proteins. Reproduced with permission from PhD thesis "Investigating Amyloid $\beta$ toxicity in Drosophila melanogaster”, 2017, Maria Jonson.

Amyloid fibrillation is known to be a nucleation-dependent process including three main phases: the lag, growth and stationary phases. In the lag phase, the native monomer is destabilized and undergoes a re-arrangement into $\beta$-sheet rich partly unfolded structures. Then the lag phase is continued by primary nucleation where interactions between the partly unfolded or misfolded monomers to form a nucleus. ${ }^{56-57}$ This process is thermodynamically disfavoured since the resulting intermolecular interactions do not overweigh the reduction in entropy and therefore considered as the rating-limited step of the aggregation process. In addition, the length of the lag phase may be shortend and even abolished by the addition of pre-formed fibrillar species. ${ }^{58}$ The growth phase begins as soon as the nucleus is established, forming fibrils which can catalyze further growth of soluble oligomers and pre-fibrillar structures, protofibrils. The stationary phase, in which mature fibrils are in assembly/disassembly equilibrium with the monomers, is reached. ${ }^{55,59}$ It was reported that the nucleation rate together with the growth rate of a fibril might influence the age of onset for amyloid-related diseases. ${ }^{60}$ 


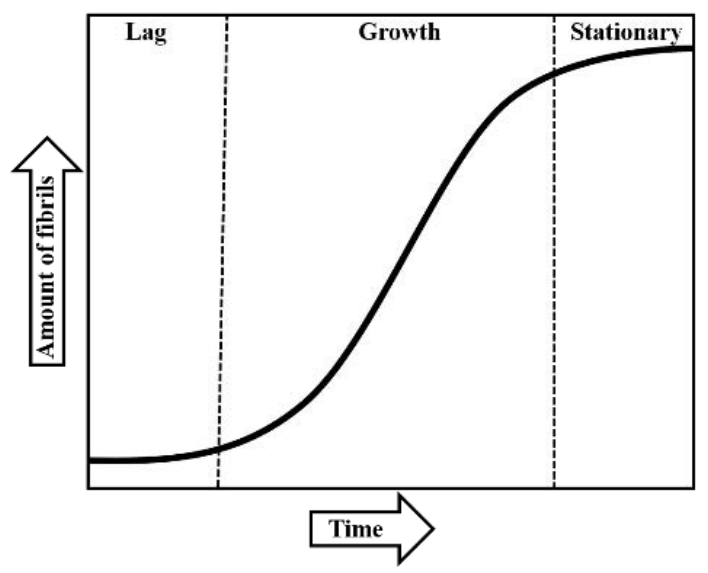

Figure 1.4 Schematic of amyloid fibrillation of a protein.

\subsection{Alzheimer's disease}

$\mathrm{AD}$ is a chronic neurodegenerative disease that was first reported by the psychiatrist Alois Alzheimer from Germany in $1906 .{ }^{61}$ AD is characterized by features including memory impairment, disorientation, mood and behavior changes as well as difficulties in expressing yourself and understanding the spoken and written language. ${ }^{62} \mathrm{AD}$ is an age-dependent disease, including three stages: early stage, middle stage and late stage, with a progressive pattern of cognitive and functional impairment. ${ }^{63}$ In 2016 about 47 million people lived with AD in the world, and this number is continuously increasing, especially due to the increased life expectancy worldwide. ${ }^{64}$ Usually, over 65 years of age in people begins with AD and about $6 \%$ of people 65 years and older worldwide is affected. ${ }^{65}$ Hence $\mathrm{AD}$ is a global public health issue, demanding huge amounts of resources, especially in developed countries. ${ }^{66}$

\subsubsection{Amyloid- $\beta$ cascade hypothesis}

To date, the effect of $\mathrm{AD}$ on the brain is clear although the causes aren't yet fully understood. It is known that less than 5\%, AD is caused by specific genetic changes. ${ }^{67}$ Many hypotheses about AD have been developed, 
including $A \beta$ hypothesis, ${ }^{68-69}$ tau hypothesis ${ }^{69-70}$ cholinergic hypothesis, ${ }^{71-72}$ and other hypotheses. ${ }^{73-75}$ The first two terms are the most dominant hypothesis in the field of AD pathogenesis.

In 1991, the amyloid cascade hypothesis was proposed by John Hardy and David Allsop that extracellular $\mathrm{A} \beta$ deposits are what initiates the cascade of events leading to pathological changes, neurodegeneration and cognitive decline in a linear pathway. ${ }^{68-69}$ The location of gene for amyloid precursor protein (APP), a transmembrane protein with a small intracellular domain and a larger extracellular domain, supports this assumption. As demonstrated in Figure 1.5, APP processing can occur in either the non-amyloidogenic pathway or the amyloidogenic pathway. Furthermore the hypothesis is strengthened by findings that a majority of mutations linked to early-onset $\mathrm{AD}$, with the most pronounced being the Swedish mutation, acts by increasing the total amount of $A \beta$. The ratio of the fibrillogenic $A \beta 1-42$ peptide compared to other alloforms are increased for certain mutations in APP, and the levels of amyloid plaques are associated with familial mutations in the presenilin 1 gene coding for the catalytic subunit of the $\gamma$-secretase cleaving APP ( $\beta$-CTF) within the membrane (Figure 1.5). ${ }^{76-77}$ However, an increasing number of studies show that the density of plaques in brain have a weak correlation with the degree of dementia, and that plaques in healthy individuals also occur. ${ }^{78}$ Therefore, the theory has been modified as evidence providing a strong correlation between soluble $A \beta$ oligomers and disease pathology. ${ }^{79}$ Studies demonstrate that these toxic $A \beta$ oligomers precede fibril formation and are responsible for the cascade involving amyloid deposition, inflammation, oxidation stress that in turn leads to clinical disease. ${ }^{80}$

All these reactions suggest that $A \beta$ is not sufficient to cause the complex pathology of $\mathrm{AD}$ and there are more to the story than $\mathrm{A} \beta$ alone ${ }^{81-82}$ This, together with recent understanding of the physiological roles of $A \beta$ is challenging the hypothesis and has revised the view on how to approach the development of therapies against AD. 


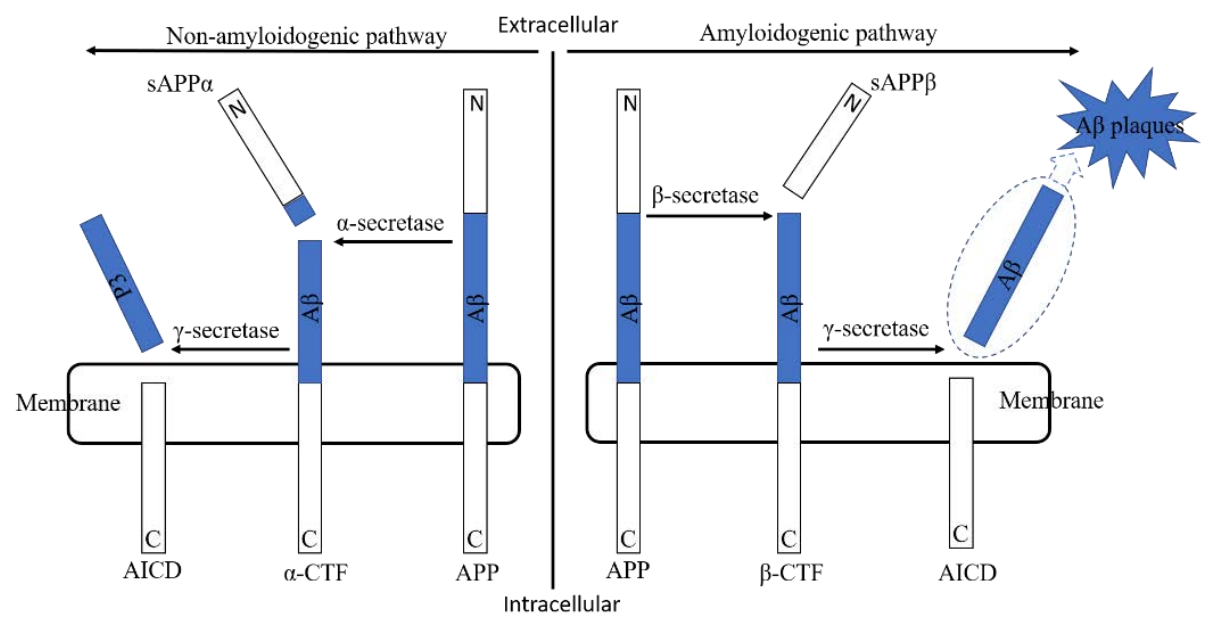

Figure 1.5 The proteolytic processing of APP including the non-amyloidogenic pathway and amyloidogenic pathway.

\subsubsection{Tau cascade hypothesis}

Tau proteins, mostly associated with microtubules, are abundant in the central nervous system with predominate expression in the axonal compartment of neurons. ${ }^{83}$ In normal adult human brain tau proteins exist in six isoforms, $0 \mathrm{~N} 3 \mathrm{R}, 1 \mathrm{~N} 3 \mathrm{R}, 2 \mathrm{~N} 3 \mathrm{R}, 0 \mathrm{~N} 4 \mathrm{R}, 1 \mathrm{~N} 4 \mathrm{R}$ and $2 \mathrm{~N} 4 \mathrm{R}$, ranging from 352 to 441 amino acids (Figure 1.6A). ${ }^{84}$ In AD where tau filaments are present, tau is hyperphosphorylated and the functional consequences of this have been under investigation for a long time. The tau hypothesis indicates that tau protein aggregation causes the disease cascade. ${ }^{69} \mathrm{Hy}-$ perphosphorylated tau accumulates as paired helical and straight filaments and finally forms aggregated tau protein (also known as tau neurofibrillary tangles, NFTs) (Figure 1.6B). ${ }^{84}$ The loss of microtubule-stabilizing tau protein leads to the degradation of the cell's cytoskeleton which collapses the neuron's transport system, resulting in malfunctions in biochemical communication between neurons and, ultimately the death of the cells. ${ }^{85-86}$ 
(A)

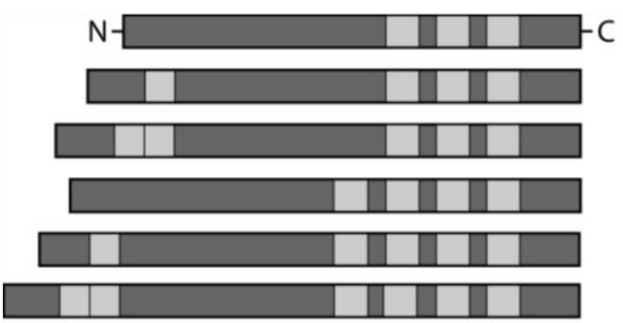

0N3R 352 aa

1N3R 381 aa

2N3R 410 aa

0N4R 383 aa

1N4R 412 aa

2N4R 441 aa

(B)

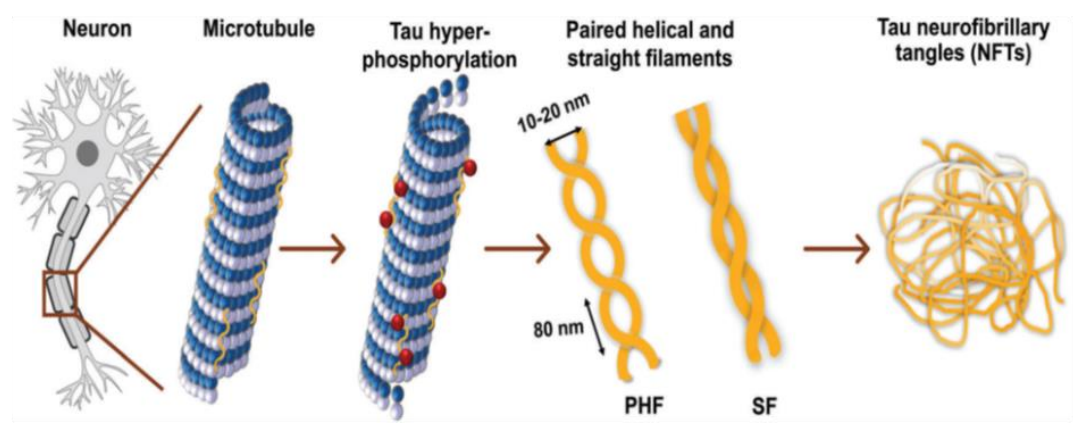

Figure 1.6 A) Six tau isoforms in adult human brain. ${ }^{84} \mathrm{~B}$ ) The formation process of NTFs. ${ }^{84}$ (B) reproduced with permission from Chem. Soc. Rev. 47, 2249-2265.

\subsection{Amyloid ligands}

To date, the pathological mechanism of AD is elusive. Food and Drug Administration (FDA)-approved medications currently available including one N-methyl-D-aspartate receptor (NMDA) receptor antagonist and four acetylcholinesterase inhibitors, only provide temporary relief from symptoms. None of these treatments halts the progression of this terminal disease. This argues that more research is needed on early-stage diagnosis to further understand and treat this disorder.

The past decade has seen great progress in the aspect of imaging probes for the non-invasive detection of A $\beta$ plaques and NFTs, mainly depending on techniques such as positron emission tomography (PET), singlephoton emission computed tomography (SPECT) and magnetic resonance imaging (MRI). ${ }^{87-89}$ Recently, optical imaging, especially near-infrared fluorescence (NIRF) imaging, when compared to PET, SPECT and 
MRI, is highly promising because it is real-time, not radioactive, inexpensive and of high-resolution both in vivo and ex vivo. ${ }^{90}$ Optical imaging is an imaging technique using ultraviolet, visible, and infrared light for imaging. Especially, NIRF probes are favorable for $\mathrm{A} \beta$ and Tau detection in vivo because emission wavelengths in the NIR range $(650-900 \mathrm{~nm})$ are distinct from the autofluorescence of biological matter, which is suitable for in vivo applications. In addition, for a NIRF imaging setup, when compared with PET, costs are much lower, the data analysis takes less time, and specialized personnel and labs are not needed.

In principle, an ideal fluorescent probe for imaging of $A \beta$ plaques or tau tangles should have the following properties. ${ }^{91-94}$

Straightforward synthesis.

* High selectivity and binding affinity.

* High quantum yield and significant changes in the fluorescence properties upon binding to A $\beta$ plaques or NFTs.

- A suitable wavelength of excitation and emission greater than 450 $\mathrm{nm}$ to minimize background fluorescence from brain tissue, ideally $650-900 \mathrm{~nm}$ for in vivo detection.

* High blood-brain barrier (BBB) permeability (logP values between 2 and 3.5, or $\operatorname{cog} \mathrm{P}<5.0$ are considered optimal). ${ }^{95}$

* High metabolic stability.

* Fast washout kinetics from normal brain regions.

Low toxicity.

\subsubsection{Pan-amyloid probes}

There is a significant overlap between the characteristics and architectures of chemical probes for both $A \beta$ plaques and tau tangles as well as other amyloids, since these targets share some striking similarities. For instance both exhibit $\beta$-sheet conformation and stacking at the core of 
their structure and represent an environment that is significantly less hydrophilic than the surrounding medium. Initially, staining of amyloid in brain sections for pathological post-mortem analysis was performed using traditional tissue staining dyes such as Crystal violet, Hoffman's violet and Methyl green. Other probes used for this purpose are the phenothiazines including Toluidine blue. These dyes show a colour change when bound to amyloids, as compared to their staining of the surrounding tissue (Figure 1.7).

Thioflavin T and S (ThT and ThS, Figure 1.7) are prototypical molecular rotors, showing a dramatic increase in fluorescence when their rotational freedom is restricted. Owing to their flat structure, these probes are particularly well suited to bind to $\beta$-sheet rich aggregates. Therefore, they show significantly strong staining on $A \beta$ plaques and tau tangles.

Congo Red (Figure 1.7) is commonly used for fluorescent staining of the plaques and tangles in post-mortem brain sections of $\mathrm{AD}$ patients. ${ }^{96}$ Congo red binding resulting in green birefringence under crossed polarizers is a criterion of diagnosis of amyloid deposites. ${ }^{20}$ Chrysamine-G (CG) (see structure in Figure 1.7), the first derivative of CR, was synthesized and used by Klunk et al. as an amyloid dye. ${ }^{97-98}$ This soon led to the synthesis of a number of bis-styrylbenes with strong binding affinity, which include X-34, ${ }^{99} \mathrm{FSB},{ }^{100} \mathrm{BSB},{ }^{101-102}$ ISB (see structures in Figure 1.7). ${ }^{103}$ These compounds represent a more lipophilic version of $C G$ to increase the potential for BBB penetration. However, neither of these compounds is selective for $A \beta$ plaques or tau tangles, rather staining all of the proteinaceous aggregates in the brain. Klunk et al. further synthesized Methoxy-X04 (Figure 1.7) by removing all carboxylic acid groups, resulted in efficient BBB penetration and in vivo staining of the brain amyloid content. ${ }^{104}$ Sharing a $\pi$-conjugated backbone of similar length, curcumin (Figure 1.7), a natural probe extracted from turmeric, has been shown to fluorescently stain various protein aggregates including $A \beta$ and tau fibrils. 

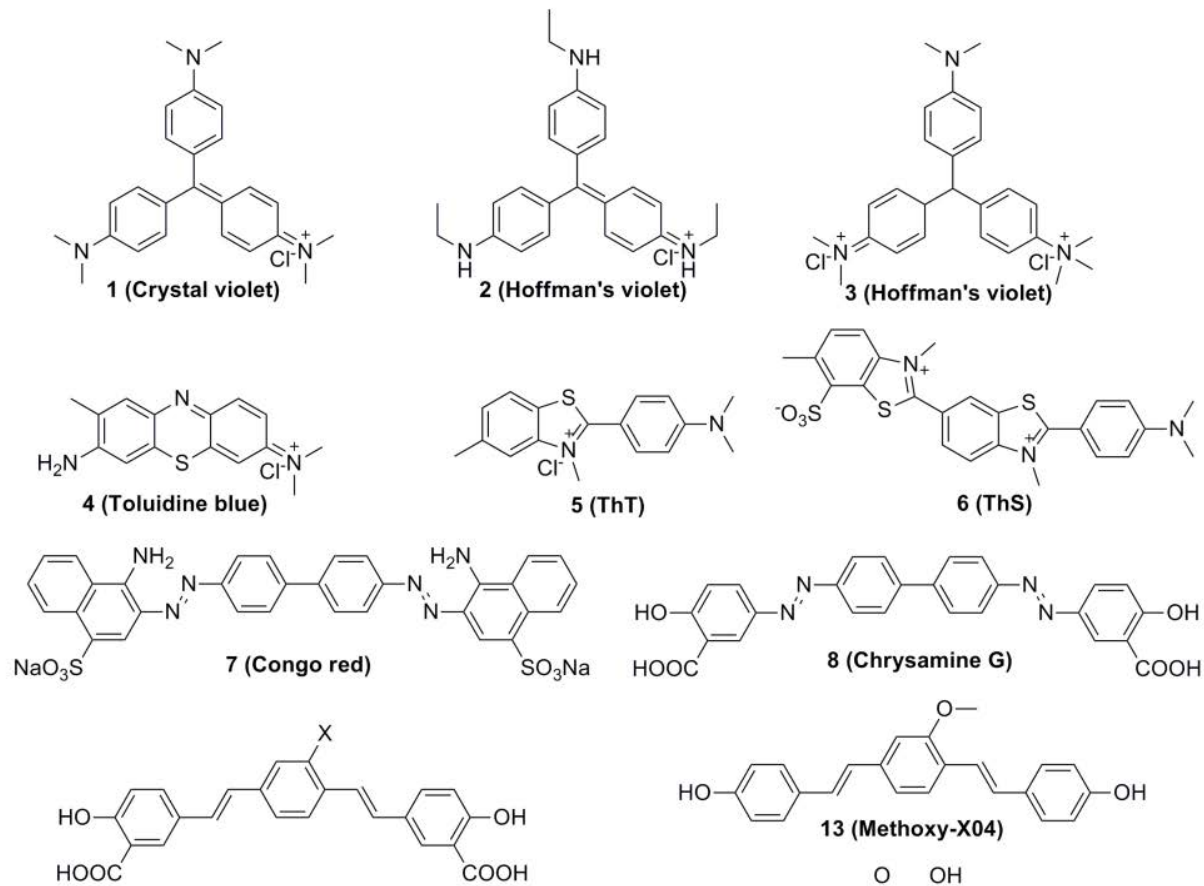

\begin{tabular}{l|c|c|c|c} 
& $9(\mathrm{X}-34)$ & 10 (BSB) & $11(\mathrm{FSB})$ & 12 (ISB) \\
\hline $\mathrm{X}$ & $\mathrm{H}$ & $\mathrm{Br}$ & $\mathrm{F}$ & $\mathrm{I}$
\end{tabular}

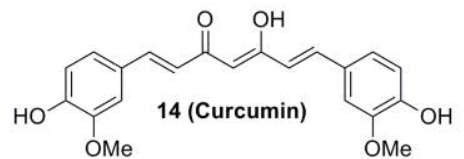

Figure 1.7 Chemical structures of the pan-amyloid probes. ${ }^{96-104}$

\subsubsection{A $\beta$ fibril fluorescent probes}

Currently, the reported $A \beta$ fibril fluorescent probes largely share a common push-pull structure and are highly sensitive to solvent polarity. They are essentially non-fluorescent in aqueous solutions, but highly fluorescent upon binding to $A \beta$ fibrils or in nonpolar solvents. In this section, I will introduce the different scaffold features of this mode.

\section{Thioflavin-T and its derivatives}

The fluorescent probe ThT (Figure 1.7) has become the widely used "gold standard" for selective amyloid aggregates identification in vitro and in vivo since first introduced in 1959. Then a variety of derivatives of ThT have been developed during the past years. Although many of them are 
radiolabelled for PET or SPECT imaging, there are still some probes that display high affinity for $A \beta$ aggregates.

Compound 15 (BTA-1, Figure 1.8) is a neutral ThT derivative, which showed an excellent affinity $\left(\mathrm{K}_{\mathrm{d}}=3 \mathrm{nM}\right)$ in in vitro binding assay using A $\beta 1-40$ fibrils. When $\left[{ }^{11} \mathrm{C}\right]$ BTA-1 was injected into mice, it displayed an excellent brain penetration with an initial brain uptake at 2 min of 3.0\% dose /organ. ${ }^{105}$ Compound 16 (12a, Figure 1.8) is a benzothiazole Schiffbase and has a high affinity towards $\mathrm{AD}$ brain homogenates with a $\mathrm{K}_{\mathrm{i}}$ value of $4.4 \mathrm{nM}$ and this compound can label $\mathrm{A} \beta$ plaques of $\mathrm{AD}$ brain tissue. ${ }^{106}$ Compound 17 (Figure 1.8), from Jung's group, showed a high affinity $\left(\mathrm{K}_{\mathrm{d}}=3.3 \mu \mathrm{M}\right)$ for $\mathrm{A} \beta$ fibrils and a significant fluorescence increase (36.1-fold) as well as a $\log \mathrm{P}=3.7$ suitable for potential $\mathrm{BBB}$ penetration. ${ }^{107}$ Kung et al. reported a ThT derivative, compound 18 (IMPY, Figure 1.8), displaying a much better binding affinity towards $A \beta 1-40$ fibrils in vitro $\left(K_{i}=15 \pm 5 \mathrm{nM}\right)$ and selective $A \beta$ plaque labelling on post-mortem $\mathrm{AD}$ brain sections. ${ }^{108}$ However, the fluorescence spectra of the above-mentioned probes are still in a range that limits their potential use in vivo.

Ono et al. designed and synthesized two push-pull benzothiazole derivatives, compound 19 (PP-BTA-1, Figure 1.8) and 20 (PP-BTA-2, Figure 1.8 ), with either benzothiazole or styryl-benzothiazole as the highly polarized bridge. ${ }^{109}$ Results of inhibition assays on the binding to $A \beta$ aggregates indicated that $\mathbf{1 9}$ and $\mathbf{2 0}$ may occupy a binding site on $\mathrm{A} \beta$ aggregates similar to that of ThT with $\mathrm{IC}_{50}$ values for $\mathbf{1 9}$ and $\mathbf{2 0}$ were 0.12 and $0.11 \mu \mathrm{M}$, respectively. In addition, 19 and 20 can clearly stain $\mathrm{A} \beta$ plaques in both transgenic mice and human AD brain sections.

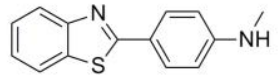

15 (BTA-1)

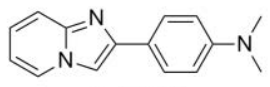

18 (IMPY)

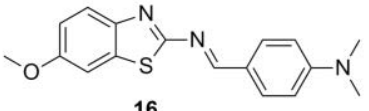

16

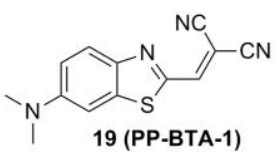

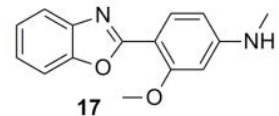

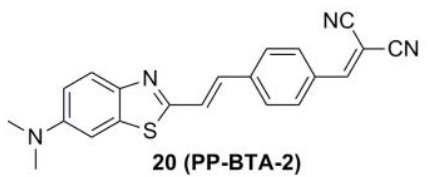

Figure 1.8 Chemical structures of Thioflavin-T derivatives. ${ }^{105-109}$ 


\section{Curcumin and its derivatives}

In $\mathrm{AD}$ research, curcumin (Figure 1.7) has been reported to have the following properties: anti-oxidation, anti-A $\beta$ aggregation, inhibition of $\beta$ secretase and acetylcholinesterase, and $\mathrm{A} \beta$-induced inflammation in vitro. ${ }^{110}$ Cole et al. reported that curcumin can label amyloid plaques , like $\mathrm{ThS}$ in $\mathrm{AD}$ and transgenic mice brain sections, and crosses the $\mathrm{BBB}$ to bind to plaques in vivo. ${ }^{111}$ However, due to its short emission wavelength, practical applications of curcumin in vivo are limited.

Moore and colleagues designed and synthesized a novel class of NIRF probes derived from curcumin. In this structure, a difluoroboronate moity and two $p$-dimethyamino phenyl groups were integrated into the curcumin scaffold to form a donor-accepter-donor architecture. Among them, compound 21 (CRANAD-2, Figure 1.9) functions as a smart probe because of drastic fluorescence changes (70-fold fluorescence intensity increase and $90 \mathrm{~nm}$ hypochromic shift), a lifetime change, and quantum yield improvement upon binding to $A \beta$ aggregates. This probe has a high affinity $\left(\mathrm{K}_{\mathrm{d}}=38.0 \mathrm{nM}\right)$ for $\mathrm{A} \beta$ aggregates, a reasonable $\log \mathrm{P}=3$ and a weak albumin interaction. Because bulky analogs 22 (CRANAD-6, Figure 1.9) didn't show significant fluorescence change, it was proved that the binding site of $\mathbf{2 1}$ is stereo-hindered, likely to be the hydrophobic site containing the core fragment (KLVFF). ${ }^{112}$ Compound 21 was capable to selectively stain of A $\beta$ plaques in a brain section of APP-PS1 transgenic mouse. ${ }^{112}$ In another report from the same group, 21 was used as nonconjugated FRET pair in combination with compound $\mathbf{2 3}$ (CRANAD-5, Figure 1.9) for differentiating $A \beta$ monomers from higher aggregated $A \beta$ species. ${ }^{113}$

The same group reported another probe, compound 24 (CRANAD-3, Figure 1.9) by replacing benzene with pyridine and dimethylamino with diethylamino groups, with subsequent removal of the difluoroboron bridge. The big difference from 21 was that it also interacted with soluble A $\beta$ monomers and dimers, and displayed fluorescence signal change except for significant fluorescence property changes upon binding to $\mathrm{A} \beta$ aggregates. $^{114}$ 
Recently, more new analogs of $\mathbf{2 1}$ were designed and synthesized as NIRF probes for detection of soluble and insoluble $A \beta$ species and inhibition of copper-ion induced $A \beta$ aggregation. ${ }^{112}$ Zhang et al. studied the structural stereohindrance compatibility of $A \beta$ species and designed and synthesized a compound 25 (CRANAD-58, Figure 1.9). Compound 25 displayed different fluorescence response for soluble (monomers, dimers and oligomers) and insoluble $A \beta$ species. In vitro staining assay revealed 25 could specifically highlight $A \beta$ plaques that co-stained with ThS. In vivo NIRF imaging indicated that 25 was capable of differentiating transgenic and wild-type mice at the age of 4 months. ${ }^{115}$ Another analog, compound 26 (CRANAD-17, Figure 1.9) containing two copper coordinating imidazoles, could compete and interfere with copper induced A $\beta$ crosslinking. In vitro anti-crosslinking studies indicated that $\mathbf{2 6}$ could induce $68 \%$ more of $A \beta$ monomers as compared with non-treated samples, suggesting potential usage as a theragnostic agent. ${ }^{112}$
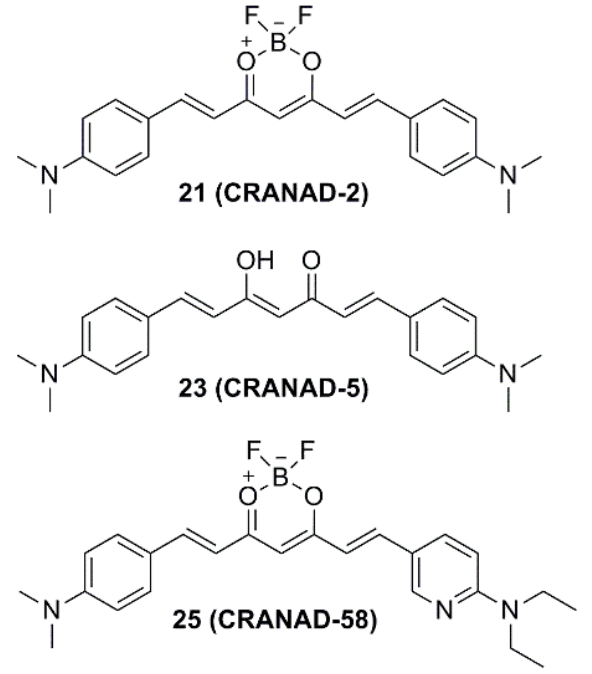
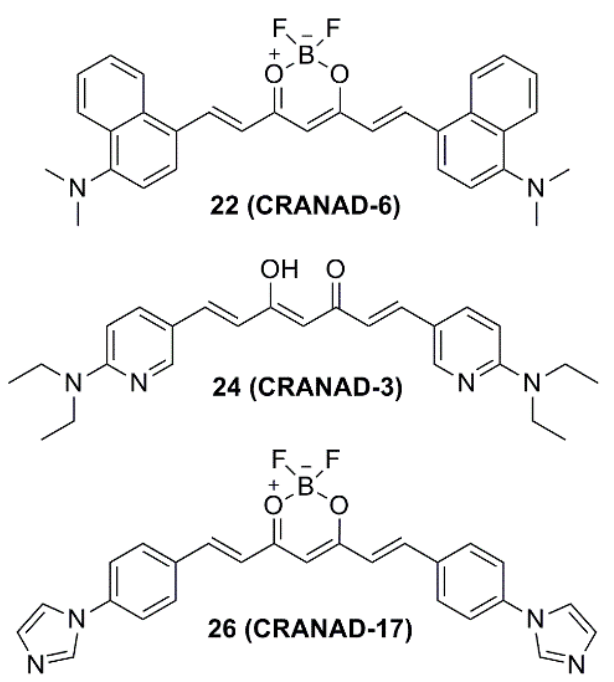

Figure 1.9 Chemical structures of curcumin derivatives. ${ }^{12-115}$

\section{BODIPY-derived probes}

Boron-dipyrromethene, BODIPY, is a classical fluorescent probe applied in a variety of fields. ${ }^{116}$ Boens et al. reviewed the notable features of BODIPY, all contributing to the appeal of this structure as an important 
tool in a variety of imaging applications. ${ }^{117}$ One et al. reported the first BODIPY-derived fluorescence/SPECT dual probe 27 (BODIPY-7, Figure 1.10) containing a conjugated thiophene-phenyl chain for $A \beta$ fibril detection. ${ }^{118} 27$ has a modest affinity $\left(\mathrm{K}_{\mathrm{i}}=108 \mathrm{nM}\right)$ for $\mathrm{A} \beta$ aggregates and is able to detect $A \beta$ plaques in in vitro staining of brain sections. The low BBB permeability, the short wavelengths of absorption/emission, at $606 / 613 \mathrm{~nm}$, and the narrow Stokes shift restrict in vivo imaging applications. ${ }^{118}$ Then another BODIPY-derived probe, 28 (BAP-1, Figure 1.10) with a maximal emission wave length of $648 \mathrm{~nm}$, displayed excellent efficacy both in vitro and in vivo. 28 showed a high affinity $\left(\mathrm{K}_{\mathrm{d}}=44.1 \mathrm{nM}\right)$ for $A \beta$ aggregates and clearly stained $A \beta$ plaques in the brains of transgenic mice. Further studies indicated that $\mathbf{2 8}$ could clearly differentiate between 25-month-old wild-type and $\mathrm{Tg} 2576$ mice at $1 \mathrm{~h}$ post-injection and possesses good metabolic kinetics in vivo. ${ }^{119}$ In 2013, several BAP-1 analogs. 29, 30, 31 and 32 (BAP-2, BAP-3, BAP-4 and BAP-5, Figure 1.10), which contain most of the advantageous features of 28 but a better maximal emission wavelength, up to $700 \mathrm{~nm}$, were disclosed. ${ }^{120}$ The measured $K_{d}$ values for 29, 30, 31, and 32 were 55, 149, 27, and $18 \mathrm{nM}$, respectively, suggesting a high affinity for A $\beta 1-42$ aggregates. Similar to $\mathbf{2 8}$, they could selectively label $A \beta$ plaques in vitro. However, the probe, 29, was selected for in vivo imaging but failed due to the same problem of higher accumulation in the scalp than in the brain. This result indicates that appropriate structural modifications to BODIPY derivatives are necessary for future in vivo applications.

Sozmen et al. developed a library of styryl-conjugated BODIPY probes (EUA1-5, Figure 1.10) with emission wavelengths ranging from 654 to $763 \mathrm{~nm}$ for optical imaging of $A \beta$ plaques. ${ }^{121}$ The measured $K_{d}$ values of EUA1-5 were 320, 230, 320, 48.6 and $97 \mathrm{nM}$, respectively. Among them, 33 (EUA-1), 34 (EUA-2) and 35 (EUA-4) efficiently stained A $\beta$ plaques in Tg2576 mice brain sections and demonstrated good BBB penetration. ${ }^{121}$ The probe, 35, the highest affinity and best fluorescence staining, would be a promising diagnostic agent after further modification. 


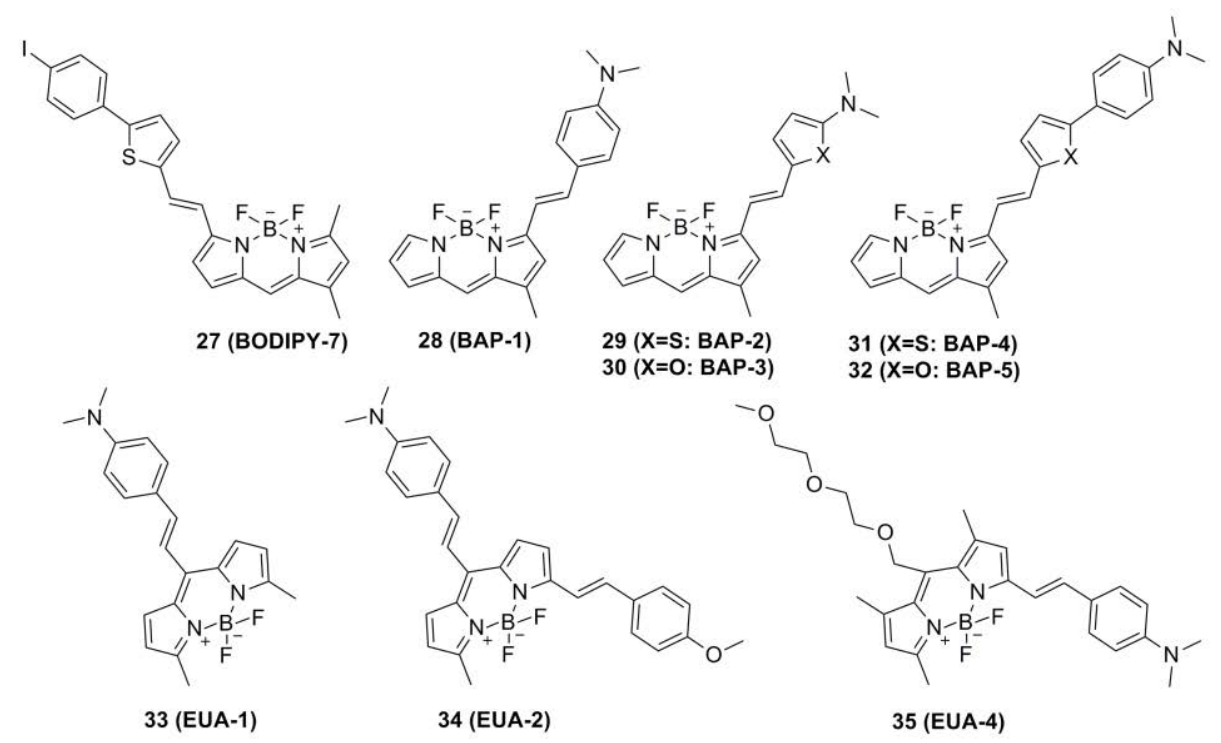

Figure 1.10 Chemical structures of BODIPY derivatives. ${ }^{118-121}$

\section{Alkatriene derivatives}

Recently, Ono, Cui and co-workers developed a new series of structurally simplified $A \beta$ fluorescent probes DANIRs, with a traditional donor ( $p$ dimethylamino phenyl moiety)-acceptor (dicyanomethylene) structure bridged by an alkatriene chain. ${ }^{122-123}$ This design significantly reduced molecular weights of the probes and was reported to improve its pharmacodynamics. Among them, the best probe, 36 (DANIR 2c, Figure 1.11) showed favourable optical properties (665 nm emission wavelength), a 12 -fold increase in intensity upon binding to $A \beta$ aggregates, and excellent affinity for $A \beta$ aggregates $\left(K_{i}=37 \mathrm{nM}, K_{d}=27 \mathrm{nM}\right)$. Further studies indicated that it was able to efficiently penetrate the $\mathrm{BBB}$ and label $\mathrm{A} \beta$ plaques with a fast washout rate of the unbound probe. This probe could differentiate between transgenic and wild type mice as early as $30 \mathrm{~min}$ after in vivo administration. 36 meets most of the requirements as an optimal probe for in vivo imaging of $A \beta$ plaques. ${ }^{122}$ The blue-shift of the probe emission wavelength to $625 \mathrm{~nm}$ (shorter than $650 \mathrm{~nm}$ required for good in vivo imaging) upon binding to $A \beta$ plaques is one of the shortcomings, which limits the in vivo applications. 
Inspired by the excellent performance of 36 (DANIR 2c), Cui et al. then designed and synthesized four analogs. 37 (MAAD-3, Figure 1.11), 38 (DMDAD-3, Figure 1.11), 39 (MCAAD-3, Figure 1.11) and 40 (DMMAD-3, Figure 1.11) by differing the donor group. ${ }^{123}$ These probes showed extended emission wavelength and significantly reduced binding affinity to $A \beta$ aggregates compared with $\mathbf{3 6}$. Docking simulations revealed that these probes likely bind to the same binding site as IMPY, which has a thin hydrophobic groove parallel to the fibrillar axis formed by VAL 18 and PHE 20. Among them, 37 had the highest affinity $\left(K_{d}=\right.$ $106 \mathrm{nM}$ ), good brain kinetics including rapid initial uptake and fast egress and emission wavelength up to $654 \mathrm{~nm}$ when bound to $\mathrm{A} \beta$ aggregates, leading to a better NIRF probe for in vivo imaging than $\mathbf{3 6}$.
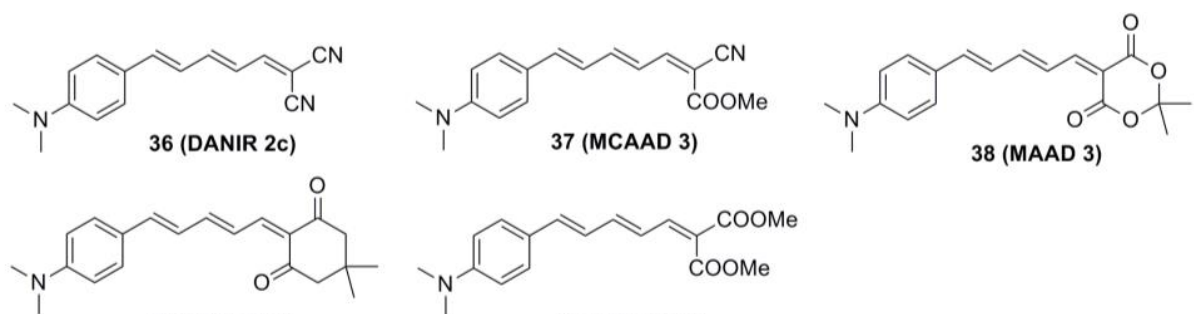

39 (DMDAD 3)

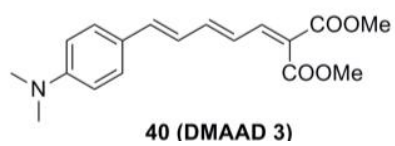

Figure 1.11 Chemical structures of alkatriene derivatives. ${ }^{122-123}$

\section{Thiophene-based derivatives}

In 2005, Swager et al. ${ }^{124}$ designed and synthesized the fluorescent probe, 41 (NIAD-4, Figure 1.12) based upon the push-pull architecture with a terminal donor ( $\mathrm{p}$-hydroxyphenyl group) moiety, acceptor (dicyanomethylene group) moiety and interconnected by a highly polarizable dithienylethenyl $\pi$-conjugated bridge. 41 displayed excellent binding affinity $\left(\mathrm{K}_{\mathrm{i}}=10 \mathrm{nM}\right)$ for $\mathrm{A} \beta$ aggregates and an approximately 400 -fold fluorescence enhancement, caused by reduced free rotation of aromatic rings in the excited state. Additionally, in vivo studies in transgenic mice indicated 41 efficiently crossed the BBB and clearly labelled both $A \beta$ plaques and cerebrovascular amyloid angiopathies. However, the maximum emission wavelength of $\mathbf{4 1}$ is only $603 \mathrm{~nm}$, outside the optimal range of 650-900 $\mathrm{nm}$. Then the same group subsequently developed a series of $\mathbf{4 1}$ analogs, including 42 (NIAD-11, $\lambda_{\mathrm{em}}=690 \mathrm{~nm}$, Figure 1.12) and 43 
(NIAD-16, $\lambda_{\mathrm{em}}=720 \mathrm{~nm}$, Figure 1.12). ${ }^{125-126} 42$ showed a dramatic fluorescent increase and a $15-\mathrm{nm}$ red-shift in the emission wavelength when mixing with $A \beta$ aggregates. $\mathbf{4 3}$ intensely stained $A \beta$ plaques in the $A D$ mouse brain sections.

Peter Nilsson and co-workers rationally designed and synthesized a series of luminescent conjugated oligothiophenes and found that in contrast to large polythiophenes, oligothiophenes, especially pentathiophenes 44 (pFTAA, Figure 1.12) are able to spectrally discriminate between NFTs and senile plaques. ${ }^{127}$ Although the highly charged nature, $\mathbf{4 4}$ was able to efficiently penetrate the BBB. In addition, 44 labelled senile plaques showing a vibronic fine structure spectrum with double peaks at 520 and 545 $\mathrm{nm}$, whereas NFTs displayed a broad featureless emission centred at 558, allowing for the identification of both aggregates using the same fluorophore in AD brain sections. When analyzing the probes, the authors found that 44 differed from the others in its solvatochromic behavior. ${ }^{128}$ As such, 44 showed much stronger conformational restrictions on binding $\mathrm{A} \beta$ fibrils, as proved by the presence of the vibronic double peaks as well as the reduced Stokes shift, whereas the binding site on tau fibrils would be less conformationally restricted and more polar. In addition, the function of the terminal carboxylates would seem to be to extend the electronic conjugation in planar conformations of 44. Its replacement with acetyl groups $\mathbf{( 4 5}$, p-KTAA in Figure 1.12) leads to a 3.75-fold stronger dependence on the solvent polarity and a larger difference between the emission wavelengths (570 nm for senile plaques and $595 \mathrm{~nm}$ for NFTs). And it should be noted that no vibronic peaks in the case of senile plaque binding were observed for this fluorophore. ${ }^{128}$ In short, the presence of both inner two acetic acid groups as well as the terminal carboxylic acids were thought to be crucially important to allow for spectral discrimination. $^{127}$ 

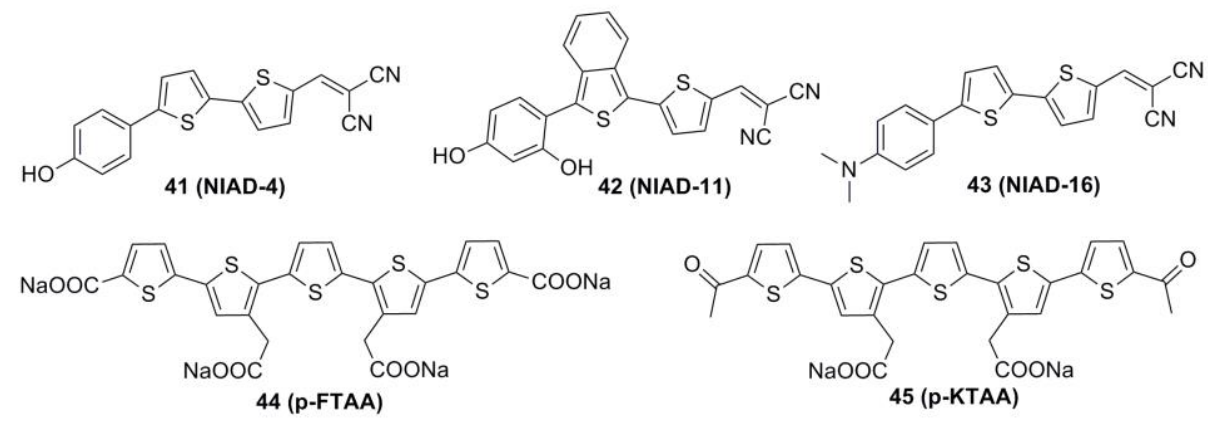

Figure 1.12 Chemical structures of thiophene-based probes. ${ }^{124-128}$

\section{Other probes}

In 2005, Gremlich et al. designed and synthesized a collection of oxazinederivative NIRF probes, including 46 (AOI-987, Figure 1.13) which could readily cross $\mathrm{BBB}$ and bind to $\mathrm{A} \beta$ plaques. ${ }^{129}$ However, due to the low fluorescence enhancement upon binding to $A \beta$ aggregates observed in vitro, the signal contrast between the wild-type and APP23 transgenic mice was not significant.

Chang et al. designed and synthesized a new family of fluorescent probes with a nitrogen donor group and a cyano-acrylate electron acceptor containing water solubilizing groups (WSGs) connected via a naphthalene unit. ${ }^{91}$ Among them, 47 (ANCA-11, Figure 1.13) showed the highest binding affinity $\left(\mathrm{K}_{\mathrm{d}}=1.4 \mu \mathrm{M}\right)$ and a 7.7-fold fluorescence intensity increase upon binding to $\mathrm{A} \beta$ aggregates. Further in vitro assays demonstrated that $\mathbf{4 7}$ could fluorescently stain amyloid deposits in human AD brain tissues. It is found that structural modification using WSG group does not significantly affect the binding affinity.

$\mathrm{Li}$ et al. reported a series of styryl probes. One of these compounds, 48 (STB-8, Figure 1.13) exhibited a binding affinity of $\mathrm{K}_{\mathrm{d}}=3.2 \mathrm{uM}$ to $\mathrm{A} \beta$ fibrils in vitro and strong $\mathrm{A} \beta$ plaques staining in $\mathrm{AD}$ brain sections. In in vitro assays, 48 stained the $\mathrm{A} \beta$ plaques, co-stained by $\mathrm{ThS}$ and in vivo staining to overlap with Congo Red in AD transgenic mice. The results of in vivo and in vitro imaging clearly indicated its BBB permeability and specific $\mathrm{A} \beta$ plaques staining in $\mathrm{AD}$ mice. ${ }^{130}$ 


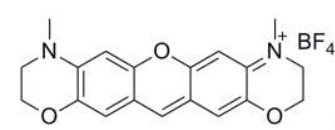

46 (AOI-987)

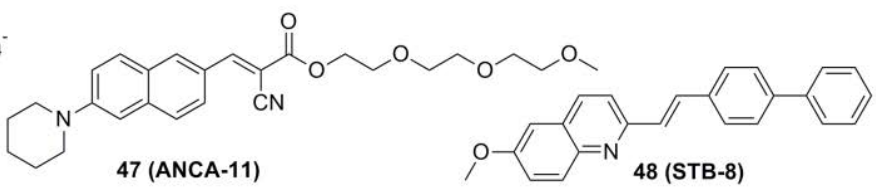

Figure 1.13 Chemical structures of other probes. ${ }^{91,}$ 129-130

\subsubsection{Tau fibril fluorescent probes}

To date, several studies by Braak et al. have apparently demonstrated a much more rigorous correlation between the NFT burden and AD progression. ${ }^{131}$ Therefore, tau NFTs have become an attractive target in the development of clinical diagnostic probes, mainly based on the PET imaging. ${ }^{132-133}$ Although there is some overlap between tau probes for PET and fluorescence imaging, we will focus on the fluorescence imaging in the current section.

\section{Thioflavin-based tau fibril ligands}

In the past decade, the non-specific thioflavin probes have been the starting point for a number of probes with increased selectivity and affinity for tau NFTs in the presence of A $\beta$ plaques. In this section, we will focus on the fluorescent probes whose development represent a major step forward in gaining tau selectivity.

Maruyama et al. proposed the hypothesis that specific-tau probes should consist of a narrow $\pi$-conjugated D-A molecule and also the length of the conjugation should ideally be larger than $13 \AA$. Therefore, they reported a series of $\pi$-extended thioflavin analogues: PBB1-5. ${ }^{134}$ Some interesting aspects were observed that a) all probes exhibited a propensity to fluorescently stain tau aggregates; $b$ ) the affinity for $A \beta$ aggregates decreased with decreased probe lipophilicity, and reciprocally therewith, the selectivity for tau aggregates increased. 49 (PBB-5, Figure 1.14) as the most hydrophilic and red-shifted fluorophore, showed the largest selectivity for tau aggregates with NIR fluorescence emission at $685 \mathrm{~nm}$. In vivo assays indicated that this probe was demonstrated to enable discrimination between a transgenic human P301S mutant tau mouse model and a normal control. However, the presence of the benzothiazolium group re- 
sulted in metabolic instability and a reduced BBB penetrability as compared with the other PBB probes. Another analog. 50 (PBB-3, Figure 1.14) could be as the most promising candidate for in vivo tau imaging with an emission peak in the 500-550 $\mathrm{nm}$ range. Interestingly, following intravenous injection of PBB-3, labelling of tau tangles and the diffusion through the blood vessels as well as subsequent infiltration in the surrounding tissues could clearly be seen. ${ }^{134}$

$\mathrm{Gu}$ et al. designed and synthesized a collection of 2-styrylindolium based fluorescent probes including compound 51 and 52 (7a and 7b, Figure 1.14). ${ }^{135}$ In vitro assays revealed that they could clearly stain tau NFTs in $\mathrm{AD}$ brain sections while only demonstrating faint fluorescence in the presence of $A \beta$ plaques. These compounds displayed a relatively low toxicity of in a zebrafish assay, however the indolium cation would be expected to hinder efficient BBB penetration.

Kudo et al. disclosed a family of D-A type probe showing a multichromic response to either $A \beta$ or tau aggregates. The first member of this family was compound 53 (BF-126, Figure 1.14), showing an emission maximum at $490 \mathrm{~nm}$ when bound to $\mathrm{A} \beta$ plaques and an emission maximum at 540 $\mathrm{nm}$ when bound to tau NFTs. ${ }^{136}$ The $\pi$-extended analogue compound 54 (BF-188, Figure 1.14) resulted in an even larger difference with maxima of emission at $520 \mathrm{~nm}$ and $600 \mathrm{~nm}$ for A $\beta$ plaques and tau NFTs, respectively. ${ }^{137}$ However, this effect completely disappears when the benzimidazole group is replaced by the analogous benzoxazole and benzothiazole rings, suggesting the involvement of $\mathrm{H}$-bond interactions in the binding modes.

The group of Peter Nilsson developed a series of oligothiophenes, especially pentathiophenes, which are able to spectrally discriminate between senile plaques and NFTs. ${ }^{127}$ Further investigations into the chromophore led to the oligothiophene-PBB3 hybrids 55-59 (bTVBT1-5, Figure 1.14). ${ }^{138}$ Herein, these compounds do not show dual staining for NFTs and senile plaques, but rather exhibit a very high selectivity for tau aggregates at low concentrations of dye. bTVBT1-5 showed emission maxima in the 600-630 $\mathrm{nm}$ range with spectral tails reaching well into the NIR window. Intriguingly, the replacement of the benzothiophene ring of 
bTVBT1 by a benzimidazole resulted in high affinity senile plaque binding. The styrene bond was also determined to be significantly important, as a result of replacement with a thiophene ring either removed the probes' affinities for both NFTs and senile plaques or made the probe non-selective.

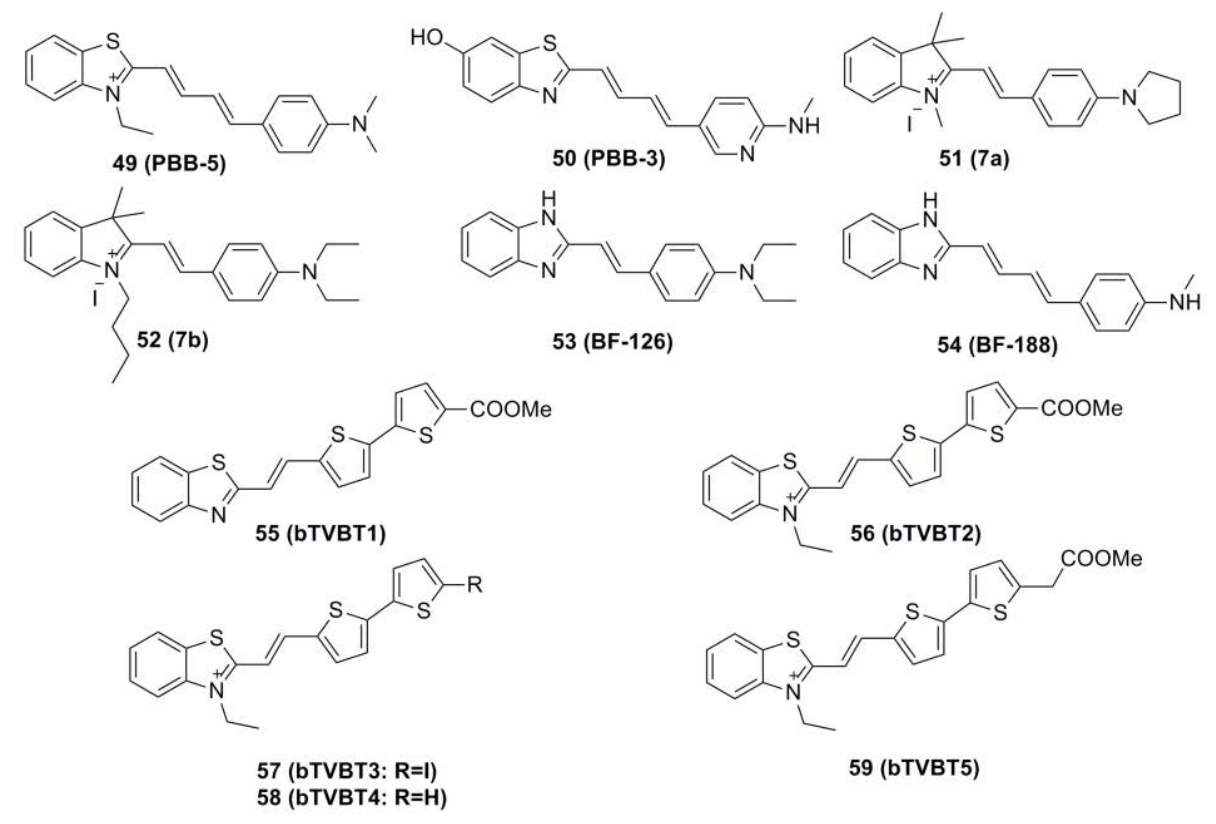

Figure 1.14 Chemical structures of thioflavin-based probes. ${ }^{134-138}$

\section{Curcumin-based tau fibril ligands}

Schmidt et al. developed a library of curcumin-like donoracceptor-donor (D-A-D) compounds with a pyrazine, pyrimidine or pyridazine core structure. Among them, two of the pyrimidine containing compounds 60 and 61 (Figure 1.15), showed a significantly higher affinity for tau tangles over $A \beta, 13.5$ - and 26-fold for $\mathbf{6 0}$ and 61, respectively, in a competition assay with Thiazine Red R. ${ }^{139}$ In in vitro experiments, $\mathbf{6 0}$ demonstrated efficient two-photon imaging. In in vitro tissue slices, however, $\mathbf{6 0}$ did reveal efficient staining of A $\beta$ plaques, while not showing any fluorescence derived from NFTs. 61 failed to show any fluorescence. 
Chong et al. designed and synthesized a family of curcumin-analogue compounds. ${ }^{140}$ Among them, 62 (Figure 1.15) exhibited a fluorescence turn-on of 22.9-fold and was able to stain aggregates of tau 2N4R-GFP (green fluorescent protein) conjugate in vitro. Due to the electron-donating dimethylaniline groups and the significantly increased D-A-D intramolecular charge transfer (ICT) efficiency, the emission wavelength of 62 was red-shifted up to $620 \mathrm{~nm}$. Neither in vivo or tissue staining experiments, nor competition experiments with $A \beta$ were performed. Using the same donor moiety, the same group reported a collection of $D-\pi$-A probes 63 and 64 (Figure 1.15), displaying an impressive 49- and 108-fold fluorescence intensity increase upon binding tau aggregates. ${ }^{141}$ Furthermore, 63 and 64 showed a fluorescence intensity selectivity of 5.7- and 3.8-fold fold higher for tau aggregates than $A \beta$, whereas for both compounds the binding affinity is higher for $A \beta$ than for tau fibrils. The probes showed a clear co-localization with GFP-labelled tau aggregates in vitro, staining of human brain sections did reveal the absence of fluorescence in normal brains, whereas bright fluorescence was observed in the case of AD pathology. As a result of the strong D- $\pi$-A strength, the fluorescence emission wavelength approaches the NIR window cut-off (> $650 \mathrm{~nm})$.

Inspired by a strategy that has previously been proven to be successful in the CRANAD series A $\beta$-specific fluorophores, the same group synthesized a more lipophilic and brighter fluorescent probe $\mathbf{6 5}$ (Figure 1.15) by aromatizing the $\beta$-diketonate of the curcumin structure with difluoroboron. The D-A curcumin-like compound $\mathbf{6 5}$ showed a high turn-on ratio in the presence of tau fibrils with a 14-fold selectivity for tau over $A \beta$ and an emission maximum in the NIR up to $660 \mathrm{~nm}$. In in vitro assays, the molecule showed an excellent overlap with a fluorescently labelled antibody for tau tangles in human AD brain sections, whilst only displaying a relatively low staining of core $A \beta$ plaques of the most dense plaques. ${ }^{142}$ 

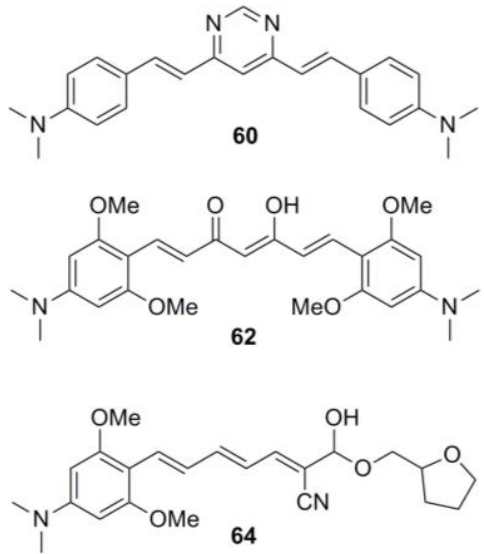
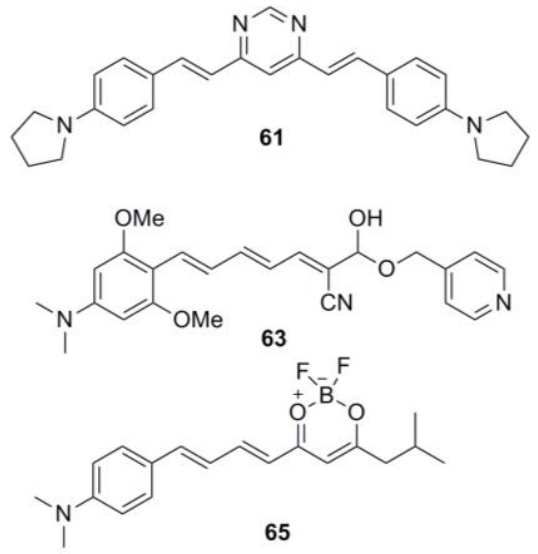

Figure 1.15 Chemical structures of curcumin-based fluorophores. ${ }^{139-142}$

\section{BODIPY-based tau fibril ligands}

Vedamalai et al. recently reported the first BODIPY-based probe $\mathbf{6 6}$ (Figure 1.16) with a high affinity for tau aggregates. ${ }^{143} \mathbf{6 6}$ displayed a 7-fold fluorescence enhancement at $579 \mathrm{~nm}$ upon binding to tau aggregates. No data in the presence of $A \beta$ fibrils were reported.

Lim et al. reported probe 67 (BD-tau, Figure 1.16) which showed a 5.5fold fluorescence enhancement upon the addition of tau protein aggregates in vitro with an emission maximum around $590 \mathrm{~nm} .{ }^{144}$ However, in the presence of $A \beta$ or insulin fibrils a 3.5- to 4-fold fluorescence enhancement was observed as well. Additionally, BD-tau did reveal a clear colocalisation in tau protein expressing cells and brain sections of a tauopathy mouse model.

Verwilst et al. developted the rational design of 68 and 69 (Tau 1 and Tau 2 , Figure 1.16) through the $\pi$-elongation of a known $A \beta$-selective BODIPY probe. ${ }^{145}$ Solution studies revealed a fluorescence enhancement based on the surrounding solvent polarity, rather than the viscosity. It is noted that 68 and 69 showed a fluorescence enhancement of 6.4- and 9.3fold, respectively, in the presence of tau aggregates, whereas virtually no enhancement was observed in the case of $\mathrm{A} \beta$-fibrils. In in vitro experiments, 68, exhibiting the highest solubility, indicated the efficient labelling of NFTs in both acute and transgenic mouse models for tauopathy 
and $\mathrm{AD}$, with minimal labelling of the core $\mathrm{A} \beta$ plaques. In addition, the authors revealed the BBB crossing of $\mathbf{6 8}$ and the ability for in vivo staining of tau aggregation status in a transgenic mouse model compared to a control.

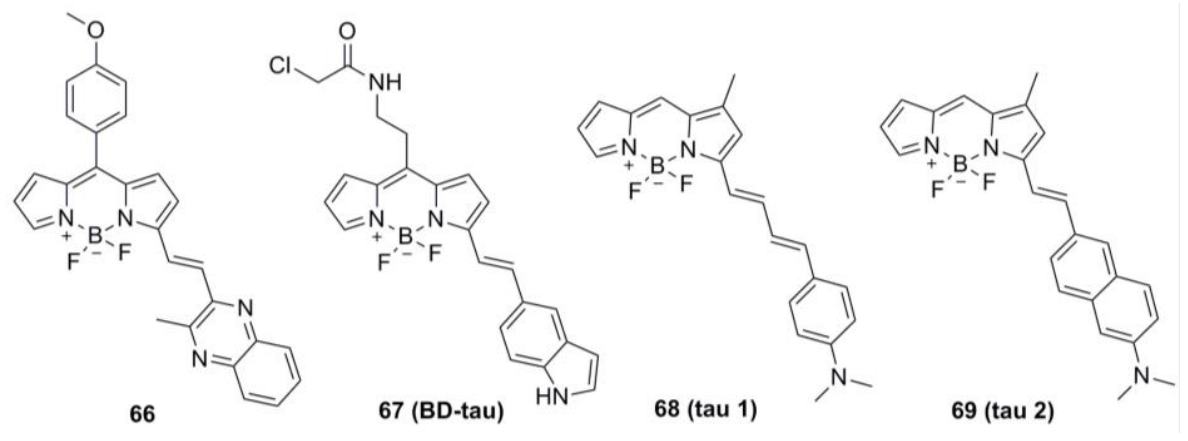

Figure 1.16 Chemical structures of BODIPY probes. ${ }^{143-145}$

\section{Other scaffolds for tau fibril ligands}

This section describes a few compounds that have no or very small structural overlap with the classes of probes described above. As the first example, compound 70 (BSc3504, Figure 1.17) showed strong interactions with tau tangles in AD brain sections, as proved by fluorescence in the DAPI window (415-475 nm), while displaying considerably less pronounced staining of senile plaques. ${ }^{146}$ Interestingly, in in vitro experiments, the compound also exhibited a very strong tau aggregation inhibition, making this compound a potential fluorescent theranostic agent, although much longer wavelengths would be required for in vivo applications.

Cyanine probes have long been used in biological imaging, due to their generally high brightness with emission maxima at around $570 \mathrm{~nm}$, and relatively low toxicity. Schmidt et al. developed a small library of trimethine cyanines of 2,3,3-trimethyl indolinium as more sensitive and benign probes, such as compound 71 (Figure 1.17). All compounds could intensely stain NFTs in AD brain tissues, but did not stain senile plaques in the same tissues. The reason for this observation however is not fully understood. ${ }^{147}$ One potential explanation could be that the human brain contains all 6 isoforms as well as many posttranslational modifications in 
NFTs, whereas tau aggregation assays usually only use one isoform of tau protein (often $2 \mathrm{~N} 4 \mathrm{R}$ ).

Rejc et al. recently published a small collection of long-range D-A probes, for example compound $\mathbf{7 2}$ (Figure 1.17), showing good affinity to tau tangles. Whereas the compounds all displayed some degree of binding to $A \beta, 72$ displayed the lowest affinity to $A \beta$ in a competition assay. ${ }^{148}$ The library of compounds was pre-screened in a PHF6 docking assay, demonstrating a tight fit for all compounds in the tyrosine channel. $\mathbf{7 2}$ showed an emission maximum at 580 and $595 \mathrm{~nm}$ for senile plaques and NFTs, respectively, allowing for a visual identity of the aggregates in tissue slices (green versus orange, respectively).

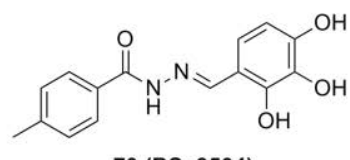

70 (BSc3504)

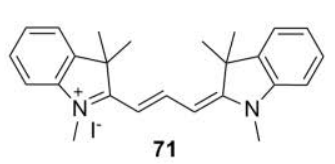

71

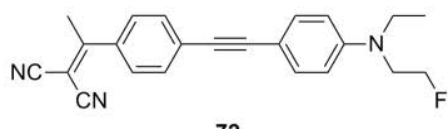

72

Figure 1.17 Chemical structures of other probes. ${ }^{146-148}$ 


\section{Research aim}

The overall aim in the study was to synthesize and evaluate novel fluorescent stilbene-based probes for detection and imaging of disease-associated protein aggregates.

More specific aims were:

a) To elucidate the connection between probe design and its properties as an amyloid ligand.

b) Vary the design of amyloid ligand to change the photophysical properties of the probe. 


\section{Methodology}

Fluorescence, a form of luminescence, is a physical phenomenon in which a particular molecule emits light of a particular color very shortly after having absorbed light. In most cases, fluorescence has a longer wavelength than that of the absorbed radiation. The Jablonski diagram in Figure 3.1 is often used to visualize this process. Fluorescence has some general rules including Kasha's rule, mirror image rule and Stokes shift, which are useful for understanding fluorescence. ${ }^{149}$

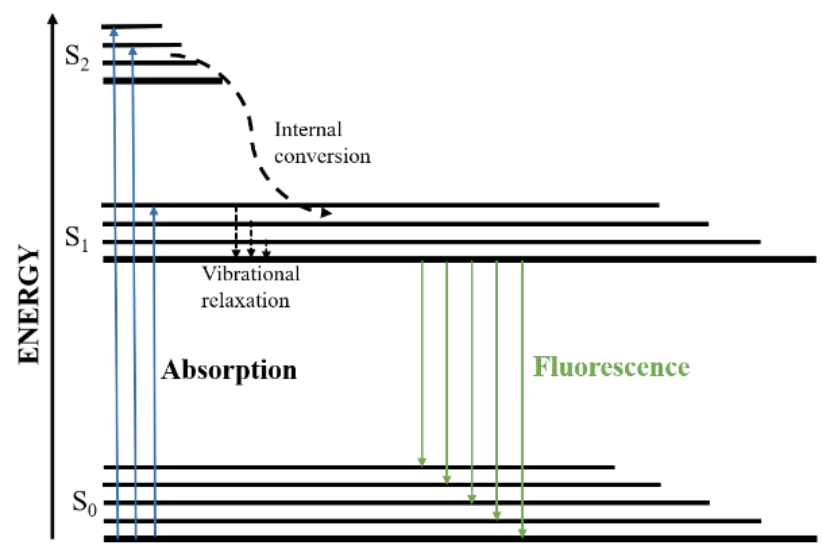

Figure 3.1 Jablonski diagram of absorption and fluorescence. The blue arrows represent absorption, the dashed arrow represents internal conversion from excited state $S_{2}$ to $S_{1}$, the short-dashed arrows vibrational relaxation, and the gree arrows represent fluorescence. Both the absorption and internal conversion processes are generally very fast, within a few femtoseconds to some 10ths of picoseconds (ps), whereas fluorescence, if present, is in the order of 100 ps to 200 nanoseconds for molecules in solutions.

1) Kasha's rule, named after American spectroscopist Michael Kasha, stating that photon emission (fluorescence or phosphorescence) occurs in appreciable yield only from the lowest excited state of a given multiplicity. ${ }^{149}$

2) Mirror image rule, usually the emission spectrum is a mirror image of the absorption spectrum. ${ }^{149}$ 
3) Stokes shift, the emitted fluorescence light has a longer wavelength than the absorbed light. This phenomenon is due to energy loss, usually to vibrations and electrostatic relaxation of the environment. 149

\subsection{Fluorescence spectroscopy}

Fluorescence spectroscopy (also known as fluorometry or spectrofluo rometry) is a type of optical spectroscopy that analyzes emitted light including emission wavelengths and the strength of different wavelengths. ${ }^{149}$ It involves using a beam of light, usually ultraviolet to visible light, that excites the electrons in molecules of certain compounds and causes them to emit light of longer wavelength. The background signal is generally low as the emission is collected at other frequencies than that of the excitation.

The emission wavelength maximum $\left(\lambda_{\mathrm{em}}\right)$ is a main feature of the fluorescence spectrum. It's important to note that $\lambda_{\mathrm{em}}$ is sensitive to the environment, usually the organic solvent. If the solvent is polar, then more energy is required to reorient their dipoles, and if the solvent is apolar, then the excited state will induce the dipole formation in the solvent, which requires less energy. After the relaxation the excited molecule will then decay by emitting a photon, which will thus have a longer wavelength than the absorbed photon, and this difference is called the Stokes shift. General speaking, the more polar the environment is for a given fluorophore, the longer stokes shift becomes. For similar reasons, the lifetime of the fluorescence is usually shorter in the polar environment than in the nonpolar environment, although there are exceptions to these rules. The well-known text-book of Lackowicz 'Fluorescence Spectroscopy', (Springer Verlag) gives a comprehensive introduction to the topic including many examples applied in biophysically related sciences. 


\subsection{Fluorescence microscopy}

The "fluorescence microscope" refers to any microscope that uses fluorescence to generate an image, such as an epifluorescence microscope with a more simple set up or a confocal microscope with a more complicated design. In brief, instead of using a bright white light source going through the sample through the condenser under the sample holder, the excitation light is normally coming from above onto the sample. The emitted light is collected as normal, but the scattered excitation light is filtered away by using dichroic filters (see Figure 3.2). Due to the importance of fluorescence microscopy for chemistry, Eric Betzig, William Moerner and Stefan Hell were awarded the Nobel Prize in chemistry for "the development of super-resolved fluorescence microscopy" in 2014.

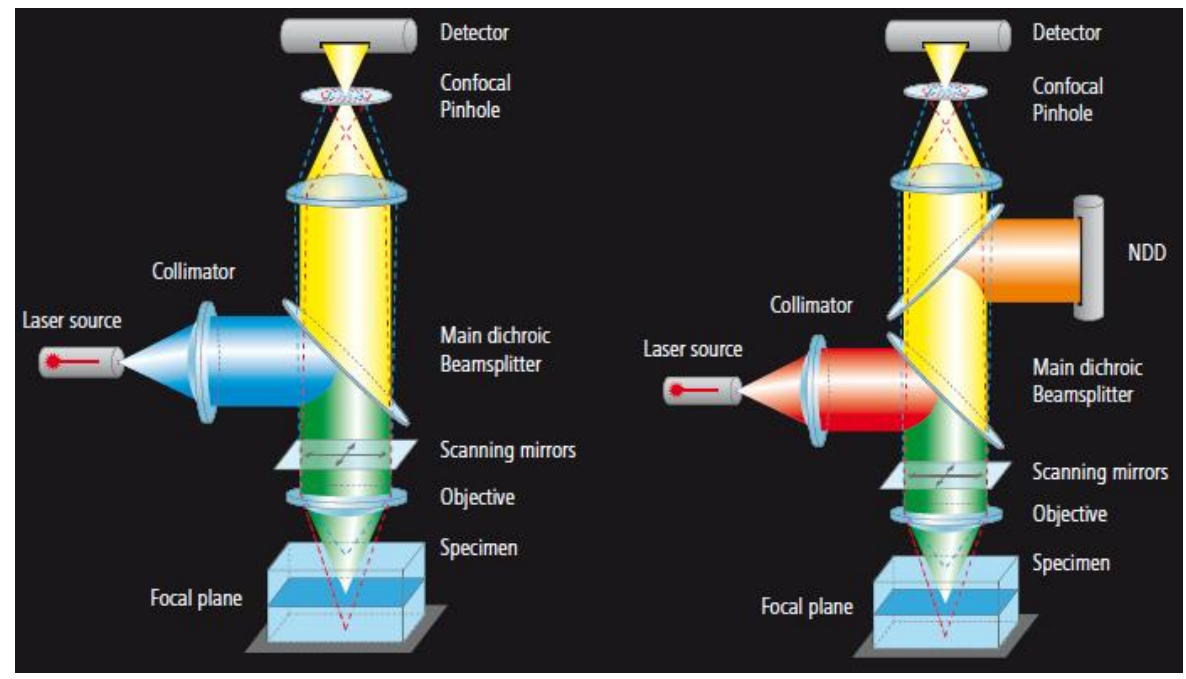

Figure 3.2 The principle of LSM 780 confocal and multiphoton laser scanning microscopy (picture from ZEISS).

In this thesis, we use this technique to visualize the location of a certain protein in a tissue when labelled by fluorescent probes. The most frequently used imaging technique is confocal fluorescence microscopy. In a confocal microscope, excitation of your sample is performed point-bypoint using a scanner, together with the use of a pinhole, which eliminates 
out-of-focus signals. This gives you a much better optical resolution compared to conventional fluorescence microscopy, where the whole sample is flooded with light at once. ${ }^{150}$ Tissue samples used throughout this thesis were produced according to the way that the tissue is embedded in TissueTek O.C.T. and cut in thin sections $(10-20 \mu \mathrm{m})$ using cryo-sectioning. When preparing the tissue for histology analyses one usually starts by fixing the sample to ensure that the tissue is stabilized and maintains its cellular structure. Thereafter the sample is stained, washed to remove the unbound probe and mounted on special slides for microscopy.

\subsection{Time-correlated single-photon counting (TCSPC)}

Fluorescence lifetimes were determined using the time-correlated single photon counting (TCSPC) technique. Here a high pulse repetition laser diode (or lamp) is used as excitation source. The system measures the time between the excitation pulse is sent out, until the emitted light reached the detector. By repeating this many times a histogram representing the life-time decay is obtained. As seen in Figure 3.3, the TCSPC technique is based on the principle that the statistical probability distribution for the emission of a single fluorescent photon is equivalent to the actual intensity versus time distribution for all photons emitted, the so called ergodic principle. ${ }^{149}$

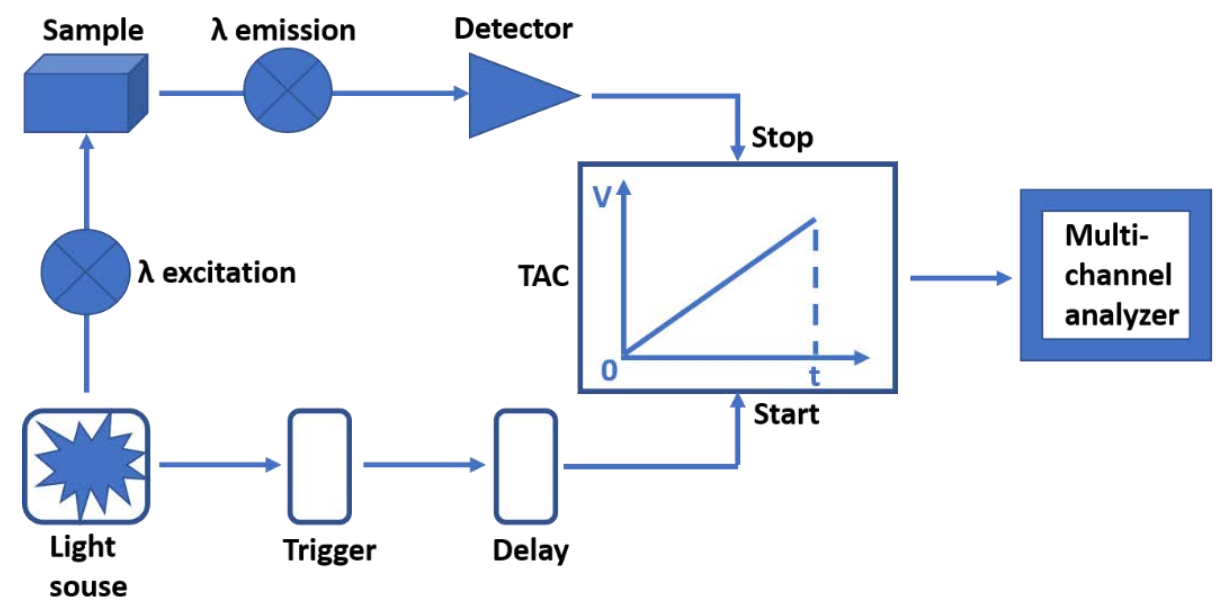

Figure 3.3 Principle and scheme of the TCSPC experiment. 
Fluorescence decays were measured using an IBH-TCSPC spectrometer. Even though short pulsed excitation ( $\leq$ ns duration) is used, and the system has short response time in the TCSPC mode, the relaxation times are of comparable orders of magnitude. This requires an additional recording of the instrumental response function (prompt) of the excitation pulse, prior to any analysis of the decay curve, so called deconvolution fitting, using the commercial spectrometer software (IBH). The decays were assumed to be a sum of exponentials (eq. 1).

$$
I(t)=\sum_{i} \alpha_{i} \exp \left(-t / \tau_{i}\right)
$$

Here $\alpha_{i}$ are the pre-exponential factors associated with the decay time $\tau_{i}$. The quality of the fit was evaluated from the $\chi 2$ parameter and the random distribution of the residuals as well as the autocorrelation of the residuals. The average lifetime of fluorescence decay was calculated according to the following equation,

$$
\tau_{\text {avg }}=\frac{\sum \alpha_{i} \tau_{i}^{2}}{\sum \alpha_{i} \tau_{i}}
$$

\subsection{Determination of fluorescence quantum yield}

In this work, fluorescence quantum yield (QY) was calculated using a relative determination based on a standard sample with known QY. ${ }^{151} \mathrm{QY}$ is then determined using the following equation:

$$
\emptyset_{\text {sample }}=\varnothing_{\text {stand }}\left(\mathrm{F}_{\text {sample }} / \mathrm{F}_{\text {stand }}\right) \times\left(\mathrm{A}_{\text {stand }} / \mathrm{A}_{\text {sample }}\right) \times\left(\mathrm{n}_{\text {sample }}^{2} / \mathrm{n}_{\text {stand }}^{2}\right)
$$

Where $\varnothing=$ Quantum yield, $F=$ Integrated area of the fluorescence spectrum, $\mathrm{A}=$ Absorption maximum, and $\mathrm{n}=$ Refractive index of solvent. Quinine hemisulfate salt monohydrate $\left(\varnothing=0.58\right.$ in $\left.0.1 \mathrm{M} \mathrm{H}_{2} \mathrm{SO}_{4}\right)$, fluorescein $(\varnothing=0.95$ in $0.1 \mathrm{M} \mathrm{NaOH})$ and coumarin $314(\varnothing=0.68$ in ethanol $)$ were used as the standards in this work. The quantum yields of these standards are mostly independent of the excitation wavelength, allowing them to be used wherever they display useful absorption. We chose the best standard for each ligand according to its absorption. 


\subsection{Dissociation constant $\left(K_{d}\right)$ by fluorescence spectroscopy}

In this thesis the binding affinity of ligands to fibrils or fibrils to ligands (due to the low solubility in water, paper I) was investigated by measuring the dissociation constant $\left(\mathrm{K}_{\mathrm{d}}\right)$ using fluorescence spectroscopy. The $\mathrm{K}_{\mathrm{d}^{-}}$ value from fluorescence spectroscopy was determined by adding ligands to fibrils or fibrils to ligands and the fluorescence signal was expected to change upon binding. The change in emission intensity was then plotted versus ligand concentration (paper II-IV) or fibril concentration (paper I).

The following equation describes the binding of a ligand to a protein:

$$
\mathrm{P}+\mathrm{L} \leftrightarrow \mathrm{PL}
$$

The dissociation constant $\mathrm{K}_{\mathrm{d}}$ is defined at equilibrium by

$$
\mathrm{K}_{\mathrm{d}}=\frac{[P][L]}{[P L]}
$$

Where $[\mathrm{P}]$ is concentration of free protein, $[\mathrm{L}]$ is concentration of free ligand and $[\mathrm{PL}]$ is the concentration of the PL complex.

The $K_{d}$ binding curve was generated by GraphPad Prism 7.0 by using the following equations:

$$
\begin{gathered}
\mathrm{Y}=\mathrm{B}_{\max } * \mathrm{X} /\left(\mathrm{K}_{\mathrm{d}}+\mathrm{X}\right) \\
\mathrm{Y}=\mathrm{B}_{\max } \mathrm{Hi} * \mathrm{X} /\left(\mathrm{K}_{\mathrm{d}} \mathrm{Hi}+\mathrm{X}\right)+\mathrm{B}_{\max } \mathrm{Lo} * \mathrm{X} /\left(\mathrm{K}_{\mathrm{d}} \mathrm{Lo}+\mathrm{X}\right)
\end{gathered}
$$

Where $\mathrm{X}$ is concentration of ligand and $\mathrm{Y}$ is change in fluorescence intensity. $\mathrm{B}_{\max }$ is the maximum specific binding having the same unit as $\mathrm{Y}$. 


\title{
4. Summary of papers
}

\subsection{Paper I: Trans-stilbenoids with extended fluorescence lifetimes for the characterization of amyloid fibrils}

\begin{abstract}
Aim: The aim of the first paper was to synthesize two new trans-stilbenoids with expanded aromatic ring systems (anthracene and pyrene). The series of four analogous trans-stilbenoids with benzene, naphthalene, anthracene, and pyrene were investigated with respect to their photophysical properties free in solution and when bound to amyloid fibrils (insulin, lysozyme and $A \beta 1-42$ ), including time-resolved fluorescence measurements.
\end{abstract}

Results and discussion: Previously, we successfully reported that two naphthyl-based trans-stilbene probes, $\mathbf{7 3}$ and 75, can bind both native TTR and misfolded proto-fibrillar TTR at physiological concentrations, displaying distinct shift in emission maxima ( $>100 \mathrm{~nm})$, allowing conformational discrimination by fluorescence spectroscopy. ${ }^{152}$ Herein, this class of compounds having a trans-stilbene or trans-stilbenoid structure are indeed a promising fluorescent probe scaffold for amyloid research. Accordingly, we designed and prepared two new analogues (76 and 77, see the structures in Figure 4.1) with expanded aromatic ring systems (anthracene and pyrene), to investigate their spectral discrimination of binding native and proto-fibrillar TTR as well as three other canonical amyloid proteins (insulin, lysozyme and $A \beta$ 1-42). Subsequently, the emission properties of these analogues (74-77) with different aromatic ring moieties (benzene, naphthalene and anthracene as well as pyrene) were investigated using steady-state and time-resolved fluorescence spectroscopies, which demonstrate the feasibility of these new scaffolds for amyloid fibril characterization. 


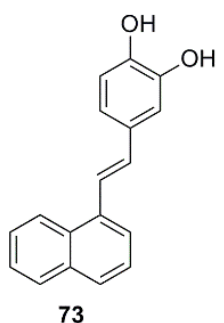

73

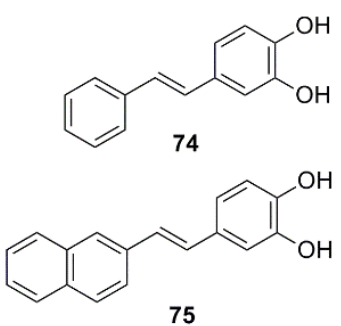

75

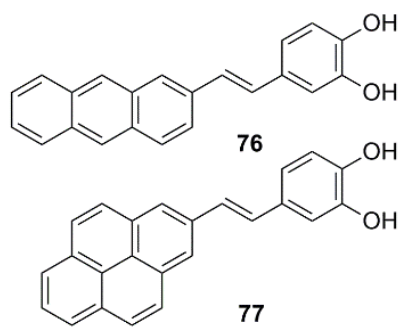

77

Figure 4.1 Chemical Structures of trans-Stilbenoids: 73, 74, and $\mathbf{7 5}$ have been reported previously by our group. ${ }^{152} \mathbf{7 6}$ and 77 were synthesized in this paper.

Synthesis procedures: Pyrene derivatives are important and well-studied organic chromophore with long excited state lifetime. Structural modifications allow for many applications, including fluorescent probes, ${ }^{153} \mathrm{bi}$ ological labeling, ${ }^{154}$ molecular electronics, ${ }^{111}$ photovoltaic cells, and field-effect transistors. ${ }^{155}$ Most reported pyrene derivatives involve substitution at the 1,3,6,8-positions and/or functionalization at the 4,5,9,10positions. To substitute pyrene at the 2- or 2,7-positions is synthetically challenging because of the presence of the nodal plane of the highest occupied molecular orbital (HOMO) and the lowest unoccupied molecular orbital (LUMO), which lies perpendicular to the molecular plane and passes through the 2- and 7-positions. ${ }^{156}$ However, pyrene derivatives with substituents at the 2,7-positions are particularly interesting. These derivatives have a geometrically linear molecular structure that is useful for the construction of large optoelectronic systems with well-defined architectures.

The synthesis of 2,7-substituted pyrene derivatives often requires tedious multistep procedures. ${ }^{157}$ Recently, Marder et al. have reported the synthesis of 2- and 2,7- functionalized pyrene derivatives including compounds $\mathbf{7 9}$ and $\mathbf{8 0} .{ }^{158}$ Our approach for the synthesis of the trans-stilbene derivatives 76 and 77 was to apply the palladium-catalyzed Heck reaction of 82 to the corresponding 80 (2-bromopyrene) and $\mathbf{8 3}$ (2-bromoanthracene). Employing the catalyst that was prepared in situ by the reaction of [Ir(u-OMe) cod $]_{2}$ with 4,4'-di-tert-butyl- 2,2'-dipyridyl (dtbpy), the product 79 was obtained in $62 \%$ yield. Then, the reaction of compound 79 with 3 equiv of $\mathrm{CuBr}_{2}$ in methanol/ $\mathrm{H}_{2} \mathrm{O}(1: 1)$ gave $\mathbf{8 0}$ in $78 \%$ yield. From 81 (3,4-dihydroxybenzaldehyde), 82 was obtained by a witting reaction 
in 59\% isolated yield, in which the Heck reaction with $\mathbf{8 3}$ and $\mathbf{8 0}$ yielded the target molecules $\mathbf{7 6}$ and 77 in $35 \%$ and $28 \%$ isolated yields, respectively. Figure $4.2 \mathrm{~B}$ depicts the synthesis of the target molecules.

(A)

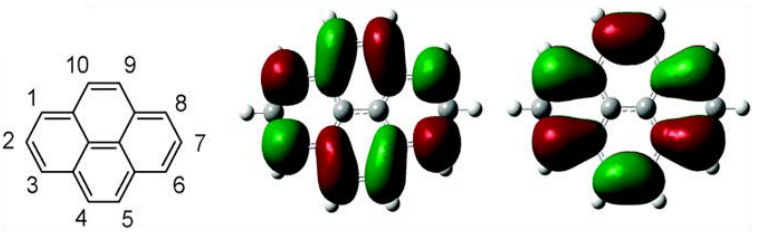

78 (Pyrene)

LUMO

номо

(B)
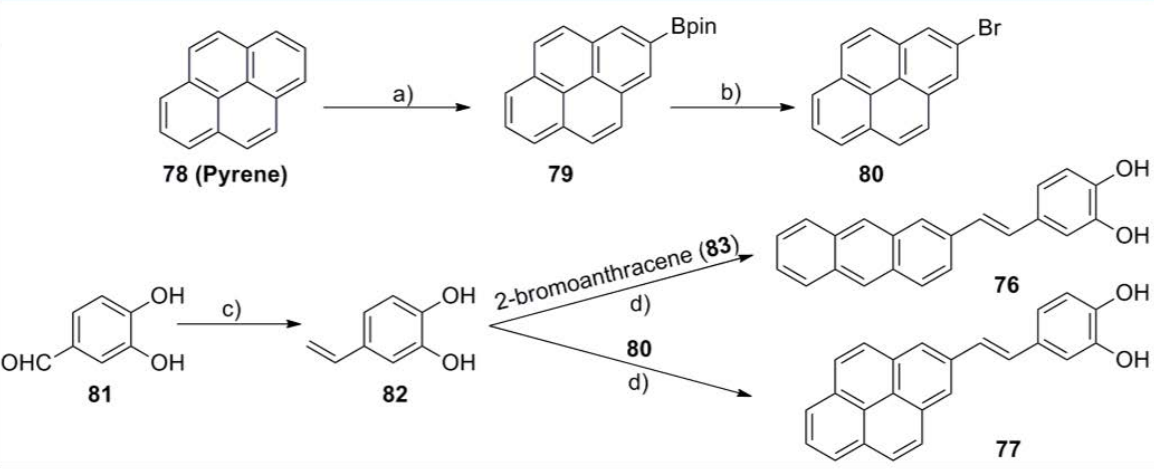

Reagents and conditions: (a) $\mathrm{B}_{2} \mathrm{Pin}_{2}$ (1.1 equiv), $[\mathrm{Ir}(\mathrm{u}-\mathrm{OMe}) \operatorname{cod}]_{2}(1 \% \mathrm{~mol})$, dtbpy $(2 \% \mathrm{~mol})$, hexane, $80{ }^{\circ} \mathrm{C}$, overnight, $60 \%$. (b) $\mathrm{CuBr}_{2}$ (3 equiv), methanol/ $\mathrm{H}_{2} \mathrm{O}(1: 1), 90{ }^{\circ} \mathrm{C}$, overnight, $75 \%$. (c) $\mathrm{Ph}_{3} \mathrm{PCH}_{3} \mathrm{Br}$ (1.5 equiv), ${ }^{\mathrm{B}} \mathrm{BuOK}$ (4 equiv), THF, rt, $6 \mathrm{~h}, 58 \%$. (d) $\mathrm{Pd}(\mathrm{OAc})_{2}(20 \% \mathrm{~mol})$, triethanolamine $\left(4\right.$ equiv), dry DMF, $100{ }^{\circ} \mathrm{C}, 24 \mathrm{~h}$. $[\mathrm{Ir}(\mu-\mathrm{OMe}) \operatorname{cod}]_{2}=(1,5-$ cyclooctadiene)(methoxy)iridium(I) dimer, dtbpy $=4,4^{\prime}$-di-tert-butyl-2,2'-dipyridyl.

Figure 4.2 A) Position numbering and HOMO and LUMO plots of pyrene. B) Synthesis of compounds $\mathbf{7 6}$ and $\mathbf{7 7}$.

Both probes, 76 and 77, can bind to both native and proto-fibrillar TTR, displaying indiscriminate shift in emission maxima when bound to the two different TTR conformations. The amyloid-binding propensity for four analogous trans-stilbenoids (74-77) with different aromatic ring moieties was compared. All studied probes can bind specifically to amyloid fibrils of vastly heterologous proteins (insulin, lysozyme, TTR, and A $\beta 1-42$ fibrils) with apparent fluorescence intensity augmentation and moderate affinities. One specific aim was to develop long lifetime fluorescent probes to allow measurements of solution dynamics of amyloid species. To our knowledge, no small-molecule amyloid targeting probes have been reported with pyrene or anthracene directly binding to the amyloid fibril binding sites. The fluorescence lifetimes of the amyloid 
probes described in this work in degassed methanol are ranked as $(\mathbf{7 4}<$ $0.05 \mathrm{~ns})<\mathbf{7 5}=0.52 \mathrm{~ns}<\mathbf{7 6}=4.23 \mathrm{~ns}<\mathbf{7 7}=19.11 \mathrm{~ns}$, indicating that the different aromatic ring moieties determine the respective probe residence time in the excited state. When bound to $A \beta 1-42$ fibrils, the lifetimes are $1.3 \mathrm{~ns}$ (74), $1.5 \mathrm{~ns}$ (75), $5.7 \mathrm{~ns}$ (76), and $29.8 \mathrm{~ns}$ (77). Hence, each probe bound to $A \beta 1-42$ fibrils showed longer lifetime than in degassed methanol, suggesting that the probe binding sites are hydrophobic and wellshielded from the surrounding water solvent. The pyrene-based 77 showed the longest fluorescence lifetime, opening the opportunity for size determination of the oligomerization process by dynamic fluorescence spectroscopy.
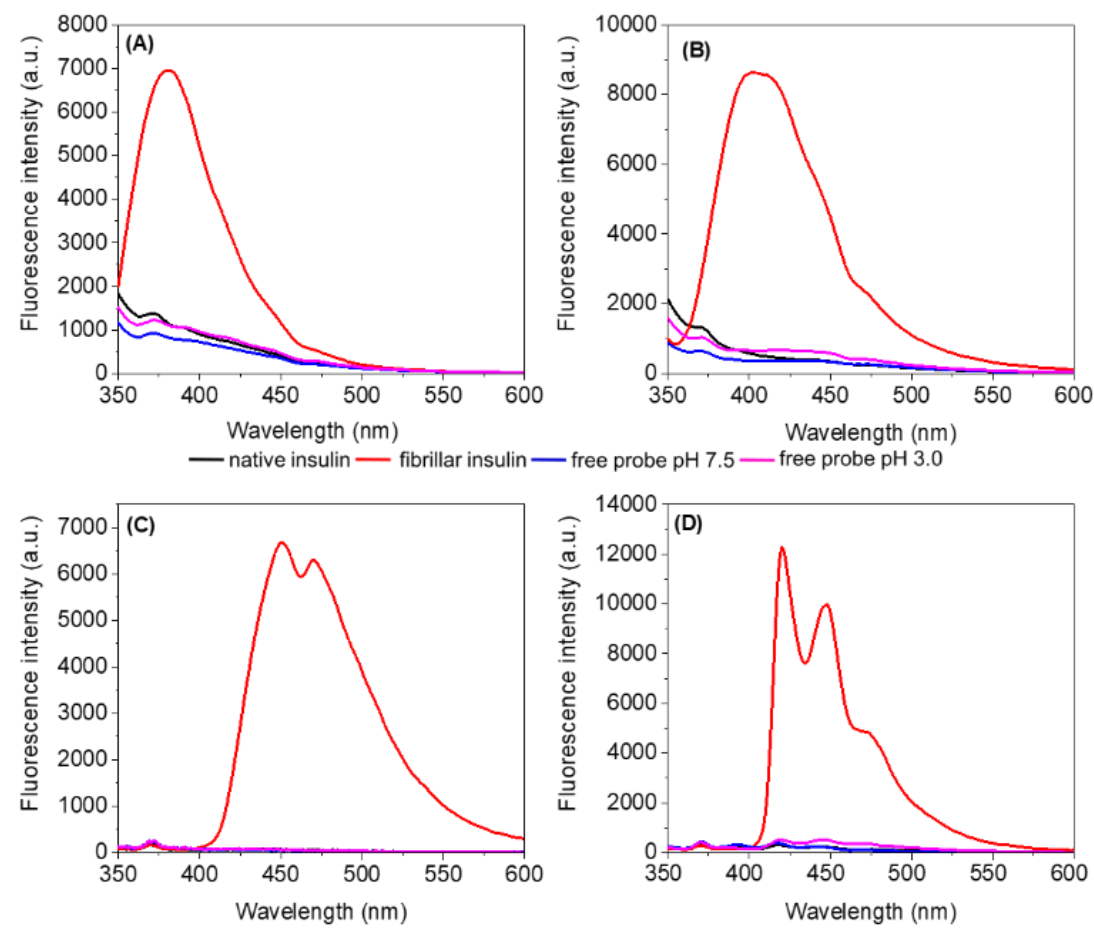

Figure 4.3 Emission spectra of (A) 74, (B) 75, (C) 76, and (D) 77 bound to either native insulin or insulin fibrils in PBS buffer ( $\mathrm{pH}$ 7.4). $1 \mu \mathrm{M}$ was used for probe and $5 \mu \mathrm{M}$ (on a monomer basis) was used for native insulin and insulin fibrils. Ex $=330 \mathrm{~nm}$ for all probes. Reproduced with permission from ACS Omega 2017, 2, 4693-4704. 
In summary: To make a palpable overall comparison of the probes against various amyloid fibrils, we generated a starplot (Figure 4.4A) to compare various $\mathrm{K}_{d}$ values and fluorescence increase for the respective probe. This graphical representation illustrates that $\mathbf{7 6}$ shows the strongest fluorescence increase for fibrils at acidic $\mathrm{pH}$ and that the affinity (low $\mathrm{K}_{\mathrm{d}}$ ) generally increases as the hydrophobicity of the probe increases, with the strongest binding for 77. Furthermore, a star-plot representation of the photophysical properties including Stokes shift and fluorescence lifetimes clearly display a similar separation with highest Stokes shift for $\mathbf{7 6}$ and the longest fluorescence lifetimes for 77 (Figure 4.4B). We foresee that this class of probes will be useful for amyloid fibril research.

(A)

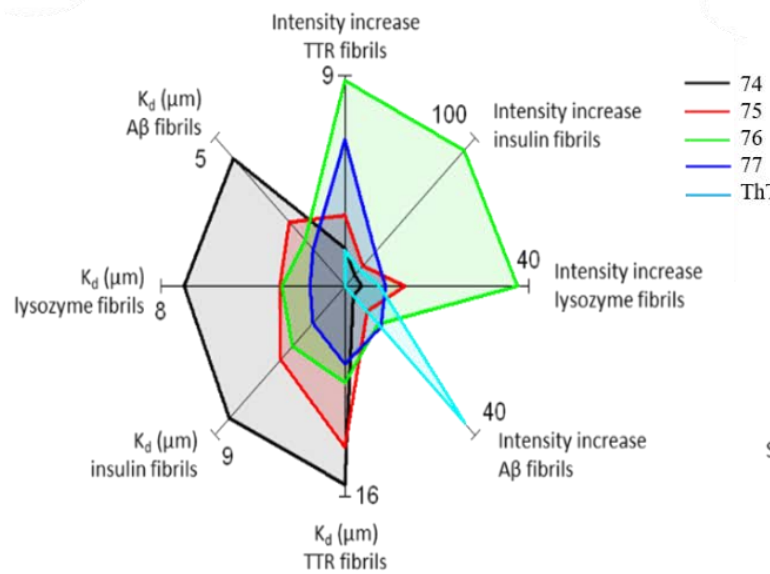

(B)

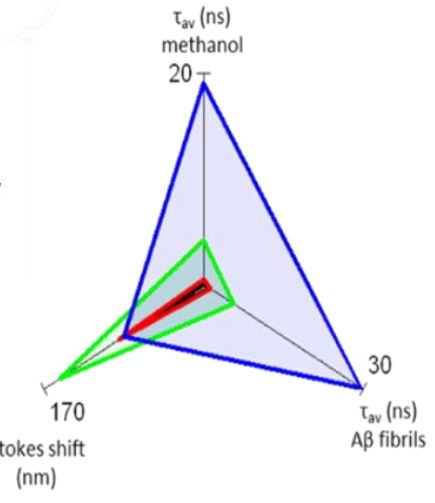

Figure 4.4 Star-plot representation to compare all probe parameters in graphical format. (A) Binding properties including dissociation constants $\left(K_{d}\right.$ in $\left.\mu \mathrm{M}\right)$ of the probes against different fibril types and the fold increase of fluorescence intensity of the fibril-bound probe compared with the free probe. (B) Star-plot representation of the photophysical properties including Stokes shift (nm) and average fluorescence lifetime ( $\tau_{\mathrm{avg}}$ in $\mathrm{ns}$ ) of the probes. Reproduced with permission from ACS Omega 2017, 2, 4693-4704. 


\subsection{Paper II: Intramolecular proton and charge transfer of pyrene-based trans-stilbene salicylic acids applied to detection of aggregated proteins}

Aim: The aim of the second paper was to synthesize two pyrene-based trans-stilbene salicylic acids (Py1SA and Py2SA). The emission spectra of both molecules when bound to native and fibrillar A $\beta 1-42$ were investigated and their intrinsic photophysical properties were also studied in different solvents [DMSO, ethanol (EtOH) and toluene] for a wide range of concentrations by steady-state absorption and emission.

Results and discussion: Our approach for the synthesis of the trans-1 and 2-styryl-pyrene derivatives (Py1 and Py2 derivatives) was to apply the palladium-catalyzed Heck reaction of styrene derivatives to the corresponding 84 (1-bromopyrene) and 80 (2-bromopyrene). The first synthesis of $\mathbf{8 4}$ was reported in 1937 by Lock, via the bromination of pyrene parent. ${ }^{159}$ Then similar approaches have been developed using reagents such as $\mathrm{NBS},{ }^{160} \mathrm{CuBr}_{2},{ }^{161}$ and $\mathrm{HBr}$ with $\mathrm{H}_{2} \mathrm{O}_{2} .{ }^{162}$ In this work, 84 was

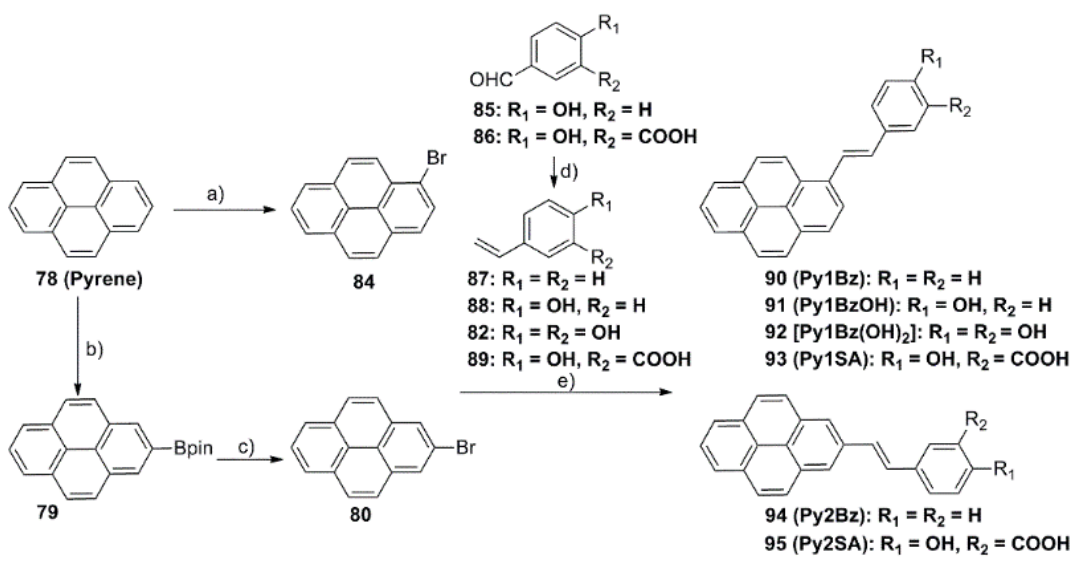

Scheme 4.1 Synthesis of trans-1 or 2-styryl-pyrene derivatives (Py1 and Py2 derivatives). Reagents and conditions: a) $\mathrm{HBr}(48 \%), \mathrm{H}_{2} \mathrm{O}_{2}(30 \%), \mathrm{MeOH} / \mathrm{Et}_{2} \mathrm{O}$ (1:1), rt, $92 \%$; b) $\mathrm{B}_{2} \mathrm{Pin}_{2}$ (1.1 equiv), Ir (u-OMe ) $\operatorname{cod}_{2}(1 \% \mathrm{~mol})$, dtbpy ( $\left.2 \% \mathrm{~mol}\right)$, hexane, $80^{\circ} \mathrm{C}$, overnight, $60 \%$; c) $\mathrm{CuBr}_{2}$ (3 equiv.), $\mathrm{MeOH} / \mathrm{H}_{2} \mathrm{O}(1: 1), 90^{\circ} \mathrm{C}$, overnight, $75 \%$; d) $\mathrm{Ph}_{3} \mathrm{PCH}_{3} \mathrm{Br}$ (1.5 equiv.), tBuOK (4 equiv.), THF, rt, $6 \mathrm{~h}$; e) $\mathrm{Pd}(\mathrm{OAc})_{2}(10 \% \mathrm{~mol})$, triethanolamine (2 equiv.), DMF, $100{ }^{\circ} \mathrm{C}, 24 \mathrm{~h} .[\operatorname{Ir}(\mu-$ $\mathrm{OMe}) \operatorname{cod}]_{2}=(1,5$-Cyclooctadiene $)($ methoxy $)$ iridium (I) Dimer, dtbpy $=4,4^{\prime}-\mathrm{Di}$ tert-butyl-2,2'-dipyridyl. 
synthesized in $92 \%$ yield under the conditions: $\mathrm{HBr}(48 \%), \mathrm{H}_{2} \mathrm{O}_{2}(30 \%)$, $\mathrm{MeOH} / \mathrm{Et}_{2} \mathrm{O}$ (1:1), room temperature. And 80 was obtained using the same approach. ${ }^{163}$ Finally, trans-1-styryl-pyrene derivatives: 90 (Py1Bz), $91(\mathrm{Py} 1 \mathrm{BzOH})$ and $92\left[\mathrm{Py} 1 \mathrm{Bz}(\mathrm{OH})_{2}\right]$ as well as 93 (Py1SA) were prepared in $57 \%, 66 \%, 53 \%$ and $70 \%$ yields, respectively. Trans-2-styrylpyrene derivatives: 94 (Py2Bz) and 95 (Py2SA) were obtained in 35\% and $43 \%$ yields.

We first investigated the utilities of both Py1SA and Py2SA as probes for detecting A $\beta 1-42$ aggregates in PBS. As can be seen from the fluorescence spectra shown in Figure 4.5 a bright fluorescence is switched on upon mixed with $A \beta 1-42$ fibrils, but with entirely different emission bands, as reflected using a fluorescence images with distinct colors. Py1SA showed a broad emission around $498 \mathrm{~nm}$ while Py2SA displayed the characteristic pyrene emission spectrum with resolved vibrational substructure having the maximum at $419 \mathrm{~nm}$. To assess if this was specific for $A \beta 1-42$ fibrils we also assayed four other amyloid fibrils (insulin, lysozyme and Prion as well as tau) and observed very similar emission patterns even at low $\mathrm{pH}$.
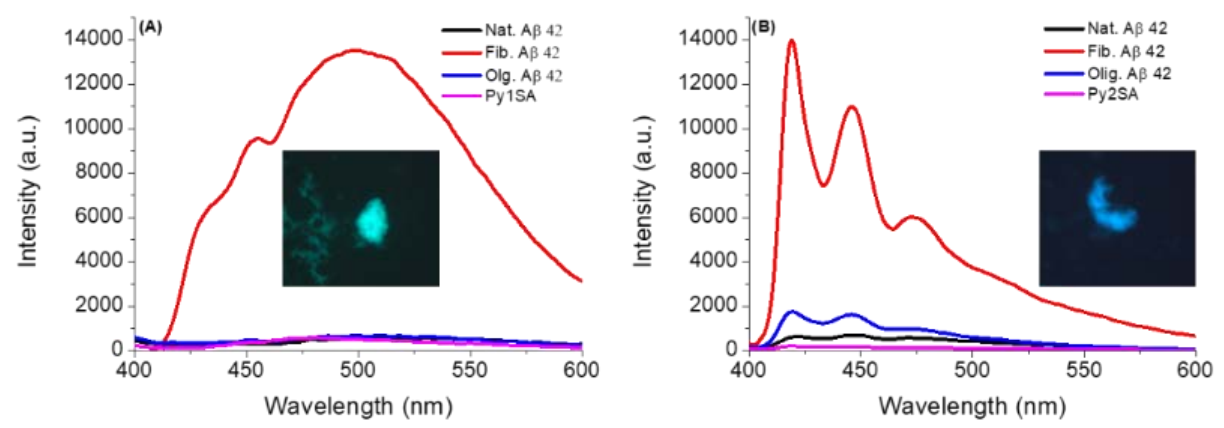

Figure 4.5 Emission spectra of Py1SA (A) and Py2SA (B) upon bound to native, fibrillar and oligomeric forms of $\mathrm{A} \beta 1-42$ in PBS buffer ( $\mathrm{pH} 7.4$ ). $5 \mu \mathrm{M}$ (on a monomer basis), was used for native, fibrillar and oligomeric forms of A $\beta 1-42.1 \mu \mathrm{M}$ was used for probes. $\lambda_{\mathrm{ex}}=390 \mathrm{~nm}$ (Py1SA), $330 \mathrm{~nm}$ (Py2SA). Insets: fluorescence images of mature $A \beta 1-42$ fibrils stained by probes.

Then we investigated the geometric, LUMO structures and photophysical properties of Py1SA and Py2SA in three organic solvents considered 
(DMSO, EtOH and toluene). As shown in Figure 4.6, the phenyl and pyrene groups of Py1SA are twisted along the ethylene group, whereas
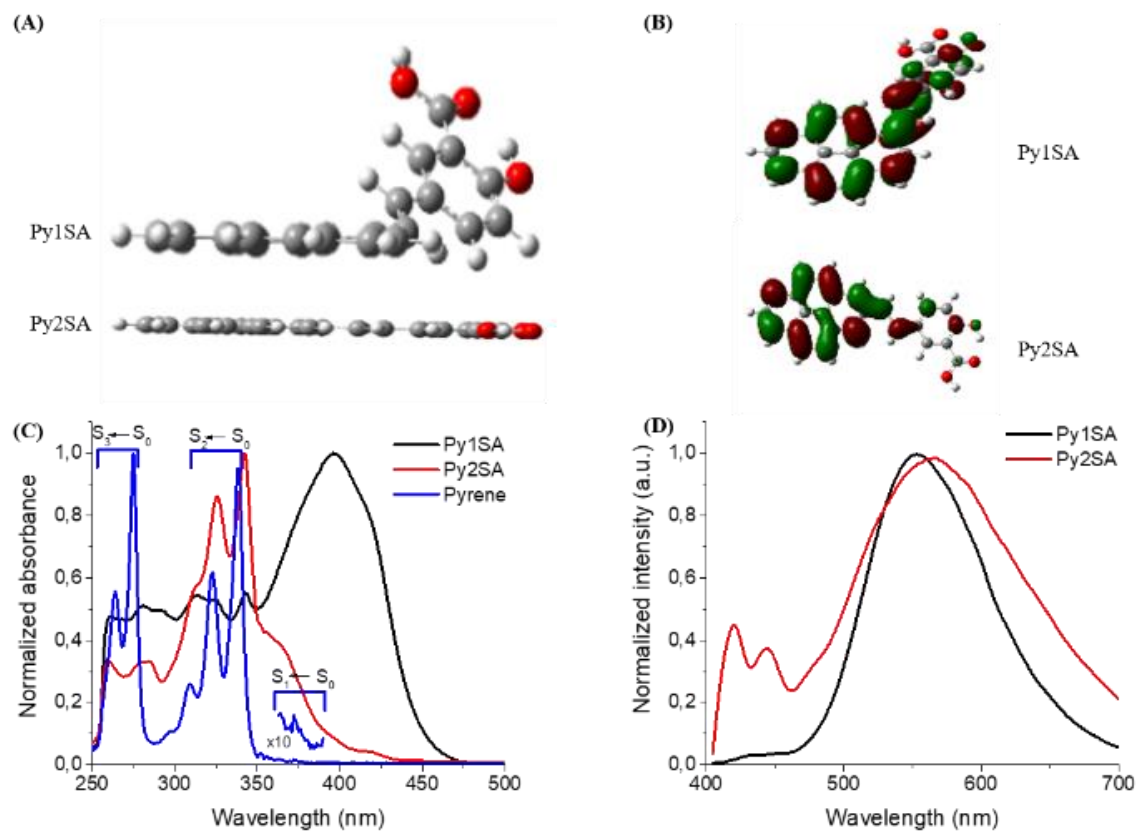

Figure 4.6 Geometric (A), LUMO structures (B) and absorption in DMSO (C) as well as emission spectra in DMSO (D) of Py1SA and Py2SA.

Py2SA is nearly planar. The structural difference between Py1SA and Py2SA is consistent with the previous observation that the 2-position of pyrene is more sterically accessible to substitution than the 1 -position. ${ }^{164-}$ ${ }^{165}$ The LUMO of Py1SA indicates that the molecular twist does not significantly disturb the conjugation of Py1SA, which is in line with previous results ${ }^{11,166-167}$, whereas the LUMO of Py2SA is more localized on the pyrene moiety with only a minor contribution from the SA carbon at the pyrene 2-position, suggesting that in Py2SA, the electronic coupling between the pyrene and SA moieties is weaker. ${ }^{165,167}$ Consistent with the strong influence on both the $\mathrm{S} 2 \leftarrow \mathrm{S} 0$ and $\mathrm{S} 1 \leftarrow \mathrm{S} 0$ excitations observed for the 1 -substituted pyrene derivatives, ${ }^{156}$ the absorption spectrum of Py1SA in DMSO showed a broad band $(395 \mathrm{~nm})$ with no clearly defined S2 $\leftarrow$ S0 and $\mathrm{S} 1 \leftarrow \mathrm{S} 0$ excitations (Figure 4.6C). While the absorption spectrum of Py2SA exhibited a pyrene-like S2 $\leftarrow$ S0 excitation $(343 \mathrm{~nm})$ with a small 
bathochromic shift $(3 \mathrm{~nm}$ ) from the $\mathrm{S} 2 \longleftarrow \mathrm{S} 0$ transition in pyrene (Figure 4.6C). Furthermore, the emission spectra of $5 \mu \mathrm{M}$ Py1SA and Py2SA in DMSO are shown in Figure 4.6D. Py1SA only showed a broad, featureless emission spectrum centered at $555 \mathrm{~nm}$, called "K emission", which is assigned to the ESIPT and ICT state of anionic K-form (anionic $\mathrm{K}_{\text {ESIPT- }}$ form + anionic $\mathrm{K}_{\mathrm{ICT}}$-form, Scheme 4.2) according to previous reports. ${ }^{168}$ While Py2SA showed two apparent emission bands: one around $565 \mathrm{~nm}$, namely, the $\mathrm{K}$ emission, the other around $416 \mathrm{~nm}$ regarded as "E emission", clearly to be attributed mainly to the locally excited (LE) state of the pyrene moiety of the neutral E-form.

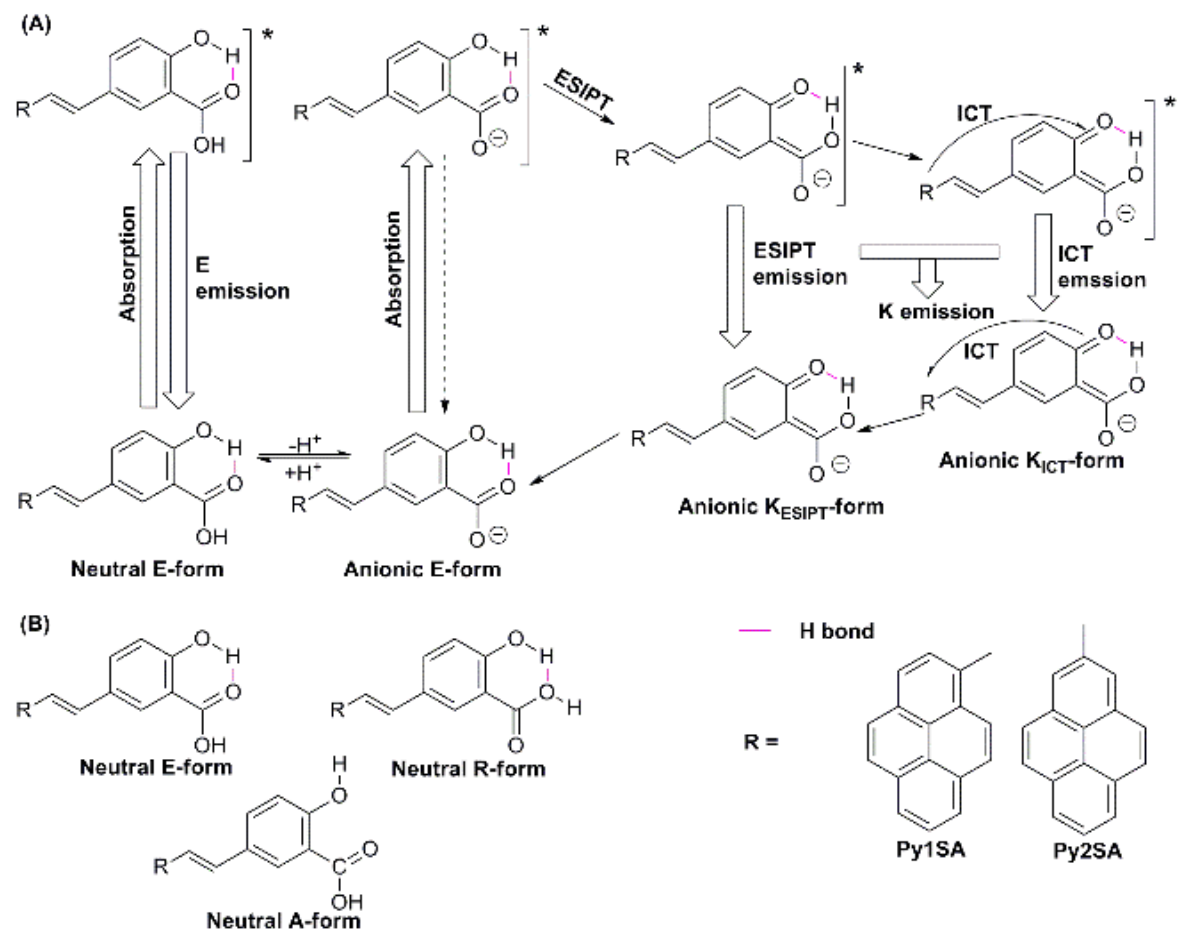

Scheme 4.2. A) The ground- and excited-state species of Py1SA and Py2SA as well as a schematic of their photo-physics. B) Different species of Py1SA and Py2SA in ground state. Reproduced with permission from Chemphyschem, 2018, 19, $1-10$. 
In summary: The DFT calculations showed that Py1SA is twisted while Py2SA is more planar. The LUMOs indicated that Py1SA has a large coefficient on the connecting carbon at the 1-position, whereas Py2SA has a low coefficient on the connecting carbon at the 2-position, reflecting that the pyrene is connected covalently but uncoupled electronically. Spectroscopic experiments showed that Py1SA and Py2SA at low concentrations, on photo-excitation exhibit dual emission corresponding to normal (E-emission) and large Stokes-shifted fluorescence (K-emission) in polar solvents. The former is attributed to a locally excited state of neutral E-form, while the latter includes ESIPT and ICT emission. We conclude that $\mathrm{K}$-emission is observed only in the anionic E-form in a polar solvent. We demonstrated that both compounds can discriminate between native and fibrillar forms of A $\beta 1-42$ and can work as probes for quantitative analysis and kinetics study of amyloid fibril formation. PylSA showed a broad emission band around $498 \mathrm{~nm}$, attributed to the strong ICT between pyrene and benzene ring, not ESIPT when bound to preformed A $\beta 1-42$ fibrils or other amyloid fibrils (insulin, lysozyme, Prp and Tau). While Py2SA displayed a pyrene-type emission spectrum with a sharp peak $419 \mathrm{~nm}$ due to the nodal plane though the 2- and 7-position of pyrene. The different spectral outputs arising from distinct ICT of the two ligands when bound to five different amyloid proteins shows that minor alterations in probe design can be used for tuning the fluorescence properties of amyloid probes. 


\subsection{Paper III: Detection and imaging of Aß1-42 and Tau fibrils by redesigned fluorescent $\mathrm{X}-34$ analogues}

Aim: the aim of the third paper was to synthesize four new ligands with distinct optical properties by replacing the central benzene unit of the Congo red analogue X-34, with other heterocyclic moieties (naphthalene, thiophene and quinoxaline as well as benzodithiazole) for imaging Alzheimer's disease (AD) pathology comprising $A \beta$ and Tau aggregates.

Results and discussion: Our approach for the synthesis of 4 new ligands was to apply the palladium-catalyzed Heck cross-coupling reaction of compound 89 with dibrominated 96 (naphthalene), 97 (thiophene) and 98 (quinoxaline) as well as 99 (benzodithiazole) to give 100 (NSB), 101 (TSB), 102 (QSB), and 103 (BTDSB) with final yields of 38\%, 64\%, $58 \%$, and $72 \%$, respectively (Scheme 4.3 ). Compound 89 was synthesized according to the methods described. ${ }^{163}$

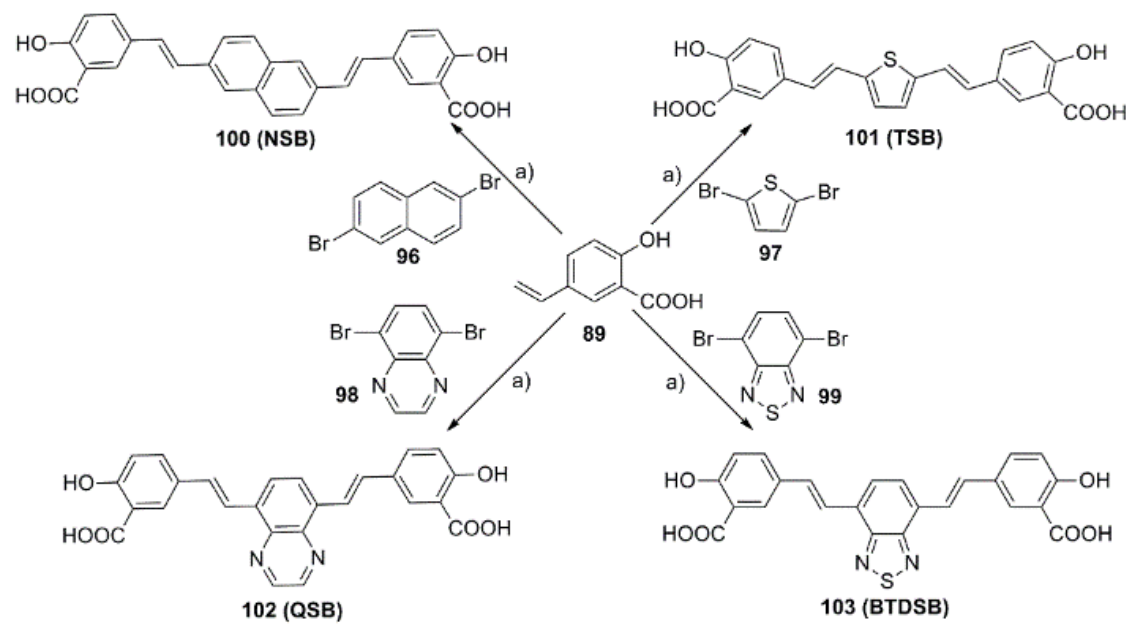

Scheme 4.3 Synthesis of NSB, TSB, QSB, and BTDSB. Reagents and conditions: a) $\mathrm{Pd}(\mathrm{OAc})_{2}(10 \% \mathrm{~mol})$, triethanolamine ( 4 equiv ), dry $\mathrm{DMF}, 100{ }^{\circ} \mathrm{C}, 24 \mathrm{~h} . R e-$ produced with permission from Chem. Eur. J., 2018, 24, 7210-7216.

Then in vitro ligand binding assays with aggregated $A \beta 1-42$ or tau were investigated as demonstrated in Figure 4.7A-C. X-34 was included for comparison in this study. All ligands exhibited significant redshifts in absorption spectra of $20,15,10,12$, and $17 \mathrm{~nm}$, respectively, upon binding 
to $A \beta 1-42$ fibrils, in agreement with that of Congo red mixed with $A \beta 1$ 40 or 1-42 fibrillar aggregates. ${ }^{169}$ This shift is assigned to fibril-induced molecular planarization of the ligand and subsequent increase in hyperconjugation. These ligands showed different degrees of fluorescence changes in the presence of A $\beta 1-42$ or tau fibrils. Especially, QSB and BTDSB showed small fluorescence changes when mixed with tau fibrils. The quantum yields of ligands bound to A $\beta 1-42$ fibrils significantly increased compared to those of free ligands in PBS, suggesting that fibril
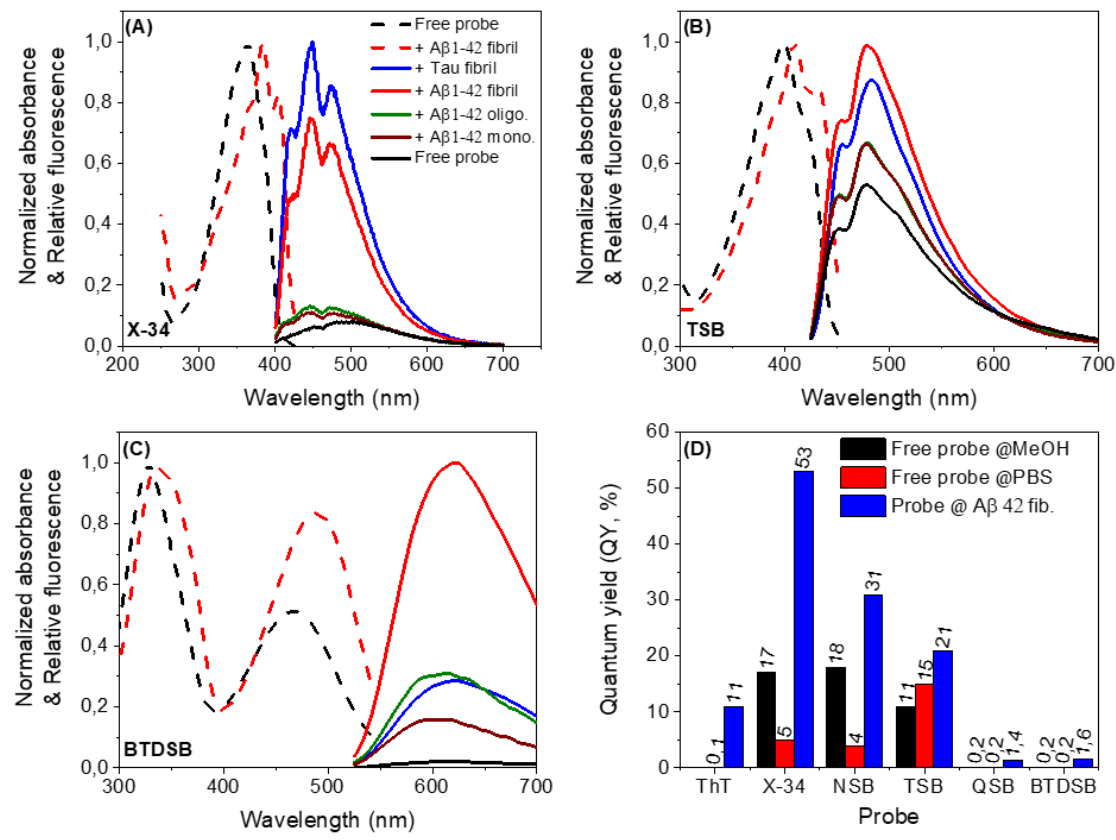

Figure 4.7 Absorption (dashed line) and emission (solid line) spectra of X-34 (A), TSB (B) and BTDSB (C) in the absence/presence of A $\beta 1-42$ peptide (monomer, oligomer and fibril) or tau fibrils in PBS buffer (pH 7.4). $5 \mu \mathrm{M}$ fibrils and $500 \mathrm{nM}$ probe were used for all experiments. Absorption spectra are normalized by the peak value. Emission spectra are presented as relative intensities. (D) Quantum yield (QY) of ligand (ThT, X-34, NSB, TSB, QSB and BTDSB) in the absence/presence of $A \beta 1-42$ fibrils in PBS buffer ( $\mathrm{pH}$ 7.4). Free probe in degassed $\mathrm{MeOH}$ is also shown. Values represent the average of three determinations. The same legend as in (A) is used in (B) and (C). Reproduced with permission from Chem. Eur. J., 2018, 24, 7210-7216. 
bound ligands were preorganized in a geometry which is close to the planarized geometry of the emissive excited state after it has reached its equilibrium (Figure 4.7D).

We then measured the binding affinity of the ligands to $A \beta 1-42$ or tau fibrillar aggregates and the competition with radiolabeled ligands, ${ }^{3} \mathrm{H}-\mathrm{PiB}$ and ${ }^{3} \mathrm{H}-\mathrm{X}-34$, which bind to distinct sites on $\mathrm{A} \beta$ fibrils. ${ }^{170}$ The detailed binding constants of ligands with aggregated $A \beta 1-42$ or tau are summaried in Table 4.1. From the binding competition, the ligands did not compete with ${ }^{3} \mathrm{H}-\mathrm{PiB}$ but it was evident that the nature of the central chemical moiety had a major influence on the $\mathrm{X}-34$ derivatives efficiency to displace ${ }^{3} \mathrm{H}-\mathrm{X}-34$ from recombinant $\mathrm{A} \beta 1-42$ fibrils. In comparison with $\mathrm{X}$ 34 , introducing a thiophene group (a weak electron-donating group) decreased the $\mathrm{EC}_{50}$ value, whereas introduction of quinoxaline $(\mathrm{Q})$ and benzodithiazole (BTD) (two electron-withdrawing groups, Q $<$ BTD), successively increased the $\mathrm{EC}_{50}$ values. Additionally, for Tau fibrils all ligands predominantly competed with ${ }^{3} \mathrm{H}-\mathrm{X}-34$ with lower $\mathrm{EC}_{50}$ values compared to that for $A \beta$ 1-42 fibrils.

Table 4.1 Binding constants of ligands with aggregated $A \beta 1-42$ or tau

\begin{tabular}{ccccc}
\hline \multirow{2}{*}{ Ligand } & \multicolumn{2}{c}{$\mathrm{K}_{\mathrm{d}}(\mathrm{nM})^{[\mathrm{a}]}$} & \multicolumn{2}{c}{$\mathrm{EC}_{50}(\mathrm{nM})^{[\mathrm{b}]}$} \\
\cline { 2 - 5 } & $\mathrm{A} \beta 1-42$ & $\mathrm{Tau}$ & $\mathrm{A} 1-42$ & tau \\
\hline ThT & $665 \pm 66$ & $2873 \pm 144$ & 5000 \\
X-34 & $299 \pm 21$ & $195 \pm 10$ & 80 & 10 \\
NSB & $264 \pm 13$ & $175 \pm 7$ & 750 & 22 \\
TSB & $13 \pm 1$ & $16 \pm 1$ & 16 & 12 \\
QSB & $124 \pm 7$ & $155 \pm 6$ & 120 & 60 \\
BTDSB & $93 \pm 5$ & $110 \pm 5$ & 140 & 12 \\
\hline
\end{tabular}

${ }^{[a]} K_{d}$ values were determined by saturation binding assays by fluorescence. Values represent the average $\pm \mathrm{SD}$ of two determinations. ${ }^{[\mathrm{b}]} \mathrm{EC}_{50}$ values of ligands competition for radioligands ${ }^{3} \mathrm{H}-\mathrm{X}-34$ binding to $\mathrm{A} \beta 1-42$ or tau fibrils. N.D. $=$ Not determined. Reproduced with permission from Chem. Eur. J., 2018, 24, 7210-7216.

Next, the X-34 derivatives, including X-34, were evaluated as fluorescent ligands in human brain tissue sections with AD pathology (Figure 4.8). All ligands exhibited specific binding to extracellular $A \beta$ plaques in the brain parenchyma and intracellular NFTs, except for QSB, which selectively and specifically only stained $A \beta$ plaques. 


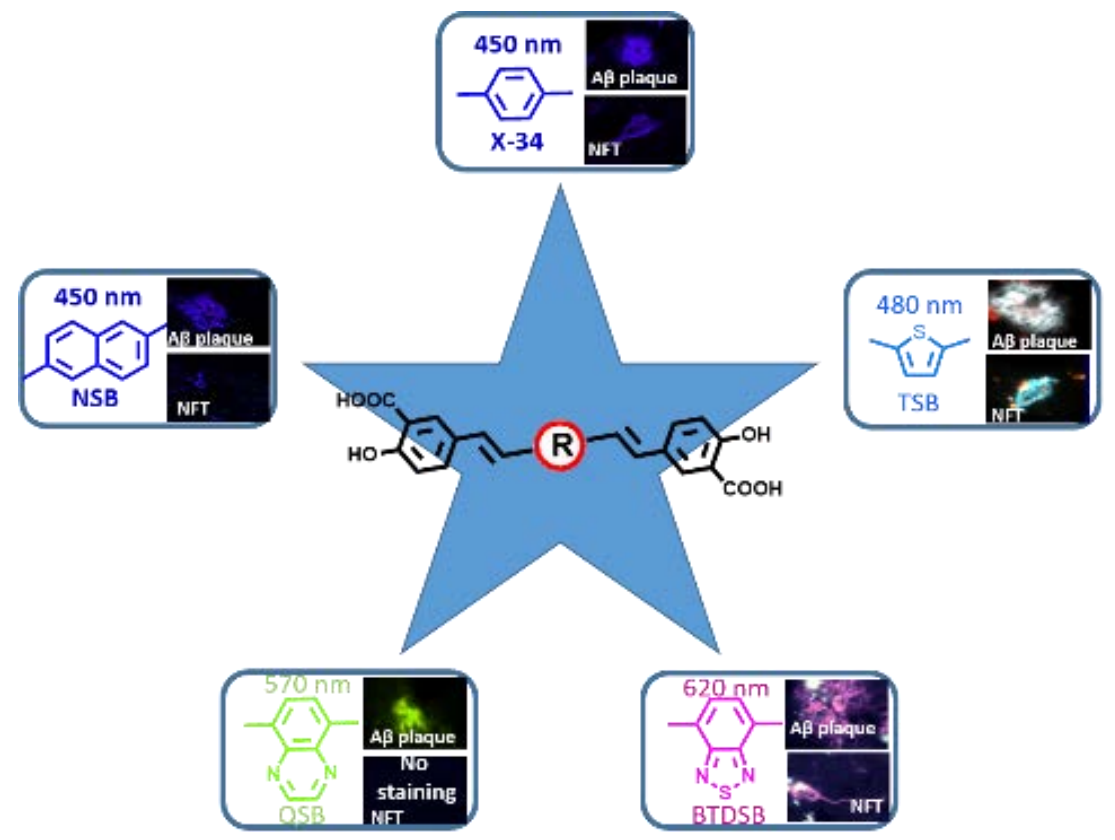

Figure 4.8 Fluorescent derivatives of the $\mathrm{X}-34$ (top structure) with distinct central chemical motifs render fluorescent ligands that can be utilized to assign $\mathrm{A} \beta$ plaques and NFTs in human AD brain sections.

In summary: We have displayed a general synthetic route, where by the central benzene unit is replaced with other heterocyclic motifs, can be used for synthesizing a selection of ligands that can be utilized for fluorescence detection of protein aggregates. We have indicated that these ligands competed for binding of ${ }^{3} \mathrm{H}-\mathrm{X}-34$, not ${ }^{3} \mathrm{H}-\mathrm{PiB}$, on pure recombinant $A \beta 1-42$ amyloid fibrils and hence retained its main binding site, being of Congo red type. The nature of the central chemical moiety appeared to be a key determinant for binding affinity and for displacing ${ }^{3} \mathrm{H}-$ $\mathrm{X}-34$ binding from A $\beta 1-42$ fibrils. Most importantly, the specific amyloid staining property of $A \beta$ plaques and NFTs in human $A D$ brain tissue was retained. We foresee that this scaffold, while rather well studied, may continue to serve a role for design of high-affinity ligands targeting $A \beta$ and tau pathology in human AD brain. Especially targeting $A \beta$ pathology independently of the PiB binding site via ligands such as QSB could potentially identify different $A \beta$ fibril polymorphs involved in various $A D$ subtypes. 


\subsection{Paper IV: Phenolic bis-styrylbenzo[c]-1,2,5- thiadiazoles as fluorescent probes for mapping microscopic A $\beta$ plaque heterogeneity}

Aim: The aim of the forth paper was to design and synthesize six 2,1,3benzothiadiazole (BTD)-based ligands with a series of bis-styryl-BTDs and different conjugated spacers to investigate their $A \beta$ binding affinities (A $\beta 1-42$ and $A \beta 1-40$ fibrils) and specificity towards $A \beta$ amyloid plaques.

Results and discuss: We synthesized a series of BTDSB analog. 107 to 116 via the classic Heck reaction using a new one-pot procedure as depicted in Figure 4.9A. Compounds $\mathbf{1 0 4}$ to $\mathbf{1 0 6}$ were prepared via Witting reaction of the corresponding aldehyde and triphenylphosphine methyl bromide utilizing a previous procedure. ${ }^{163}$ Compound 87 was purchased from Sigma-Aldrich. Compounds $\mathbf{8 8}$ and $\mathbf{8 2}$ has been reported previously by our group. ${ }^{171}$

(A)

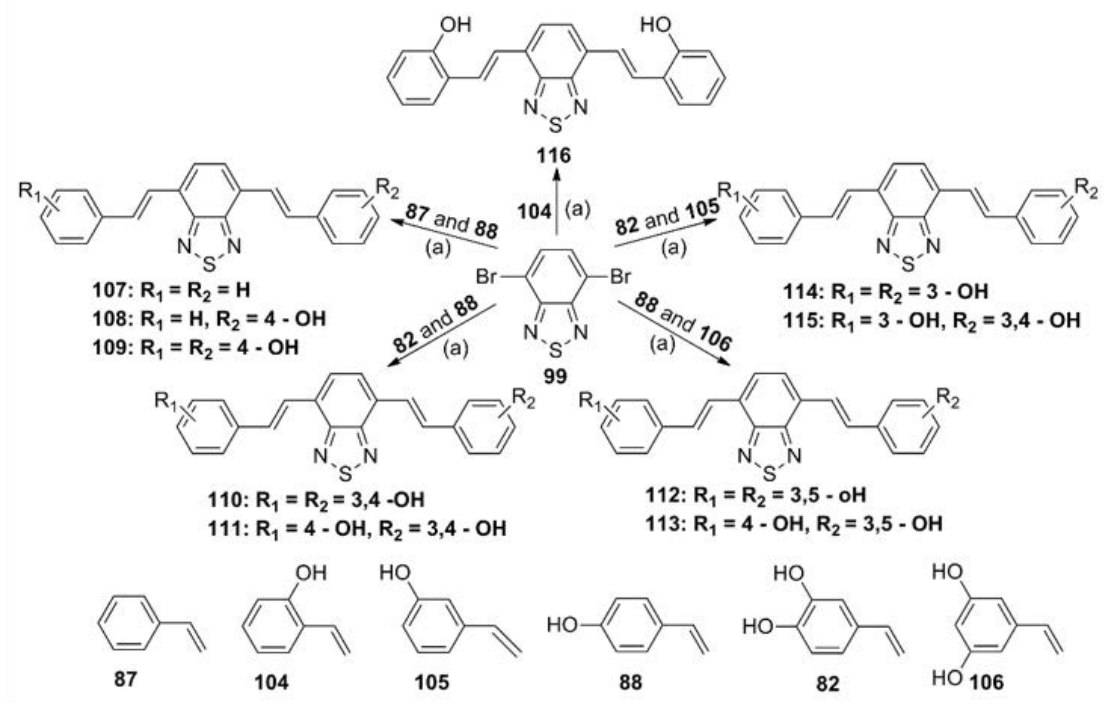

Conditions and reagents: (a) $\mathrm{Pd}(\mathrm{OAc})_{2}$, triethanolamine, DMF.

(B)

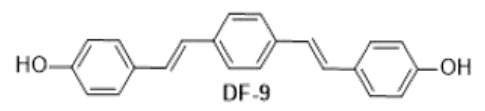

Figure 4.9 A) Synthesis of bis-styryl-BTDs. B) Chemical structure of DF-9. 
Next, we investigated the emission behavior and binding affinity of 107 to 116 and BTDSB towards A $\beta 1-42$ fibrils and A $\beta 1-40$ fibrils, using DF9 (see the structure in Figure 4.9B) and X-34 as references (Table 4.2). We found that these ligands showed larger fluorescence intensities when bound to $A \beta 1-42$ fibrils than bound to $A \beta 1-40$ fibrils. It is noticeable that these ligands showed higher binding affinity towards recombinant $A \beta 1$ 42 fibrils compared to $A \beta 1-40$ fibrils, which is consistent with their higher fluorescence enhancement for A $\beta 1-42$ fibrils. Therefore, we will focus on the $K_{d}$ values towards $A \beta 1-42$ fribils. We note that $\mathbf{1 0 9}$ had the strongest binding affinity $(19.7 \pm 1.6)$ of all ligands. The binding affinity for $\mathbf{1 0 7}$ and 108 was 3.4-fold and 2-fold less compared to 109, most likely due to the loss of H-bond stabilization. The $K_{d}$ data for 109 versus 114 and 116 suggest that the para- and ortho- are marginally superior to metasubstitution on the outer phenyl rings. Although the meta-OH could decrease the binding affinity, 112 showed higher binding affinity compared to 114 , attributed to the 2 more of H-bond stabilization by the phenol functional group. As evidenced by the 4.3-fold loss in binding affinity for BTDSB compared to 109, the carboxylic acid functional groups decreased the affinity, suggesting that acidic functional groups are not required for good $A \beta$ binding, which is in line with X-34 $(149 \pm 8 \mathrm{nM})$ versus DF-9 (137 $\pm 10 \mathrm{nM})$ for $\mathrm{A} \beta 1-42$ fibrils and comparable affinities for A $\beta 1-40$ fibrils.

Due to the highest binding affinities of 109 towards $A \beta 1-42$ and $A \beta 1-40$ fibrils, we then synthesized compounds $\mathbf{1 1 7}$ to $\mathbf{1 2 0}$ by means of palladium-catalyzed cross-coupling reactions of 4,7-dibromo-2,1,3-benzothiadiazole (99) (Scheme 4.4). 117 was achieved in 81\% yield for two same steps by the Suzuki reaction as shown in Scheme 4.4. Actually, to synthesize 117 in one step using $\mathbf{9 9}$ and 3-fold $\mathbf{1 2 1}$ failed and only gave the mono-substituted product $\mathbf{1 2 2}$ in $89 \%$ yield. The Sonogashira coupling reaction of 99 with 123 gave compound $\mathbf{1 2 4}$ in 92\% yield according to the previously reported procedures, ${ }^{172}$ then $\mathbf{1 2 4}$ was deprotected using $\mathrm{KOH}$ in $\mathrm{MeOH}$ to obtain the intermediate product, which was instantly derived to 118 by reaction with 125 (4-iodophenol) in 32\% yield. The borylation of compound 126 using 127, $\mathrm{PdCl}_{2}$ (dppf), dppf, KOAc, in 1,4dioxane was achieved according to the previously reported patent, ${ }^{173}$ then reacted with 99 by Suzuki coupling reaction to give the desired molecule 
Table 4.2 Binding properties of BTD derivatives.

\begin{tabular}{cccccc}
\hline \multirow{2}{*}{ compd. } & \multicolumn{2}{c}{$\mathrm{K}_{\mathrm{d}}(\mathrm{nM})^{[\mathrm{a}]}$} & \multicolumn{2}{c}{$\mathrm{FI}^{[\mathrm{b}]}$} & \multirow{2}{*}{$\operatorname{clog}^{[\mathrm{c}]}$} \\
\cline { 2 - 5 } & $\mathrm{A} \beta 1-42$ & $\mathrm{~A} \beta 1-40$ & $\mathrm{~A} \beta 1-42$ & $\mathrm{~A} \beta 1-40$ & \\
\hline DF-9 & $137 \pm 10$ & $58 \pm 7$ & $16.7 \pm 1.5$ & $1.3 \pm 0.4$ & 6.2 \\
BTDSB & $83 \pm 6$ & $\sim 250$ & $24.3 \pm 2.1$ & $3.7 \pm 0.5$ & 8.1 \\
$\mathbf{1 0 7}$ & $66 \pm 8$ & $109 \pm 19$ & $2,9 \pm 0.2$ & $1.1 \pm 0.1$ & 7.3 \\
$\mathbf{1 0 8}$ & $39 \pm 1$ & $61 \pm 17$ & $16.1 \pm 0.7$ & $4.4 \pm 0.3$ & 6.7 \\
$\mathbf{1 0 9}$ & $20 \pm 2$ & $46 \pm 2$ & $17.2 \pm 0.3$ & $11.7 \pm 1.3$ & 6.0 \\
$\mathbf{1 1 0}$ & $39 \pm 4$ & $187 \pm 8$ & $19.7 \pm 1.0$ & $4.8 \pm 0.8$ & 4.8 \\
$\mathbf{1 1 1}$ & $31 \pm 4$ & $110 \pm 22$ & $21.3 \pm 1.2$ & $7.0 \pm 0.9$ & 5.4 \\
$\mathbf{1 1 2}$ & $95 \pm 1$ & $284 \pm 12$ & $26.7 \pm 1.4$ & $2.2 \pm 0.4$ & 4.7 \\
$\mathbf{1 1 3}$ & $73 \pm 7$ & $170 \pm 13$ & $48,5 \pm 1.6$ & $12.4 \pm 0.6$ & 5.3 \\
$\mathbf{1 1 4}$ & $116 \pm 10$ & $133 \pm 10$ & $17.2 \pm 1.0$ & $5.4 \pm 0.7$ & 6.0 \\
$\mathbf{1 1 5}$ & $77 \pm 1$ & $83 \pm 20$ & $9.2 \pm 0.7$ & $2.7 \pm 0.2$ & 5.4 \\
$\mathbf{1 1 6}$ & $29 \pm 5$ & $106 \pm 22$ & $3.6 \pm 1.3$ & $1.5 \pm 0.7$ & 6.0 \\
$\mathbf{1 1 7}$ & $511 \pm 29$ & $250 \pm 25$ & $7.3 \pm 1.1$ & $2.1 \pm 0.7$ & 4.4 \\
$\mathbf{1 1 8}$ & $36 \pm 3$ & $59 \pm 5$ & $4.6 \pm 0.9$ & $2.7 \pm 0.2$ & 5.9 \\
$\mathbf{1 1 9}$ & $40 \pm 4$ & $>400$ & $5.1 \pm 1.3$ & $2.6 \pm 0.3$ & 8.2 \\
$\mathbf{1 2 0}$ & $10 \pm 1$ & $>400$ & $3.5 \pm 0.2$ & $1.8 \pm 0.5$ & 8.4 \\
\hline
\end{tabular}

${ }^{[\mathrm{a}]} \mathrm{K}_{\mathrm{d}}$ values were determined by saturation binding assays by fluorescence. Values represent the average \pm SD of 2 determinations. ${ }^{[b]}$ Fold increase $(\mathrm{FI})=$ fluorescence intensity of the ligand bound to $A \beta 1-42$ or A $\beta 1-40$ fibrils / intensity of the unbound ligand in PBS. Values represent the average \pm SD of 2 determinations. ${ }^{[c]}$ Calculated cLogP values using chemdraw ultra 12.0.

$\mathbf{1 1 9}$ in $21 \%$ yield. The Heck reaction of $\mathbf{9 9}$ and $\mathbf{1 2 9}$ produced compound 130 in $80 \%$ yield, then bromination to give compound 131 in $75 \%$ yield according to the previously reported procedures. ${ }^{172}$ And then $\mathbf{1 3 1}$ reacted with 121 by Suzuki reaction to obtain the desired molecule 120 in 46\% yield.

We also investigated the emission behavior and binding affinity of $\mathbf{1 1 7}$ to 120 as demonstrated in Table 4.2. These ligands showed an apparent fluorescence intensity with significant hypsochromic shift in the presence of $A \beta 1-42$ fibrils than that when bound to $A \beta 1-40$ fibrils, demonstrating that these probes are more sensitive to $A \beta 1-42$ fibrils over than $A \beta 1-40$ fibrils. Then, we measured the binding affinity of $\mathbf{1 1 7}$ to $\mathbf{1 2 0}$ towards $A \beta 1-42$ fibrils and $A \beta 1-40$ fibrils. As shown in Table 4.2, the binding affinity of these probes, in conjuncture with 109, towards $A \beta 1-40$ fibrils is weaker than towards $A \beta 1-42$ fibrils, which is consistent with the low fluorescence intensity enhancement upon bound to $A \beta 1-40$ fibrils. Therefore we 


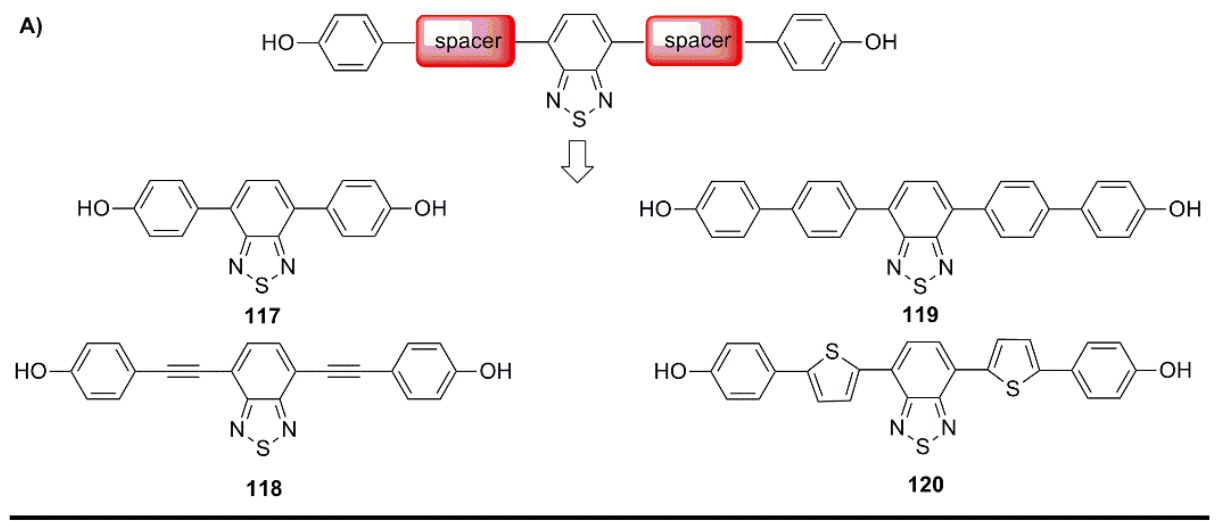

B)

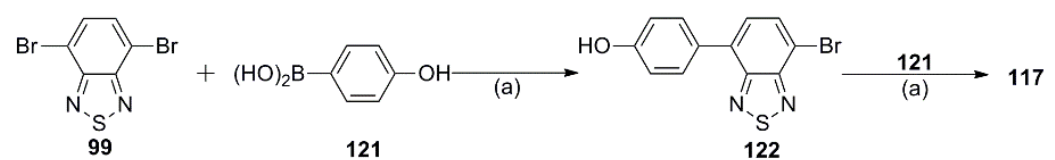

121
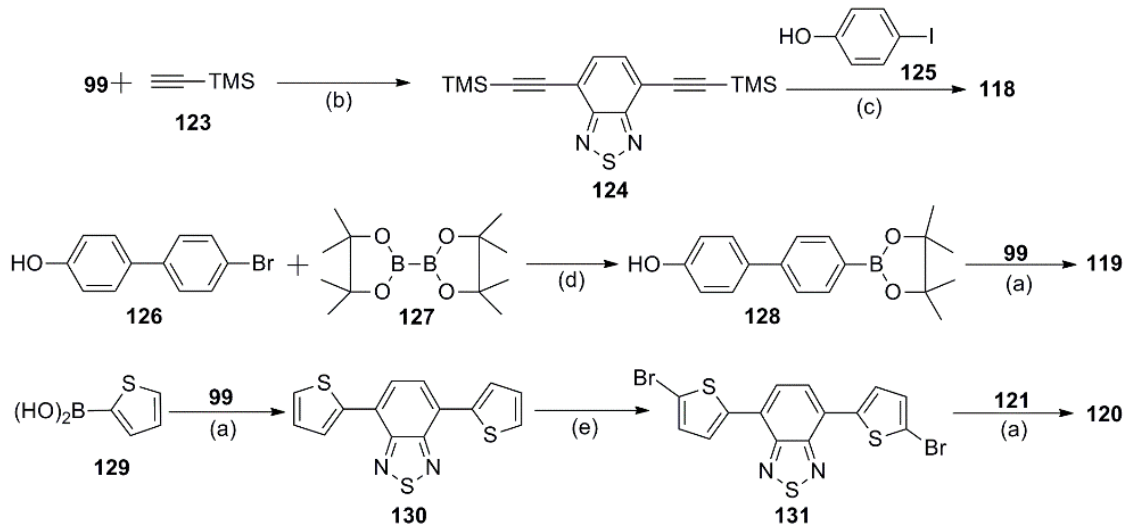

Scheme 4.4 Synthesis of BTDs with different spacers. Conditions and reagents: (a) $\mathrm{Pd}\left(\mathrm{PPh}_{3}\right)_{4}, 2 \mathrm{M} \mathrm{Na} \mathrm{CO}_{3}$, benzene-EtOH, $90{ }^{\circ} \mathrm{C}$; (b) $\mathrm{Pd}\left(\mathrm{PPh}_{3}\right)_{4}$, CuI, triethylamine, $75^{\circ} \mathrm{C}$; (c) 1) $\mathrm{KOH}$ in $\mathrm{MeOH}$, rt; 2) $\mathrm{Pd}(\mathrm{OAc})_{2}, \mathrm{PPh}_{3}, \mathrm{CuI}$, triethylamine, THF, rt; (d) $\mathrm{PdCl}_{2}$ (dppf), dppf, KOAc, 1,4-dioxane, $90{ }^{\circ} \mathrm{C}$; (e) $\mathrm{NBS}, \mathrm{CHCl}_{3}$, rt.

will focus on the binding affinity of these probes to A $\beta 1-42$ fibrils. The symmetrical 117 had the weakest binding affinity all the ligands, 26-fold weaker than that of $\mathbf{1 0 9}$ and 3-fold less than that of DF-9. This could be attributed to the shorter distance between phenol functional groups, reducing the effectiveness of 4 to form strong H-bonds with the A $\beta 1-42$ fibril binding pockets. ${ }^{174}$ Compared to $\mathbf{1 0 9}$, the more rigid linear alkyne analogous 118 had a 2-fold lower $A \beta 1-42$ fibril binding affinity, possibly 
due to an inability to attain a con-former orientation complementary to the binding pockets of the fibril. The order of the binding affinity of 109, 118, 119 and 120 are consistent with the order of their emission maxima bound to $A \beta 1-42$ fibrils, demonstrating that the effective conjugation length will affect the binding affinity. ${ }^{175-176}$

Finally, we investigated the binding specificity of 109 to 120 and BTDSB as well as DF-9 (control) by an in vitro fluorescence-based assay using APP23 transgenic mouse brain sections aged 19.6 months, an AD mouse model with later onset of amyloid plaque pathology than APP/PS1.${ }^{177}$ Old APP23 mice show a pronounced intrinsic amyloid plaque structural polymorphism likely associated with that APP23 mice generate a rather high A $\beta 1-40 / A \beta 1-42$ ratio compared to that of APP/PS1 mice. ${ }^{177-178}$ We therefore selected this mouse model to assess the possibility of probing amyloid structural polymorphism by the ligands. As shown in Figure 4.10, fluorescence from the $\mathbf{1 0 9}$ bound to plaque core and coronal plaque can be easily discriminated by virtue of their spectra (Figure 4.10A and B), which can be used to monitor plaque maturation. What is the basis for this variation? Testing 109 in various solvents with decreasing dielectric constants reveals a linear dependence on the emission peak (Figure 4.9D). The slope was most pronounced for $\mathbf{1 0 9}$ and was less pronounced for $\mathbf{1 1 4}$ (data not shown) proposing that we actually probe variations in amyloid fibril binding site hydrophobicity by 109 and 114 .

In summary: These data extend the SAR of BTD-based $A \beta$ binding and provide further direction for the development of noninvasive $A \beta$ binding ligands for early detection of AD. The new bis-styrylbenzo-1,2,5-thiadiazole prototype could serve as a building block for the design and discovery of new early diagnosis for $\mathrm{AD}$ and potentially for $\mathrm{AD}$ therapeutics. 


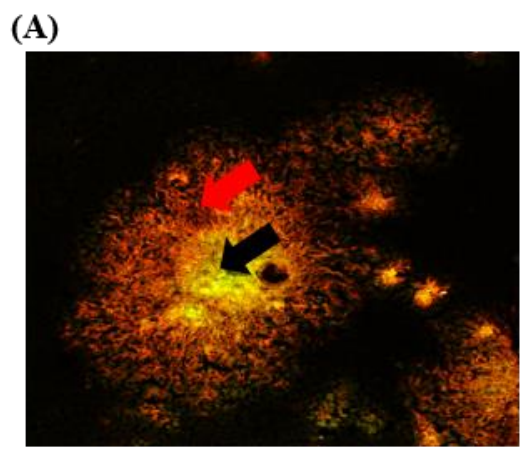

(B)

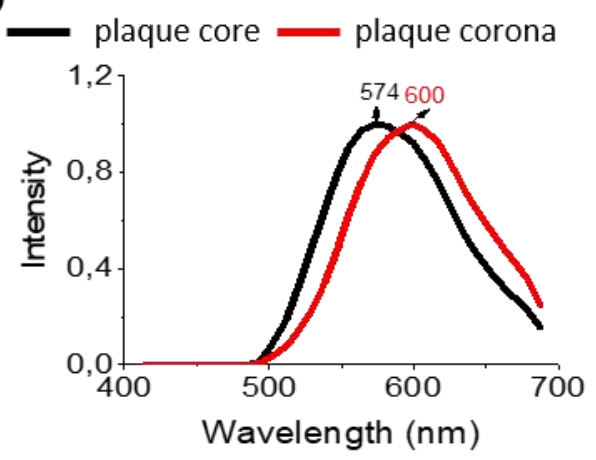

(C)

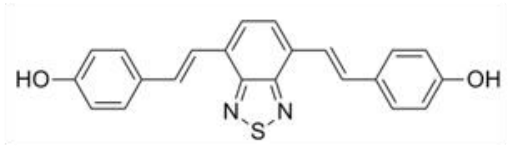

109

(D)

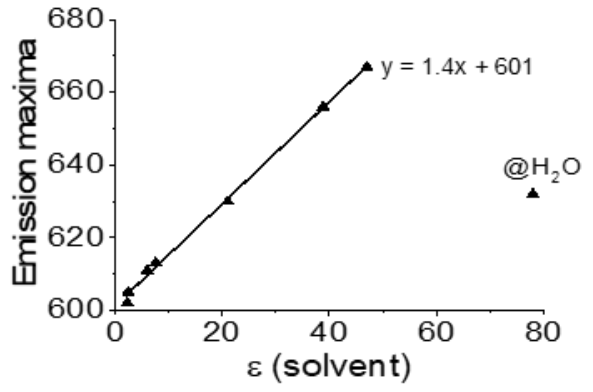

Figure 4.10 Confocal images of APP23 mouse (female, 19.5 months) brain sections (A) with accompanying normalized emission spectra of $109(500 \mathrm{nM})$ bound to $\mathrm{A} \beta$ plaque core (black arrow) and plaque corona (red arrow). Scale bars $=50$ $\mu \mathrm{m}$. C) Chemical structure of 109. D) Emission maxima dependent on polarity of 109 in different organic solvents (dioxane, toluene, EA, THF, acetone, DMF and DMSO) as well as in water. 


\section{Conclusions}

In the thesis, my work has focused on the synthesis and characterization of fluorescent stilbene-based probes targeting amyloid fibrils. Among the studies, the following conclusions can be drawn:

* In general, we have displayed a general synthetic route, whereby a functional group unit was replaced with other functional motifs. This strategy can be used for synthesizing a selection of ligands that can be utilized for fluorescence detection of protein aggregates.

* Results from all the papers strongly demonstrated that analogous compounds exhibit similar binding properties but specific fluorescence properties.

* Pyrene derivatives are important organic chromophores with long excited state lifetimes when bound to amyloid fibrils. Pyrene derivatives involving substitution at the 1-position or substitution at the 2-position have distinct geometric, electronic structures and amyloid-binding properties.

- The X-34 scaffold, while rather well studied, may continue to serve a role for design of high-affinity and near infrared fluorescent (NIRF) ligands targeting $A \beta$ and Tau pathology in human $A D$ brain. Especially these ligands target $A \beta$ pathology independently of the PiB binding site.

* Fluorescent small-molecule 2,1,3-benzothiadiazole (BTD) derivatives are a new class of bio-probes with attractive photophysical properties beyond the current classical scaffolds. This new class of bioprobes could be key player in the future of molecular probes, especially in the field of AD. 


\section{Future Perspectives}

In this thesis, many intriguing conclusions have been drawn, hopefully, leading us one step closer to understand the relationship between the design of molecular probe and amyloid-binding properties, especially, the binding with $\mathrm{A} \beta$ plaques and tau tangles in $\mathrm{AD}$. Therefore, there is still much interesting work to be done in the light of current findings.

Paper III shows four X-34 derivatives (NSB, TSB and QSB as well as $\mathrm{BTDSB}$ ) with in vitro specific amyloid staining property of $\mathrm{A} \beta$ plaque and NFTs in human AD brain tissue except for QSB, which selectively and specifically only stained A $\beta$ plaques. Especially, BTDSB displays emission in the red region $(620 \mathrm{~nm})$ with large Stokes shift $(133 \mathrm{~nm})$ and also high binding affinity $\left(\mathrm{K}_{\mathrm{d}}: 93 \pm 5 \mathrm{~nm}\right)$. Whether these ligands could stain $\mathrm{A} \beta$ plaques and NFTs in vivo using mouse or fly models of $\mathrm{AD}$ would be interesting.

Further analysis of the molecule in paper IV would be of interest. Probe 109 has specific staining properties in APP23 mouse brain sections (female, 19.5 months) and probe $\mathbf{1 2 0}$ has the strongest binding affinity among the probes as well as exhibits more than $650 \mathrm{~nm}$ emission maximum (in the NIR window from $650-900 \mathrm{~nm}$ ) when bound to A $\beta$ fibrils. But both probes have low solubility in water, especially 120. We can modify their structures by linking a sugar or triethylene glycol (TEG) to the oxygen of the para-OH phenyl to increase their solubility. It would be interesting to investigate their two-photo emission and staining properties in vitro or in vivo. Relevant work is ongoing. 


\section{References}

(1) Johansson Seechurn, C. C. C.; Kitching, M. O.; Colacot, T. J. ; Snieckus, V. Palladiumcatalyzed cross-coupling: A historical contextual perspective to the 2010 Nobel prize. Angew. Chem. Int. Edit. 2012, 51, 5062-5085.

(2) Heck, R. F. ; Nolley, J. P. Palladium-catalyzed vinylic hydrogen substitution reactions with aryl, benzyl, and styryl halides. J. Org. Chem. 1972, 37, 2320-2322.

(3) Mc Cartney, D. ; Guiry, P. J. The asymmetric Heck and related reactions. Chem. Soc. Rev. 2011, 40, 5122-5150.

(4) Jagtap, S. Heck reaction - state of the art. 2017, 7, 267-320.

(5) Cabri, W. ; Candiani, I. Recent developments and new perspectives in the Heck reaction. Acc. Chem. Res. 1995, 28, 2-7.

(6) Sonogashira, K. Development of $\mathrm{Pd}-\mathrm{Cu}$ catalyzed cross-coupling of terminal acetylenes with sp2-carbon halides. Journal of Organometallic Chemistry 2002, 653, 46-49.

(7) Chinchilla, R. ; Najera, C. The Sonogashira reaction: a booming methodology in synthetic organic chemistry. Chem. Rev. 2007, 107, 874-922.

(8) Miyaura, N. ; Suzuki, A. Palladium-catalyzed cross-coupling reactions of organoboron compounds. Chem. Rev. 1995, 95, 2457-2483.

(9) Han, F. S. Transition-metal-catalyzed Suzuki-Miyaura cross-coupling reactions: a remarkable advance from palladium to nickel catalysts. Chem. Soc. Rev. 2013, 42, 5270-5298.

(10) Amatore, C.; Jutand, A. ; Le Duc, G. Kinetic data for the transmetalation/reductive elimination in palladium-catalyzed Suzuki-Miyaura reactions: unexpected triple role of hydroxide ions used as base. Chem. Eur. J. 2011, 17, 2492-2503.

(11) Weller, A. Über die fluoreszenz der salizylsäure und verwandter verbindungen. Sci. Nat. 1955, 42, 175-176.

(12) Beens, H.; Grellmann, K. H.; Gurr, M. ; Weller, A. H. Effect of solvent and temperature on proton transfer reactions of excited molecules. Faraday Discuss. 1965, 39, 183-193.

(13) Mishra, H.; Joshi, H. C.; Tripathi, H. B.; Maheshwary, S.; Sathyamurthy, N.; Panda, M. ; Chandrasekhar, J. Photoinduced proton transfer in 3-hydroxy-2-naphthoic acid. J. Photochem. Photobiol. A 2001, 139, 23-36.

(14) Lahmani, F. ; Zehnacker-Rentien, A. Effect of Substitution on the photoinduced intramolecular proton transfer in salicylic acid. J. Phys. Chem. A 1997, 101, 6141-6147.

(15) Paul, B. K.; Samanta, A. ; Guchhait, N. Deciphering the photophysics of 5-chlorosalicylic acid: evidence for excited-state intramolecular proton transfer. Photochem. Photobiol. Sci. 2010, 9, 57-67.

(16) Lavis, L. D. ; Raines, R. T. Bright building blocks for chemical biology. ACS Chem. Biol. 2014, 9, 855-866.

(17) Neto, B. A. D.; Carvalho, P. H. P. R. ; Correa, J. R. Benzothiadiazole derivatives as fluorescence imaging probes: beyond classical scaffolds. Acc. Chem. Res. 2015, 48, 1560-1569.

(18) Dyrager, C.; Vieira, R. P.; Nystrom, S.; Nilsson, K. P. R. ; Storr, T. Synthesis and evaluation of benzothiazole-triazole and benzothiadiazole-triazole scaffolds as potential molecular probes for amyloid- $\beta$ aggregation. New J. Chem. 2017, 41, 1566-1573.

(19) Shirani, H.; Linares, M.; Sigurdson, C. J.; Lindgren, M.; Norman, P.; Nilsson, K. P. R. A Palette of fluorescent thiophene-based ligands for the identification of protein aggregates. Chem. Eur. J. 2015, 21, 15133-15137.

(20) Sipe, J. D.; Benson, M. D.; Buxbaum, J. N.; Ikeda, S. I.; Merlini, G.; Saraiva, M. J. ; Westermark, P. Amyloid fibril proteins and amyloidosis: chemical identification and clinical 
classification International Society of Amyloidosis 2016 Nomenclature Guidelines. Amyloid 2016, 23, 209-213.

(21) Kyle, R. A. Amyloidosis: a convoluted story. Br. J. Haematol. 2001, 114, 529-538.

(22) Sipe, J. D.; Benson, M. D.; Buxbaum, J. N.; Ikeda, S.;Merlini, G.; Saraiva, M. J. ; Westermark, P. Amyloid fibril protein nomenclature: 2012 recommendations from the Nomenclature Committee of the International Society of Amyloidosis. Amyloid 2012, 19, 167170 .

(23) Sipe, J. D.; Cohen, A. S. Review: history of the amyloid fibril. J. Struct. Biol. 2000, 130, $88-98$.

(24) Lin, C. Y.; Gurlo, T.; Kayed, R.; Butler, A. E.; Haataja, L.; Glabe, C. G. ; Butler, P. C. Toxic human islet amyloid polypeptide (h-IAPP) oligomers are intracellular and vaccination to induce anti-toxic oligomer antibodies does not prevent h-IAPP-induced beta-cell apoptosis in hIAPP transgenic mice. Diabetes 2007, 56, 1324-1332.

(25) Nilsson, M. R. Techniques to study amyloid fibril formation in vitro. Methods 2004, 34, 151-160.

(26) Fandrich, M. On the structural definition of amyloid fibrils and other polypeptide aggregates. Cell. Mol. Life Sci. 2007, 64, 2066-2078.

(27) Makin, O. S.; Sikorski, P.; Serpell, L. C. Diffraction to study protein and peptide assemblies. Curr. Opin. Chem. Biol. 2006, 10, 417-422.

(28) Eanes, E. D. ; Glenner, G. G. X-ray diffraction studies on amyloid filaments. J. Histochem. Cytochem. 1968, 16, 673-677.

(29) Sunde, M.; Blake, C. The Structure of Amyloid Fibrils by Electron Microscopy and X-Ray Diffraction. Academic Press, 1997, 50, 123-159.

(30) Tycko, R. Insights into the amyloid folding problem from solid-state NMR. Biochemistry 2003, 42, 3151-3159.

(31) Jayasinghe, S. A. ;Langen, R. Identifying structural features of fibrillar islet amyloid polypeptide using site-directed spin labeling. J. Biol. Chem. 2004, 279, 48420-48425.

(32) Torok, M.; Milton, S.; Kayed, R.;Wu, P.; McIntire, T.; Glabe, C. G. ; Langen, R. Structural and dynamic features of Alzheimer's Abeta peptide in amyloid fibrils studied by site-directed spin labeling. J. Biol. Chem. 2002, 277, 40810-40815.

(33) Cohen, A. S.; Calkins, E. Electron microscopic observations on a fibrous component in amyloid of diverse origins. Nature 1959, 183, 1202-1203.

(34) Serpell, L. C.; Sunde, M.; Benson, M. D.; Tennent, G. A.; Pepys, M. B. ; Fraser, P. E. The protofilament substructure of amyloid fibrils. J. Mol. Biol. 2000, 300, 1033-1039.

(35) Shirahama, T.; Cohen, A. S. High-resolution electron microscopic analysis of the amyloid fibril. J. Cell. Biol. 1967, 33, 679-708.

(36) Goldsbury, C.; Kistler, J.; Aebi, U.; Arvinte, T.; Cooper, G. J. Watching amyloid fibrils grow by time-lapse atomic force microscopy. J. Mol. Biol. 1999, 285, 33-39.

(37) Jimenez, J. L.; Nettleton, E. J.; Bouchard, M.; Robinson, C. V.; Dobson, C. M.; Saibil, H. R. The protofilament structure of insulin amyloid fibrils. Proc. Natl. Acad. Sci. U. S. A. 2002, 99, 9196-9201.

(38) Jimenez, J. L.; Tennent, G.; Pepys, M. ; Saibil, H. R. Structural diversity of ex vivo amyloid fibrils studied by cryo-electron microscopy. J. Mol. Biol. 2001, 311, 241-247.

(39) Sachse, C.; Xu, C.; Wieligmann, K.; Diekmann, S.; Grigorieff, N. ; Fandrich, M. Quaternary structure of a mature amyloid fibril from Alzheimer's Abeta(1-40) peptide. J. Mol. Biol. 2006, 362, 347-354. 
(40) Sunde, M.; Serpell, L. C.; Bartlam, M.; Fraser, P. E.; Pepys, M. B.; Blake, C. C. Common core structure of amyloid fibrils by synchrotron X-ray diffraction. J. Mol. Biol. 1997, 273, 729739.

(41) Serpell, L. C.; Sunde, M.; Blake, C. C. The molecular basis of amyloidosis. Cell. Mol. Life Sci. 1997, 53, 871-887.

(42) Makin, O. S.; Atkins, E.; Sikorski, P.; Johansson, J.; Serpell, L. C. Molecular basis for amyloid fibril formation and stability. Proc. Natl. Acad. Sci. U. S. A. 2005, 102, 315-320.

(43) Tycko, R. Progress towards a molecular-level structural understanding of amyloid fibrils. Curr. Opin. Struct. Biol. 2004, 14, 96-103.

(44) Gordon, D. J.; Balbach, J. J.; Tycko, R. ; Meredith, S. C. Increasing the amphiphilicity of an amyloidogenic peptide changes the beta-sheet structure in the fibrils from antiparallel to parallel. Biophys. J. 2004, 86, 428-434.

(45) Balbach, J. J.; Petkova, A. T.; Oyler, N. A.; Antzutkin, O. N.; Gordon, D. J.; Meredith, S. C. ; Tycko, R. Supramolecular structure in full-length Alzheimer's beta-amyloid fibrils: evidence for a parallel beta-sheet organization from solid-state nuclear magnetic resonance. Biophys. $J$. 2002, 83, 1205-1216.

(46) Petkova, A. T.; Buntkowsky, G.; Dyda, F.; Leapman, R. D.; Yau, W. M. ; Tycko, R. Solid state NMR reveals a $\mathrm{pH}$-dependent antiparallel beta-sheet registry in fibrils formed by a betaamyloid peptide. J. Mol. Biol. 2004, 335, 247-260.

(47) Petkova, A. T.; Ishii, Y.; Balbach, J. J.; Antzutkin, O. N.; Leapman, R. D.; Delaglio, F.; Tycko, R. A structural model for Alzheimer's beta -amyloid fibrils based on experimental constraints from solid state NMR. Proc. Natl. Acad. Sci. U. S. A. 2002, 99, 16742-16747.

(48) Luhrs, T.; Ritter, C.; Adrian, M.; Riek-Loher, D.; Bohrmann, B.; Dobeli, H.; Schubert, D.; Riek, R. 3D structure of Alzheimer's amyloid-beta(1-42) fibrils. Proc. Natl. Acad. Sci. U. S. A. 2005, 102, 17342-17347.

(49) Tycko, R. Amyloid Polymorphism: Structural Basis and Neurobiological Relevance. Neuron 2015, 86, 632-645.

(50) Fändrich, M.; Nyström, S.; Nilsson, K. P. R.; Böckmann, A.; LeVine, H. ; Hammarström, P. Amyloid fibril polymorphism: a challenge for molecular imaging and therapy. J. Int. Med. 2018, 283, 218-237.

(51) Gremer, L.; Scholzel, D.; Schenk, C.; Reinartz, E.; Labahn, J.; Ravelli, R. B. G.; Tusche, M.; Lopez-Iglesias, C.; Hoyer, W.; Heise, H.; Willbold, D. ; Schroder, G. F. Fibril structure of amyloid-beta(1-42) by cryo-electron microscopy. Science 2017, 358, 116-119.

(52) Stefani, M.; Dobson, C. M. Protein aggregation and aggregate toxicity: new insights into protein folding, misfolding diseases and biological evolution. J. Mol. Med. 2003, 81, 678-699.

(53) Cara, C. J.; Skropeta, D. Glycosylation and functionalization of native amino acids with azido uronic acids. Tetrahedron 2015, 71, 9357-9365.

(54) Wolynes, P.; Onuchic, J.; Thirumalai, D. Navigating the folding routes. Science 1995, 267, 1619-1620.

(55) Knowles, T. P.; Vendruscolo, M.; Dobson, C. M. The amyloid state and its association with protein misfolding diseases. Nat. Rev. Mol. Cell Biol. 2014, 15, 384-396.

(56) Harper, J. D.; Lansbury, P. T. Models of amyloid seeding in Alzheimer's disease and scrapie: mechanistic truths and physiological consequences of the time-dependent solubility of amyloid proteins. Annu. Rev. Biochem. 1997, 66, 385-407.

(57) Invernizzi, G.; Papaleo, E.; Sabate, R. ; Ventura, S. Protein aggregation: mechanisms and functional consequences. Int. J. Biochem. Cell Biol. 2012, 44, 1541-1554.

(58) Jarrett, J. T.; Lansbury, P. T. Seeding "one-dimensional crystallization" of amyloid: a pathogenic mechanism in Alzheimer's disease and scrapie? Cell 1993, 73, 1055-1058. 
(59) Bhak, G.; Choe, Y. J.; Paik, S. R. Mechanism of amyloidogenesis: nucleation-dependent fibrillation versus double-concerted fibrillation. BMB Rep. 2009, 42, 541-551.

(60) Baxa, U. Structural basis of infectious and non-infectious amyloids. Curr. Alzheimer Res. 2008, 5, 308-318.

(61) Strassnig, M.; Ganguli, M. About a peculiar disease of the cerebral cortex: Alzheimer's original case revisited. Psychiatry 2005, 2, 30-33.

(62) Holtzman, D. M.; Morris, J. C.; Goate, A. M. Alzheimer's disease: the challenge of the second century. Sci. Transl. Med. 2011, 3, 77-112.

(63) Querfurth, H. W.; LaFerla, F. M. Alzheimer's Disease. N. Engl. J. Med. 2010, 362, 329344.

(64) Prince, M.; Herrera, A. C.; Knapp, M.; Guerchet, M.; Karagiannidou, M. Improving healthcare for people living with dementia: coverage, quality and costs now and in the future. world alzheimer report 2016.

(65) Mendez, M. F. Early-onset Alzheimer's disease: nonamnestic subtypes and type 2 AD. Arch. Med. Res. 2012, 43, 677-685.

(66) Bonin-Guillaume, S.; Zekry, D.; Giacobini, E.; Gold, G.; Michel, J. P. The economical impact of dementia. Presse Med. 2005, 34, 35-41.

(67) Reitz, C.; Mayeux, R. Alzheimer disease: epidemiology, diagnostic criteria, risk factors and biomarkers. Biochem. Pharmacol. 2014, 88, 640-651.

(68) Hardy, J.; Allsop, D. Amyloid deposition as the central event in the aetiology of Alzheimer's disease. Trends Pharmacol. Sci. 1991, 12, 383-388.

(69) Mudher, A.; Lovestone, S. Alzheimer's disease-do tauists and baptists finally shake hands? Trends Neurosci. 2002, 25, 22-26.

(70) Goedert, M.; Spillantini, M. G.; Crowther, R. A. Tau proteins and neurofibrillary degeneration. Brain Pathol. 1991, 1, 279-286.

(71) Francis, P. T.; Palmer, A. M.; Snape, M.; Wilcock, G. K. The cholinergic hypothesis of Alzheimer's disease: a review of progress. J. Neurol. Neurosurg. Psychiatry 1999, 66, 137-147.

(72) Martorana, A.; Esposito, Z.; Koch, G. Beyond the cholinergic hypothesis: do current drugs work in Alzheimer's disease? CNS Neurosci. Ther. 2010, 16, 235-245.

(73) Deane, R.; Zlokovic, B. V. Role of the blood-brain barrier in the pathogenesis of Alzheimer's disease. Curr. Alzheimer Res. 2007, 4, 191-197.

(74) Su, B.; Wang, X.; Nunomura, A.; Moreira, P. I.; Lee, H. G.; Perry, G.; Smith, M. A.; Zhu, X. Oxidative stress signaling in Alzheimer's disease. Curr. Alzheimer Res. 2008, 5, 525-532.

(75) Moulton, P. V.; Yang, W. Air pollution, oxidative stress, and Alzheimer's disease. $J$. Environ. Public Health 2012, 2012, 472751.

(76) Weggen, S.; Beher, D. Molecular consequences of amyloid precursor protein and presenilin mutations causing autosomal-dominant Alzheimer's disease. Alzheimers Res. Ther. 2012, 4, 9.

(77) Kumar-Singh, S.; Theuns, J.; Van Broeck, B.; Pirici, D.; Vennekens, K.; Corsmit, E.; Cruts, M.; Dermaut, B.; Wang, R.; Van Broeckhoven, C. Mean age-of-onset of familial alzheimer disease caused by presenilin mutations correlates with both increased $\mathrm{A} \beta 42$ and decreased $\mathrm{A} \beta 40$. Hum. Mutat. 2006, 27, 686-695.

(78) Villemagne, V. L.; Pike, K. E.; Chetelat, G.; Ellis, K. A.; Mulligan, R. S.; Bourgeat, P.; Ackermann, U.; Jones, G.; Szoeke, C.; Salvado, O.; Martins, R.; O'Keefe, G.; Mathis, C. A.; Klunk, W. E.; Ames, D.; Masters, C. L.; Rowe, C. C. Longitudinal assessment of A $\beta$ and cognition in aging and Alzheimer disease. Ann. Neurol. 2011, 69, 181-192.

(79) Nhan, H. S.; Chiang, K.; Koo, E. H. The multifaceted nature of amyloid precursor protein and its proteolytic fragments: friends and foes. Acta. Neuropathol. 2015, 129, 1-19. 
(80) Lemere, C. A.; Masliah, E. Can Alzheimer disease be prevented by amyloid- $\beta$ immunotherapy? Nat. Rev. Neurol. 2010, 6, 108-119.

(81) Herrup, K. The case for rejecting the amyloid cascade hypothesis. Nat. Neurosci. 2015, 18 , 794-799.

(82) Kim, J.; Chakrabarty, P.; Hanna, A.; March, A.; Dickson, D. W.; Borchelt, D. R.; Golde, T.; Janus, C. Normal cognition in transgenic BRI2-Abeta mice. Mol. Neurodegener. 2013, 8, 15.

(83) Lee, V. M.; Goedert, M.; Trojanowski, J. Q. Neurodegenerative tauopathies. Annu. Rev. Neurosci. 2001, 24, 1121-1159.

(84) Verwilst, P.; Kim, H. S.; Kim, S.; Kang, C.; Kim, J. S. Shedding light on tau protein aggregation: the progress in developing highly selective fluorophores. Chem. Soc. Rev. 2018, 47, 2249-2265.

(85) Iqbal, K.; Alonso Adel, C.; Chen, S.; Chohan, M. O.; El-Akkad, E.; Gong, C. X.; Khatoon, S.; Li, B.; Liu, F.; Rahman, A.; Tanimukai, H.; Grundke-Iqbal, I. Tau pathology in Alzheimer disease and other tauopathies. Biochim. Biophys. Acta. 2005, 1739, 198-210.

(86) Chun, W.; Johnson, G. V. The role of tau phosphorylation and cleavage in neuronal cell death. Front Biosci. 2007, 12, 733-756.

(87) Cui, M. Past and recent progress of molecular imaging probes for beta-amyloid plaques in the brain. Curr. Med. Chem. 2014, 21, 82-112.

(88) Amatsubo, T.; Yanagisawa, D.; Morikawa, S.; Taguchi, H.; Tooyama, I. Amyloid imaging using high-field magnetic resonance. Magn. Reson. Med. Sci. 2010, 9, 95-99.

(89) Watanabe, H.; Ono, M.; Saji, H. Novel PET/SPECT probes for imaging of tau in Alzheimer's disease. Sci. World J. 2015, 2015, 124192.

(90) Zhou, M.; Wang, X.; Liu, Z.; Yu, L.;Hu, S.; Chen, L. ;Zeng, W. Advances of molecular imaging probes for the diagnosis of Alzheimer's disease. Curr. Alzheimer Res. 2014, 11, 221-231.

(91) Chang, W. M.; Dakanali, M.; Capule, C. C.; Sigurdson, C. J.; Yang, J. ; Theodorakis, E. A. ANCA: a family of fluorescent probes that bind and stain amyloid plaques in human tissue. ACS Chem. Neurosci. 2011, 2, 249-255.

(92) Weissleder, R.; Ntziachristos, V. Shedding light onto live molecular targets. Nat. Med. 2003, 9, 123-128.

(93) Nesterov, E. E.; Skoch, J.; Hyman, B. T.; Klunk, W. E.; Bacskai, B. J. ; Swager, T. M. In vivo optical imaging of amyloid aggregates in brain: design of fluorescent markers. Ang. Chem. Int. Ed. 2005, 44, 5452-5456.

(94) Ran, C.; Xu, X.; Raymond, S. B.; Ferrara, B. J.; Neal, K.; Bacskai, B. J.; Medarova, Z.; Moore, A. Design, synthesis, and testing of difluoroboron-derivatized curcumins as near-infrared probes for in vivo detection of amyloid-beta deposits. J. Am. Chem. Soc. 2009, 131, 15257-15261.

(95) Ametamey, S. M.; Honer, M.; Schubiger, P. A. Molecular imaging with PET. Chem. Rev. 2008, 108, 1501-1516.

(96) Westermark, G. T.; J ohnson, K. H.; Westermark, P. Staining methods for identification of amyloid in tissue. Methods Enzymol. 1999, 309, 3-25.

(97) Klunk, W. E.; Debnath, M. L.; Pettegrew, J. W. Development of small molecule probes for the $\beta$-amyloid protein of Alzheimer's disease. Neurobiol.Aging 1994, 15, 691-698.

(98) Klunk, W. E.; Debnath, M. L.; Pettegrew, J. W. Chrysamine-G binding to Alzheimer and control brain: Autopsy study of a new amyloid probe. Neurobiol. Aging 1995, 16, 541-548.

(99) Scot D. S; Hamilton, R. L.; Styren, G. C.; Klunk, W. E. X-34, a fluorescent derivative of Congo red: A novel histochemical stain for Alzheimer's disease pathology. J. Histochem. Cytochem. 2000, 48, 1223-1232. 
(100) Sato, K.; Higuchi, M.; Iwata, N.; Saido, T. C.; Sasamoto, K. Fluoro-substituted and ${ }^{13}$ Clabeled styrylbenzene derivatives for detecting brain amyloid plaques. Eur. J. Med. Chem. 2004, 39, 573-578.

(101) Skovronsky, D. M.; Zhang, B.; Kung, M. P.; Kung, H. F.; Trojanowski, J. Q.; Lee, V. M. Y. In vivo detection of amyloid plaques in a mouse model of Alzheimer's disease. Proc. Natl. Acad. Sci. U.S.A. 2000, 97, 7609-7614.

(102) Schmidt, M. L.; Schuck, T.; Sheridan, S.; Kung, M. P.; Kung, H.; Zhuang, Z. P.; Bergeron, C.; Lamarche, J. S.; Skovronsky, D.; Giasson, B. I.; Lee, V. M. Y.; Trojanowski, J. Q. The fluorescent Congo red derivative, (trans, trans)-1-bromo-2,5-Bis-(3-hydroxycarbonyl-4hydroxy)styrylbenzene (BSB), labels diverse $\beta$-pleated sheet structures in postmortem human neurodegenerative disease brains. Am. J. Pathol. 2001, 159, 937-943.

(103) Kung, M. P.; Hou, C.; Zhuang, Z. P.; Skovronsky, D. M.; Zhang, B.; Gur, T. L.; Trojanowski, J. Q.; Lee, V. M.; Kung, H. F. Radioiodinated styrylbenzene derivatives as potential SPECT imaging agents for amyloid plaque detection in Alzheimer's disease. J. Mol. Neurosci. 2002, 19, 7-10.

(104) Klunk, W. E.; Bacskai, B. J.; Mathis, C. A.; Kajdasz, S. T.; McLellan, M. E.; Frosch, M. P.; Debnath, M. L.; Holt, D. P.; Wang, Y.; Hyman, B. T. Imaging Abeta plaques in living transgenic mice with multiphoton microscopy and methoxy-X04, a systemically administered Congo red derivative. J. Neuropathol. Exp. Neurol. 2002, 61, 797-805.

(105) Mathis, C. A.; Holt, D. P.; Wang, Y.; Huang, G. F.; Debnath, M. L. ; Klunk, W. E. Lipophilic ${ }^{11} \mathrm{C}$-labelled thioflavin- $\mathrm{T}$ analogues for imaging amyloid plaques in alzheimer's disease. J. Label. Compd. Radiopharm. 2001, 44, 26-S28.

(106) Gan, C.; Zhou, L.; Zhao, Z.; Wang, H. Benzothiazole Schiff-bases as potential imaging agents for $\beta$-amyloid plaques in Alzheimer's disease. Med. Chem. Res. 2012, 22, 4069-4074.

(107) Jae Jung, S.; Park, Y.; Park, J.; Yang, S.; Hur, M. G.; Hyun Yu, K. Synthesis and evaluation of thioflavin-T analogs as potential imaging agents for amyloid plaques. Med. Chem.Res. 2013, 22, 4263-4268.p.

(108) Kung, M. P.; Hou, C.; Zhuang, Z. P.; Zhang, B.; Skovronsky, D.; Trojanowski, J. Q.; Lee, V. M.; Kung, H. F. IMPY: an improved thioflavin-T derivative for in vivo labeling of betaamyloid plaques. Brain Res. 2002, 956, 202-210.

(109) Ono, M.; Hayashi, S.; Kimura, H.; Kawashima, H.; Nakayama, M.; Saji, H. Push-pull benzothiazole derivatives as probes for detecting beta-amyloid plaques in Alzheimer's brains. Bioorg. Med. Chem. 2009, 17, 7002-7007.

(110) Hamaguchi, T.; Ono, K.;Y amada, M. REVIEW: Curcumin and Alzheimer's disease. CNS Neurosci. Ther. 2010, 16, 285-297.

(111) Yang, S.W.; Elangovan, A.; Hwang, K. C.; Ho, T. I. Electronic polarization reversal and excited state intramolecular charge transfer in donor/acceptor ethynylpyrenes. J. Phys. Chem. B 2005, 109, 16628-16635.

(112) Zhang, X.; Tian, Y.; Li, Z.; Tian, X.; Sun, H.; Liu, H.; Moore, A.; Ran, C. Design and synthesis of curcumin analogues for in vivo fluorescence imaging and inhibiting copper-induced cross-linking of amyloid beta species in Alzheimer's disease. J. Am. Chem. Soc. 2013, 135, 16397-16409.

(113) Ran, C.; Zhao, W.; Moir, R. D.; Moore, A. Non-conjugated small molecule FRET for differentiating monomers from higher molecular weight amyloid beta species. PLOS ONE 2011, 6, 19362.

(114) Ran, C.; Moore, A. Spectral unmixing imaging of wavelength-responsive fluorescent probes: an application for the real-time report of amyloid Beta species in Alzheimer's disease. Mol. Imaging Biol. 2012, 14, 293-300. 
(115) Zhang, X.; Tian, Y.; Li, Z.; Tian, X.; Sun, H.; Liu, H.; Moore, A.; Ran, C. Design and synthesis of curcumin analogues for in vivo fluorescence imaging and inhibiting copper-induced cross-linking of amyloid beta species in Alzheimer's disease. J. Am. Chem. Soc. 2013, 135, 16397 16409.

(116) Ulrich, G.; Ziessel, R.; Harriman, A. The chemistry of fluorescent bodipy dyes: versatility unsurpassed. Angew. Chem. Int. Ed. 2008, 47, 1184-1201.

(117) Boens, N.; Leen, V.; Dehaen, W. Fluorescent indicators based on BODIPY. Chem. Soc. Rev. 2012, 41, 1130-1172.

(118) Ono, M.; Ishikawa, M.; Kimura, H.; Hayashi, S.; Matsumura, K.; Watanabe, H.; Shimizu, Y.; Cheng, Y.; Cui, M.; Kawashima, H.; Saji, H. Development of dual functional SPECT/fluorescent probes for imaging cerebral $\beta$-amyloid plaques. Bioorg. Med. Chem. Lett. 2010, 20, 3885-3888.

(119) Ono, M.; Watanabe, H.; Kimura, H.; Saji, H. BODIPY-based molecular probe for imaging of cerebral $\beta$-Amyloid plaques. ACS Chem. Neurosci. 2012, 3, 319-324.

(120) Watanabe, H.; Ono, M.; Matsumura, K.; Yoshimura, M.; Kimura, H. ; Saji, H. Molecular imaging of beta-amyloid plaques with near-infrared boron dipyrromethane (BODIPY)-based fluorescent probes. Mol. Imaging 2013, 12, 338-347.

(121) Sozmen, F.; Kolemen, S.; Kumada, H. O.; Ono, M.; Saji, H.; Akkaya, E. U. Designing BODIPY-based probes for fluorescence imaging of $\beta$-amyloid plaques. RSC Adv. 2014, 4, 5103251037.

(122) Cui, M.; Ono, M.; Watanabe, H.; Kimura, H.; Liu, B.; Saji, H. Smart Near-infrared fluorescence probes with donor-acceptor structure for in vivo detection of $\beta$-amyloid deposits. $J$. Am. Chem. Soc. 2014, 136, 3388-3394.

(123) Fu, H.; Cui, M.; Tu, P.; Pan, Z.; Liu, B. Evaluation of molecules based on the electron donor-acceptor architecture as near-infrared $\beta$-amyloidal-targeting probes. Chem. Commun. 2014, 50, 11875-11878.

(124) Nesterov, E. E.; Skoch, J.; Hyman, B. T.; Klunk, W. E.; Bacskai, B. J. ; Swager, T. M. In vivo optical imaging of amyloid aggregates in brain: design of fluorescent markers. Angew. Chem. Int. Ed. 2005, 44, 5452-5456.

(125) Raymond, S. B.; Skoch, J.; Hills, I. D.; Nesterov, E. E.; Swager, T. M. ; Bacskai, B. J. Smart optical probes for near-infrared fluorescence imaging of Alzheimer's disease pathology. Eur. J. Nucl. Med. Mol. Imaging 2008, 35, S93-98.

(126) Meek, S. T.; Nesterov, E. E.; Swager, T. M. Near-Infrared fluorophores containing benzo[c] heterocycle subunits. Org. Lett. 2008, 10, 2991-2993.

(127) Åslund, A.; Sigurdson, C. J.; Klingstedt, T.; Grathwohl, S.; Bolmont, T.; Dickstein, D. L.; Glimsdal, E.; Prokop, S.; Lindgren, M.; Konradsson, P.; Holtzman, D. M.; Hof, P. R.; Heppner, F. L.; Gandy, S.; Jucker, M.; Aguzzi, A.; Hammarström, P.; Nilsson, K. P. R. Novel pentameric thiophene derivatives for in vitro and in vivo optical imaging of a plethora of protein aggregates in cerebral amyloidoses. ACS Chem. Biol. 2009, 4, 673-684.

(128) Simon, R. A.; Shirani, H.; Aslund, K. O.; Back, M.; Haroutunian, V.; Gandy, S.; Nilsson, K. P. Pentameric thiophene-based ligands that spectrally discriminate amyloid-beta and tau aggregates display distinct solvatochromism and viscosity-induced spectral shifts. Chem. Eur. J. 2014, 20, 12537-12543.

(129) Hintersteiner, M.; Enz, A.; Frey, P.; Jaton, A. L.; Kinzy, W.; Kneuer, R.; Neumann, U.; Rudin, M.; Staufenbiel, M.; Stoeckli, M.; Wiederhold, K. H. ; Gremlich, H. U. In vivo detection of amyloid-beta deposits by near-infrared imaging using an oxazine-derivative probe. Nat. Biotechnol. 2005, 23, 577-583. 
(130) Li, Q.; Min, J.; Ahn, Y. H.; Namm, J.; Kim, E. M.; Lui, R.; Kim, H. Y.; Ji, Y.; Wu, H.; Wisniewski, T.; Chang, Y. T. Styryl-based compounds as potential in vivo imaging agents for beta-amyloid plaques. Chembiochem 2007, 8, 1679-1687.

(131) Braak, H.; Braak, E. Neuropathological stageing of Alzheimer-related changes. Acta. Neuropathologica. 1991, 82, 239-259.

(132) Villemagne, V. L.; Fodero-Tavoletti, M. T.; Masters, C. L.; Rowe, C. C. Tau imaging: early progress and future directions. Lancet. Neurol. 2015, 14, 114-124.

(133) Kolb, H. C.; Andres, J. I. Tau positron emission tomography imaging. Cold Spring Harb. Perspect. Biol. 2017, 9.

(134) Maruyama, M.; Shimada, H.;Suhara, T.; Shinotoh, H.; Ji, B.; Maeda, J.; Zhang, M. R.; Trojanowski, J. Q.; Lee, V. M.; Ono, M.;Masamoto, K.; Takano, H.; Sahara, N.; Iwata, N.;Okamura, N.; Furumoto, S.; Kudo, Y.; Chang, Q.; Saido, T. C.; Takashima, A.; Lewis, J.; Jang, M. K.; Aoki, I.; Ito, H.; Higuchi, M. Imaging of tau pathology in a tauopathy mouse model and in Alzheimer patients compared to normal controls. Neuron 2013, 79, 1094-1108.

(135) Gu, J.; Anumala, U. R.; Lo Monte, F.; Kramer, T.; Heyny von Haußen, R.; Hölzer, J.; Goetschy-Meyer, V.; Mall, G.; Hilger, I.; Czech, C.; Schmidt, B. 2-Styrylindolium based fluorescent probes visualize neurofibrillary tangles in Alzheimer's disease. Bioorg. Med. Chem. Lett. 2012, 22, 7667-7671.

(136) Okamura, N.; Suemoto, T.; Furumoto, S.; Suzuki, M.; Shimadzu, H.; Akatsu, H.; Yamamoto, T.; Fujiwara, H.; Nemoto, M.; Maruyama, M.; Arai, H.; Yanai, K.; Sawada, T.; Kudo, Y. Quinoline and benzimidazole derivatives: Candidate Probes for $<\mathrm{em}>\mathrm{In}$ Vivo $</ \mathrm{em}>$ Imaging of Tau Pathology in Alzheimer's disease. J. Neurosci. 2005, 25, 10857-10862.

(137) Harada, R.; Okamura, N.; Furumoto, S.; Yoshikawa, T.; Arai, H.; Yanai, K.; Kudo, Y. Use of a benzimidazole derivative BF-188 in fluorescence multispectral imaging for selective visualization of tau protein fibrils in the Alzheimer's disease brain. Mol. Imaging Biol. 2014, 16, $19-27$

(138) Shirani, H.; Appelqvist, H.; Bäck, M.; Klingstedt, T.; Cairns, N. J. ; Nilsson, K. P. R. Synthesis of thiophene-based optical ligands that selectively detect Tau pathology in Alzheimer's disease. Chem. Eur. J. 2017, 23, 17127-17135.

(139) Boländer, A.; Kieser, D.; Voss, C.; Bauer, S.; Schön, C.; Burgold, S.; Bittner, T.; Hölzer, J.; Heyny-von Haußen, R.; Mall, G.; Goetschy, V.; Czech, C.; Knust, H.; Berger, R.; Herms, J.; Hilger, I.; Schmidt, B. Bis(arylvinyl)pyrazines, -pyrimidines, and -pyridazines as imaging agents for Tau fibrils and $\beta$-amyloid plaques in Alzheimer's disease models. J. Med. Chem. 2012, 55, 9170-9180.

(140) Park, K. S; Seo, Y.; Kim, M. K.; Kim, K.; Kim, Y. K.; Choo, H.; Chong, Y. A curcuminbased molecular probe for near-infrared fluorescence imaging of tau fibrils in Alzheimer's disease. Org. Bio. Chem. 2015, 13, 11194-11199.

(141) Seo, Y.; Park, K. S.; Ha, T.; Kim, M. K.; Hwang, Y. J.; Lee, J.; Ryu, H.; Choo, H.; Chong, Y. A smart near-infrared fluorescence probe for selective detection of Tau fibrils in Alzheimer's disease. ACS Chem. Neurosci. 2016, 7, 1474-1481.

(142) Park, K. S.; Kim, M. K.; Seo, Y.; Ha, T.;Yoo, K.; Hyeon, S. J.; Hwang, Y. J.; Lee, J.; Ryu, H.; Choo, H.; Chong, Y. A difluoroboron beta-diketonate probe shows "turn-on" nearinfrared fluorescence specific for Tau fibrils. ACS Chem. Neurosci. 2017, 8, 2124-2131.

(143) Mani, V.; Krishnakumar, V. G.; Gupta, S.; Mori, S.; Gupta, I. Synthesis and characterization of styryl-BODIPY derivatives for monitoring in vitro Tau aggregation. Sens. Actuators B 2017, 244, 673-683. 
(144) Lim, S.; Haque, M. M.; Su, D.; Kim, D.; Lee, J. S.; Chang, Y. T.; Kim, Y. K. Development of a BODIPY-based fluorescent probe for imaging pathological tau aggregates in live cells. Chem. Commun. 2017, 53, 1607-1610.

(145) Verwilst, P.; Kim, H.R.; Seo, J.; Sohn, N. W.; Cha, S. Y.; Kim, Y.; Maeng, S.; Shin, J. W.; Kwak, J. H.; Kang, C.; Kim, J. S. Rational design of in vivo Tau tangle-selective near-infrared fluorophores: expanding the BODIPY universe. J. Am. Chem. Soc. 2017, 139, 13393-13403.

(146) Taghavi, A.; Nasir, S.; Pickhardt, M.; Heyny-von Haussen, R.; Mall, G.; Mandelkow, E.; Mandelkow, E. M.; Schmidt, B. N'-benzylidene-benzohydrazides as novel and selective tau-PHF ligands. J. Alzheimers Dis. 2011, 27, 835-843.

(147) Gu, J.; Anumala, U. R.; Heyny-von Haussen, R.; Holzer, J.; Goetschy-Meyer, V.; Mall, G.; Hilger, I.; Czech, C.; Schmidt, B. Design, synthesis and biological evaluation of trimethine cyanine dyes as fluorescent probes for the detection of tau fibrils in Alzheimer's disease brain and olfactory epithelium. ChemMedChem 2013, 8, 891-897.

(148) Rejc, L.; Šmid, L.; Kepe, V.; Podlipnik, Č.; Golobič, A.; Bresjanac, M.; Barrio, J. R.; Petrič, A.; Košmrlj, J. Design, syntheses, and in vitro evaluation of new fluorine-18 radiolabeled Tau-labeling molecular probes. J. Med. Chem. 2017, 60, 8741-8757.

(149) Lakowicz, J. R. Principles of Fluorescence Spectroscopy, Springer US, 2006.

(150) Vallée, R. A. L.; Vancso, G. J.; van Hulst, N. F.; Calbert, J. P.; Cornil, J.; Brédas, J. L. Molecular fluorescence lifetime fluctuations: on the possible role of conformational effects. Chem. Phys. Lett. 2003, 372, 282-287.

(151) Glimsdal, E. Spectroscopic characterization of some platinum acetylide molecules for optical power limiting applications. PhD thesis 2009.

(152) Campos, R. I.; Wu, X.; Elgland, M.; Konradsson, P.; Hammarström, P. Novel transstilbene-based fluorophores as probes for spectral discrimination of native and protofibrillar transthyretin. ACS Chem. Neurosci. 2016, 7, 924-940.

(153) Perry, M.; Carra, C.; Chrétien, M. N.; Scaiano, J. C. Effect of hexafluorobenzene on the photophysics of pyrene. J. Phys. Chem. A 2007, 111, 4884-4889.

(154) Sugahara, D.; Amano, J.; Irimura, T. Fluorescence labeling of oligosaccharides useful in the determination of molecular interactions. Anal. Sci. 2003, 19, 167-169.

(155) Moorthy, J. N.;Natarajan, P.;Venkatakrishnan, P.;Huang, D. F. ;Chow, T. J. Steric inhibition of $\pi$-stacking: 1,3,6,8-tetraarylpyrenes as efficient blue emitters in organic light emitting diodes (OLEDs). Org. Lett. 2007, 9, 5215-5218.

(156) Crawford, A. G.; Dwyer, A. D.; Liu, Z.; Steffen, A.; Beeby, A.; Palsson, L. O.; Tozer, D. J.; Marder, T. B. Experimental and theoretical studies of the photophysical properties of 2- and 2,7-functionalized pyrene derivatives. J. Am. Chem. Soc. 2011, 133, 13349-13362.

(157) Kawano, S. i.; Baumgarten, M.; Chercka, D.; Enkelmann, V.; Müllen, K. Electron donors and acceptors based on 2,7-functionalized pyrene-4,5,9,10-tetraone. Chem. Commun. 2013, 49, 5058-5060.

(158) Crawford, A. G.; Liu, Z.; Mkhalid, I. A. I.; Thibault, M. H.; Schwarz, N.; Alcaraz, G.; Steffen, A.; Collings, J. C.; Batsanov, A. S.; Howard, J. A. K. ;Marder, T. B. Synthesis of 2- and 2,7-functionalized pyrene derivatives: an application of selective $\mathrm{C}-\mathrm{H}$ borylation. Chem. Eur. J. 2012, 18, 5022-5035.

(159) Lock, G. Über Abkömmlinge des Pyrens. Ber.Dtsch. chem. Ges. 1937, 70, 926-930.

(160) Djerassi, C. Brominations with N-bromosuccinimide and related compounds. The WohlZiegler Reaction. Chem. Rev. 1948, 43, 271-317.

(161) Schulze, M. Synthesis of 1-bromopyrene and 1-pyrenecarbaldehyde. Org. Syn. 2016, 93. $100-114$. 
(162) Yukawa, S.; Omayu, A.; Matsumoto, A. Thermally stable fluorescent maleimide/isobutene alternating copolymers containing pyrenyl and alkynylpyrenyl moieties in the side chain. Macromol. Chem. Phys. 2009, 210, 1776-1784.

(163) Zhang, J.; Sandberg, A.; Wu, X.; Nyström, S.; Lindgren, M.; Konradsson, P.; Hammarström, P. Trans-stilbenoids with extended fluorescence Lifetimes for the characterization of amyloid fibrils. ACS Omega 2017, 2, 4693-4704.

(164) Qiao, Y.; Zhang, J.; Xu, W. ; Zhu, D. Novel 2,7-substituted pyrene derivatives: syntheses, solid-state structures, and properties. Tetrahedron 2011, 67, 3395-3405.

(165) Li, Y. F.; Xie, X.; Gong, X. J.; Liu, M. L.; Chen, R. F.; Gao, D. Q. ; Huang, W. Two bipolar blue-emitting fluorescent materials based on 1,3,5-triazine and peripheral pyrene for organic light-emitting diodes. Dyes and Pigments 2017, 145, 43-53.

(166) Sharif, M.; Reimann, S.; Wittler, K.; Knöpke, L. R.; Surkus, A.E.; Roth, C.; Villinger, A.; Ludwig, R. ; Langer, P. 1-(Arylalkenyl)pyrenes - synthetic, structural, photophysical, theoretical, and electrochemical investigations. Eur. J. Org. Chem. 2011, 2011, 5261-5271.

(167) Wanninger-Weiß, C.; Wagenknecht, H. A. Synthesis of 5-(2-Pyrenyl)-2'-deoxyuridine as a DNA modification for electron-transfer studies: The critical role of the position of the chromophore attachment. Eur. J. Org. Chem. 2008, 2008, 64-71.

(168) Fiebig, T.; Stock, K.; Lochbrunner, S.; Riedle, E., Femtosecond charge transfer dynamics in artificial donor/acceptor systems: Switching from adiabatic to nonadiabatic regimes by small structural changes. Chem. Phys. Lett. 2001, 345. 81-88.

(169) Yokoyama, K.; D. Fisher, A.; R. Amori, A.; R. Welchons, D.; E. McKnight, R., Spectroscopic and calorimetric studies of Congo red dye-amyloid $\beta$ peptide complexes, $J$. Biophys. Chem. 2010, 1. 153-163.

(170) Back, M.; Appelqvist, H.; LeVine, H., 3rd; Nilsson, K. P. Anionic oligothiophenes compete for binding of X-34 but not PIB to recombinant $\mathrm{A} \beta$ amyloid fibrils and Alzheimer's disease brain-derived A $\beta$. Chem. Eur. J. 2016, 22, 18335-18338.

(171) Zhang, J.; Wang, J.; Sandberg, A.; Wu, X. Y.; Nyström, S.; LeVine, H. 3rd; Konradsson, P.; Hammarström, P.; Durbeej, B.; Lindgren, M. Intramolecular proton and charge transfer of pyrene-based trans-stilbene salicylic acids applied to detection of aggregated proteins. Chemphyschem 2018, 19, 1-10.

(172) Kato, S. i.; Matsumoto, T.; Ishi-i, T.; Thiemann, T.; Shigeiwa, M.; Gorohmaru, H.; Maeda, S.; Yamashita, Y.; Mataka, S. Strongly red-fluorescent novel donor- $\pi$-bridge-acceptor- $\pi$-bridgedonor (D- $\pi-\mathrm{A}-\pi-\mathrm{D})$ type 2,1,3-benzothiadiazoles with enhanced two-photon absorption crosssections. Chem. Commun. 2004, 2342-2343.

(173) Tong, Y. S.; Claiborne, A. K.; Li, G. Q.; Lin, N. H.; Sham, H.; Tao, Z. F.; Sowin, T. Fused tri and tetracyclic pyrazole kinase inhibitors. 2004, WO2004/80973 A1.

(174) Flaherty, D. P.; Kiyota, T.; Dong, Y.; Ikezu, T.; Vennerstrom, J. L. Phenolic bisstyrylbenzenes as $\beta$-amyloid binding ligands and free radical scavengers. J. Med. Chem. 2010, 53, 7992-7999.

(175) Cui, M.; Ono, M.; Watanabe, H.; Kimura, H.; Liu, B.; Saji, H. Smart near-infrared fluorescence probes with donor-acceptor structure for in vivo detection of beta-amyloid deposits. J. Am. Chem. Soc. 2014, 136, 3388-3394.

(176) Zhou, K.; Fu, H.; Feng, L.; Cui, M.; Dai, J.; Liu, B. The synthesis and evaluation of nearinfrared probes with barbituric acid acceptors for in vivo detection of amyloid plaques. Chem. Commun. 2015, 51, 11665-11668.

(177) Sturchler-Pierrat, C.; Abramowski, D.; Duke, M.; Wiederhold, K. H.; Mistl, C.; Rothacher, S.; Ledermann, B.; Burki, K.; Frey, P.; Paganetti, P. A.; Waridel, C.; Calhoun, M. E.; Jucker, M.; Probst, A.; Staufenbiel, M.; Sommer, B. Two amyloid precursor protein transgenic 
mouse models with Alzheimer disease-like pathology. Proc. Natl. Acad. Sci. U. S. A. 1997, 94, 13287-13292.

(178) Nystrom, S.; Psonka-Antonczyk, K. M.; Ellingsen, P. G.; Johansson, L. B.; Reitan, N.; Handrick, S.; Prokop, S.; Heppner, F. L.; Wegenast-Braun, B. M.; Jucker, M.; Lindgren, M.; Stokke, B. T.; Hammarstrom, P.; Nilsson, K. P. Evidence for age-dependent in vivo conformational rearrangement within Abeta amyloid deposits. ACS Chem. Biol. 2013, 8, 1128 1133. 


\section{Papers}

The papers associated with this thesis have been removed for copyright reasons. For more details about these see:

http://urn.kb.se/resolve?urn=urn:nbn:se:liu:diva-152345 